\title{
Einleitung.
}

Die Anfänge der ritterlichen Lyrik im zwölften Jahrhundert weisen uns nach dem südöstlichen Dentschland, nach Oesterreich, wo seit dem elften Jahrhundert eine rege Thätigkeit im Betriebe dentscher Poesie herrschte. Diese salteste Liederdichtung von volksthümlicher Einfachheit trägt noch häufig ein episches Gewand; die Erzählung tritt an die Stelle der persőnlichen Empfindung, die Gefühle werden mehr angedeutet als ansgeftihrt. Was ihr an Kunst abgeht, ersetzt sie reichlich durch Natürlichkeit und Frische; sie bedarf noch nicht gesuchter Wendungen, weil das spăter tausendmal gesagte hier zum erstenmale seinen Ausdruck fand, weil es noch nicht galt durch Originalităt der Einkleidung einen Gedanken neu erscheinen zu lassen. Von Oesterreich drang die Poesie in das benachbarte Baiern, auch hier ihren einfachen Charakter nicht verlengnend. Im Gegensatze zu dieser schlichten deutschen volksthümlichen Lyrik begegnet ihr, vom Niederrhein kommend, im letzten Viertel des zwölften Jahrhunderts eine auf wesentlich anderer Grundlage beruhende, angeregt durch die früher und reicher entwickelte französische, in Deutschland eingefuihrt durch Heinrich ron Veldeke, der seiner Heimath nach den natirlichen Vermittler deutscher und romanischer Elemente bildet. Wie in der Epik, so verdrängt auch in der Lyrik der franzosische Geschmack sehr rasch den einheimischen, die raffinierte Künstlichkeit der Formen und eines ausgebildeten hofischen Frauendienstes die ältere Einfachheit, Deutschland mit scheinbarer Fulle überschutttend, aber innerlich die Poesie kanm gehaltroller machend. Unmittelbares Nachahmen provenzalischer und französischer Muster währte swar nur kurze Zeit; aber mittelbar blieb der Stempel der romanischen Kunstlyrik im eigentlichen Minneliede der deutschen Lyrik aufgeprägt. An Tiefe und Innigkeit des Gemuthes steht die letztere vor ihrem Vorbilde ebenso wie an Vertiefung der Gedanken die Epik; doch nur 
wenige Dichter verstanden es, eine dichterische Persönlichkeit zu bewahren und nicht im Strome allgemeinster Empfindungen aufgehen zu lassen. Die grosse Masse der lyrischen Sänger seit dem Ende des zwölften bis in den Anfang des vierzehnten Jahrhunderts beherrscht zwar die von den Meistern geschaffene Form und die Sprache in einer Weise wie seitdem kanm wieder die lyrische Kunst der Deutschen gethan; im Inhalt aber gleichen die meisten einander so sehr, dass, wenn uns nicht die Namen überliefert wären, wir in den wenigsten Fällen im Stande sein wirden, das Eigenthum auszusondern. Wenn in rorliegender Sammlung die Eintönigkeit nicht 80 bemerklich wird, 80 hat das seinen Grand darin, dass des allzu farblosen nur wenig aufgenommen wurde. Ohne diesen günstigeren Eindruck als ein Verdienst der Auswahl bezeichnen zn wollen, darf er doch zur Rechtfertigung des Gedankens, eine Auswahl aus den deutschen Liederdichtern des Mittelalters zu geben, etwas beitragen.

Drei Abschnitte in der Geschichte der mittelhochdeutschen Lyrik können wir unterscheiden: der erste, bis etws 1190 reichend, zeiǵt auf der einen Seite die volksthümlichen Anfänge derselben und anf der andern den Einfluss, den dann die romanische Kunstlyrik ausübte. Der zweite beginnt da wo die unmittelbare Nachahmung der letzteren aufhört; in ihm erreicht die deutsche Lyrik gleichzeitig mit der Epik ihre höchste Vollendung nach Inhalt und Form, geniesst die Gunst der Fürsten und Herren und der grösste Theil ihrer Träger gehört dem ritterlichen Stande an. Der dritte, dem Herbste vergleichbar, wird durch das Zurücktreten des ritterlichen, das Hervortreten des bürgerlichen Standes, das Ueberwiegen des lehrhaften Elementes, der Spruchpoesie, bezeichnet und verlänft in den eigentlichen Meistergesang, der bis zum Schlusse des Mittelalters und darüber hinans sein Leben fristet.

Den Mittelpankt der deutschen wie jeder andern Lyrik bildet das Verbältniss der Geschlechter, das im Liebesliede seinen Ausdruck findet. Nach ihm sind unsere mhd. Liederdichter vorzugsweise minnesinger, minnesenger ${ }^{1}$ genannt, und der Ausdruck minneliet ", minnewise " oder minnesanc ${ }^{\star}$ darf daher anf den grössten Theil der Lieder dieser Sammlung angewendet werden. Der Name meistersanc ${ }^{5}$ bezeichnet ursprünglich bloss vortrefflichen Gesang, ohne den Gegensatz, den wir heute zwischen Minnesängern und Meistersängern machen.

Ein ziemlich durchgehender Zug des Minneliedes ist es, dass der Dichter mit einer Naturschilderung, der Lust des Sommers oder dem

${ }^{1} 18,89.57,19 . \quad 25,699 . \quad 357,10 . \quad 442,121 . \quad * 78,13$. 
Leide des Winters, anhebt und an sie seine Gefühle knüpft. Mögen nun dieselben ein Abbild der Jahreszeit darstellen oder mit ihr im Widerspruche stehen, immer bildet diese Anknüpfung eine ungesuchte Vermittelnng der äussern und innern Welt, wenngleich ihr hänfiges Vorkommen etwas Ermüdendes haben kann. Die Art und Weise, wie der Liebende seinen Gefühlen Worte leiht, ist selbstverstăndlich ungemein manichfaltig; doch ist auf einen charakteristischen Unterschied der älteren und späteren Lyrik hinzuweisen. In jener finden wir noch das natürliche Verhältniss der Geschlechter: die Liebende blickt zu dem geliebten Manne als za einem höheren Wesen empor, um dessen Huld sie bittet, ${ }^{\circ}$ während er ihrer Liebe trotzig entfliehen will.' Sie ist ihm in Treue unterthan, ${ }^{\circ}$ wünscht seine Liebe allein $2 n$ besitzen ${ }^{\circ}$ und klagt dass er um einer andern willen sie vernachlässige. 10 Dem Geschiedenen ruft sie sehnsilichtig nach; ${ }^{14}$ das Weib ist es, das nach der Liebe des Mannes sich sehnt, der wie ein Falke von ihr gehegt und gepflegt ihr treulos entflogen. ${ }^{19}$ Wenn der jüngste Dichter unserer Sammlung dasselbe Bild anwendet, ${ }^{13}$ so gewinnt es etwas Komisches hier die Liebende den Wunsch aussprechen zn hören, sie möchte statt des entflogenen Falken wenigstens einen Blaufuss, eine geringere Falkenart, haben.

Der Einfluss der französischen Lyrik gestaltete jenes Verhältniss ewischen Mann und Frau wesentlich anders. Da lässt die Frau sich um ihre Huld bitten und wehrt den Mann ab, der zu hohen Lohn für seinen Dienst begehrt; ${ }^{14}$ da beginnt das immer wiederkehrende Flehen um Gnade, um eine kleinere oder grossere Gunst; von nun an finden wir jene oft edle und herrliche, oft aber überschwängliche Verehrung der Franen im allgemeinen wie im einzelnen. Am schönsten hat wohl Walther ${ }^{18}$ die Frauen und zumal die deutschen Franen gepriesen; in allegorisches Gewand hüllt ein ungenannter Dichter die Franentugenden ein. ${ }^{10}$ Dass die Geliebte die schönste in allen Landen, ${ }^{17}$ ist ein begreiflich oft wiederkehrender Gedanke. Aber nicht die Schönheit allein, auch die Anmuth (liebe) wird hervorgehoben ${ }^{18}$ und Anmuth und Schönheit daher streitend eingeführt. ${ }^{10}$ Der Markgraf von Hohenburg weiss, dass es schönere Weiber als seine Dame gibt; aber er kann nur die Vereinigung von Schönheit und Herzensgüte wirklich lieben." Ja Heinrich von Rugge sagt, man solle nach der Schönheit von Fraven nicht fragen, wenn sie nur gut seien." Was jedes Geschlecht an dem

\footnotetext{
${ }^{0} 1,4 . \quad 71,21 . \quad{ }^{85}, 1 . \quad{ }^{2} 2,20 . \quad{ }^{10} 98,44 . \quad{ }^{11} 98,23.39 .298 . \quad 121,85$.

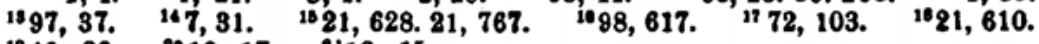
19 16, 29. ${ }^{20} 18,17.2110,15$.
} 
andern als die wiinschenswerthesten Eigenschaften schätzt, lăsst Walther im Gespräche einen Ritter und eine Dame entwickeln," und Frauenlob lehrt eine Frau, wie sie selbst und wie der Mann sein müsse, den sie lieben solle. ${ }^{2 s}$

Wie von Zauber wähnt der Liebende sich umfangen;" die ihn umgebende Welt erscheint ihm verwandelt und er selbst im Besitze tibernatïrlicher Krăfte." In der Gegenwart der Geliebten ist er verstummt, whihrend er sonst um Worte nicht verlegen. ${ }^{20}$ Sie ist sein Hort," sein Gold, seine Edelsteine; ${ }^{\text {" }}$ der Wind, der von ihr herweht, entzückt ihn." Er beneidet, den Anger, auf dem ihre zarten Füsse gewandelt, "0 und das Kind, das sie vor seinen Angen geherzt, zieht er an sich heran und kïsst es an dieselbe Stelle, wo sie es gektisst." Wenn sie es verlangt, singt er, "2 und weil ihre Huld ihm fehlt, ist er verstummt. "s Noch ein halber Knabe, ehe er weiss was Minne ist, liebt er sie; ${ }^{84}$ von klein auf hat er ihr treu gedient; ${ }^{\text {ss }}$ aber seine Treue hilft ihm nicht, "c er muss ohne Lohn dienen, ${ }^{\circ 7}$ und wird nicht ablassen, auch wenn er daruber stürbe, und wünscht, dass man auf seinem Grabsteine lese wie tren er gewesen: ${ }^{28}$ seine Hoffnung ist, dass sein Sohn, schöner als er, ihn an der Geliebten räche. ${ }^{20}$ Vergebens versuchte er ihr zu entfliehen, über Länder und Meere, sie hielt ihn fest und zog ihn immer wieder zurück. " In Zweifel versunken misst er den Halm, an ihm sein 'sie liebt, sie liebt nicht, sie liebt' abzuzahlen und Hoffnung darans za schöpfen. " Die Natur ruft er zu Hïlfe, den Mai, die Sommerwonne, den Klee, die Sonne, und klagt ihnen die Grausamkeit der Geliebten; aber wenn sie ihm helfen wollen, da bangt er, sie mőchte es nicht ertragen, und fleht um Schonung für sie. ${ }^{4} \mathrm{Ja}$ er droht ihr, Recht beim Könige, Kaiser und Pabste zu suchen, lässt sich aber leicht durch sie besănftigen. "s Auch würde es ihm ja nichts nützen, seine Sache vor Gericht zu bringen, ds er ihren Namen nicht nennen darf. " In Träumen malt er sich sein Glück, wie ein Rosenbaum mit zwei blihenden Aesten ihn umfieng, und deutet den Traum anf Erfüllung seiner Wünsche. ${ }^{\text {s }}$ Diese sind bescheidenster und kuhnster Art. Ein Winken und heimliches Sehen, wenn die Năhe anderer nicht mehr gestattet, beglitckt schon; ${ }^{*}$ ein Gruss von ihr macht ihn froh. Er bittet um ein 'ja' statt des beständigen hartnäckigen 'nein', “" und winscht, wo am Fribling alle Welt sich freue, dass auch ihm ein

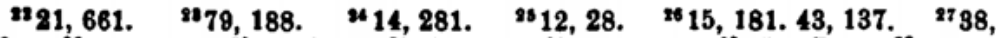

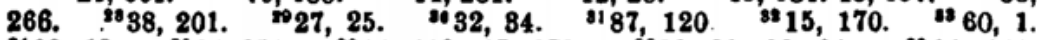
$*_{66}, 19$. 14,250 . *14, 110. 15, 273. $38,81.82,64$. *14, 141.

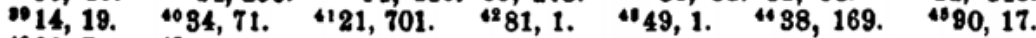
$488,71.4714,280$.
} 
fröidelin zu Theil werde. ${ }^{48}$ Seine Sorge warde entschwinden, wenn sie ihm ein Küissen leihen wollte; ${ }^{* 0}$ mit einem Kusse möchte er sich an ihrem Mündlein răchen und dazu sprechen 'das habe dir für deine Röthe', ${ }^{\text {so }}$ und verspricht, wenn es ihm gelungen ein Küsschen zu stehlen, es gewissenhaft wieder an den Platz, wo er es genommen, hintragen $z u$ wollen. ${ }^{\text {s1 }}$ Aber noch höher versteigen die Wünsche sich: wenn er den Kuss erreicht, dann will er wieder etwas wïnschen;"2 in Gedanken hält er die allerbeste nmfangen, ss und oft genng wird unverhohlen diese höchste Gunst gefordert. Wenn sie ihn fragt was Minpe sei, von der er so viel rede, so verheisst er sies zu lehren, wenn sie eine Weile mit ihm allein sein wolle. ${ }^{\text {st }}$

Die überschwänglichen Liebesversicherungen konnten mit Recht Zweifel an der Echtheit der Empindungen wecken; und so verwahrt sich Hadloub gegen solche Bedenken, weil er gesund und gar nicht kränklich aussehe; ${ }^{\text {ss }}$ 'ihr seid zn feist,' sagt ein anderer, 'wäre euch euer Liebesgram Ernst, ihr wäret lange todt. ss Es begreift sich, dass bei so überströmendem Lobe die Frauen etwas preciös werden mussten, und mit ihren Liebhabern sich allerlei Spott erlanbten: Tanhauser zählt eine Menge unmöglicher Dinge auf, die seine Geliebte von ihm verlange, ehe sie ihn erhöre. ${ }^{87}$ Ebenso erklärlich ist, dass die Münner ihrerseits die Launen satt bekamen, und mit der Dame wechselten: nach lange erlittenem Unrecht entschliesst der Sänger sich sie zu verlassen, ${ }^{38}$ und wünscht, dass sein neues Werben ihm besser als sein früheres glücke. ${ }^{\text {so }}$ Hartmann will von ritterlichen Franen nichts mehr wissen, bel denen er nichts gewinne als dass er mude werde vom langen Stehen, und zieht es vor die Zeit mit armen Weibern besser zu vertreiben. ${ }^{\circ 0}$ Steinmar aber, dem seine Geliebte nicht lohnen will, beschliesst die Freuden des Herbstes zu preisen. ${ }^{\circ 1}$

Die letzte Erwähnung, in der die Liebe ironisch behandelt wird, gehört der Zeit des Verfalles an; aber die Klagen über denselben beginnen schon im zwölften Jahrhundert. Walther klagt, dass Unfuge die Herrschaft erlangt und dass darum sein Singen nicht mehr so minniglich wie einst erklinge; "s und der tugendhafte Schreiber nennt nicht Minne, sondern Unminne, was jetzt kānflich sei und Minne heisse. "s Eine Jungfran betrauert den Untergang der alten Zeit; jetzt nenne man einen treuen Liebhaber nur spöttisch ein argez minnertin. ${ }^{\circ 4}$ Walther von Metz wünscht, es möchten treue und falsche Minner äusserlich

${ }^{48} 28,92 . \quad{ }^{49} 85,60 . \quad{ }^{60} 92,18.93,13 . \quad{ }^{81} 15,118$. 34 85, 75. ${ }^{85} 87,141$. ${ }^{6067}, 7$. ${ }^{67} 47,131$ und Anm.

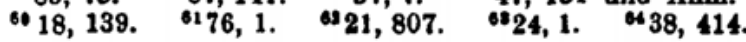

B252, $24 . \quad 3998,88$.

${ }^{88} 38,91$. ${ }^{80} 28,32$. 
unterschieden sein, "s und Heinrich ron Veldeke klagt bereits, dass die Mănner die Frauen schelten. " Daher ist es nicht zu verwundern, wenn die Fran zweifelnd den Werbenden abweist, da seine Lieder einer andern gelten. " Dass der mittelalterliche Liebescultus 80 frühe in Rohheit und Sittenlosigkeit ausartete, findet seine Hanpterklärung in dem Umstande, dass verheirathete Frauen in der Regel die vom Dichter besungenen Geliebten waren. Ein Mădchen gefeiert zu sehen, gehört zu den Ausnahmen; des Kürenbergers Liebchen ist eine Jungfrau. "s Meist ist es nur niedere Minne, die sich an Mädchen knüpft: 80 ist das froucelin bei Reinmar gemeint, das mit den Gespielinnen Ball wirf,, ${ }^{69}$ und nicht anders bei Walther. " Auch die von Vater und Mutter behütete Geliebte des Junkers ${ }^{\text {"I }}$ gehört wohl den unteren Ständen an.

Dass in der Regel verheirathete Frauen Gegenstand der Huldigung waren, erklärt verschiedene Bräuche der Liebespoesie. Znnăchst das Gesetz den Namen der Geliebten nicht zu nennen. Die Provenzalen und Franzosen bedienten sich zur Bezeichnung allegorischer Namen, und ähnlich ist wohl Veldekes Antwort auf die Frage, wer sie sei, gemeint: "es ist die Wohlgethane." ${ }^{2}$ Sicher aber ist ein Versteckname der Schône Glanz bei Heinrich von Weissensee. "s Walther nennt die Geliebte mit Bezug auf seinen eigenen Namen Hildegunde. "Wintersteten wïrde sie beim König verklagen; aber er darf sie nicht nennen. ${ }^{75}$ Der Schenk von Iimburg kann sich kaum enthalten den Namen auszusprechen; aber er besinnt sich noch im rechten Augenblicke: 'es würde mir und ihr nicht anstehen.' ${ }^{76}$ Der Herr, der den Knecht im Verdacht hat, er liebe sein Weib, verlangt von ihm den Namen der besungenen Geliebten zu wissen. ${ }^{77}$

Sodsnn das häufige Erwähnen der Merker, die bereits beim Kürenberger vorkommen; ${ }^{78}$ sie werden mit verschiedenen Namen bezeichnet, ausser merkare, merker, ${ }^{79}$ noch huote, ${ }^{80}$ huoter. ${ }^{81}$ Gegen sie richten die Dichter die stärksten Ausdrücke, weil sie in ihnen das grösste Hinderniss ihrer Wunsche sahen. Sie meint wohl Walther, wenn er diejenigen verwünscht, die ihm den Winter Freude benommen. ${ }^{82}$ Die argen schalke nennt sie ein anderer ${ }^{8 s}$ und Hadloub verfucht sie mit ihren langen

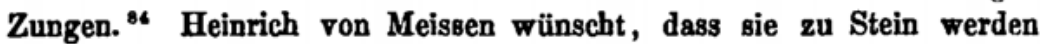
und auf dem Meer verschlagen werden möchten. ${ }^{85}$ Sie sind schuld, dass von den Wangen der Geliebten Schönheit und Farbe schwindet. ${ }^{80}$

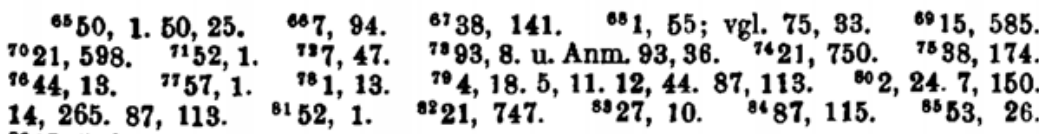

$15,608$. 
Sie zu betrügen gilt für eine Pflicht des Liebenden ${ }^{87}$ und ihren Hass zu verdienen für eine wünschenswerthe Sache. ${ }^{88}$ Die Nutzlosigkeit des Behütens wird mehrfach ausgesprochen, ja wer hüte, schade nur sich selbst und verderbe die Frauen. ${ }^{89}$

Endlich erheischte der erwähnte Umstand die grösste Vorsicht des Liebenden. Die Geliebte unbehütet zu finden, war ein seltener Glücksfall; ${ }^{90}$ meist durfte er ihr mit seinen Werbungen und Liedern gar nicht nahen und musste dieselben durch einen Boten in ihre Hände gelangen lassen. Entweder mit einem Briefe ${ }^{91}$ oder mündlich wurde die Botschaft ausgerichtet. Der Kürenberger würde gern selbst statt des Boten zu ihr gehen, wenn es nicht ihr Schade wäre. ${ }^{92}$ In einer Strophe lässt Meinloh von Sevelingen den Boten die Werbung anbringen $;^{93}$ ebenso Dietmar von Aist, ${ }^{94}$ worauf die Frau antwortet. ${ }^{95}$ Namentlich in Reinmars Liedern spielen Boten eine wichtige Rolle: die Liebende fragt den Boten nach dem Geliebten aus ${ }^{96}$ und entbietet diesem, in seinen Wünschen sich $\mathrm{zu}$ bescheiden. In einem andern ${ }^{97}$ trägt sie dem Boten auf was ihr am Herzen liegt, fügt aber am Schlusse hinzu, er möge nicht alles dem Geliebten wiedersagen. Rudolf von Rotenburg möchte tausend Boten an sie senden, damit nicht, wenn er einen schicke, dieser etwa verhindert werde; denn sie hat ihn gebeten durch Boten ihr seine Lieder zu schicken. ${ }^{98}$ Aber auch die Frau entbietet dem Manne durch einen Boten, dass er ihr hold sein möge. ${ }^{99}$ In Ermangelung eines Boten hängt Hadloub der Geliebten, als sie in der Dämmerung aus der Kirche kommt, seinen Liebesbrief an das Kleid. ${ }^{100}$ Die komische Seite des Botendienstes zeigt uns der Taler, ${ }^{101}$ der das Künzlein sendet, um seiner Geliebten die Lieder zu singen; der Angeredete aber schiebt das Amt dem Heinzlein zu, worauf dieser sich mit seiner Furcht vor Ermordung im Korne losmacht. Uneigentlich wird die Minne als Bote gesendet, ${ }^{102}$ und mit poetischer Uebertragung dient auch die Nachtigall zu diesem Amte. ${ }^{103}$

Der Botendienst, auch im dreizehnten Jahrhundert, wie wir aus Liechtenstein sehen, noch sehr im Schwange, gibt Anlass zu dramatischer Einkleidung. ${ }^{104}$ Aber auch sonst ist diese Art des Minneliedes bei romanischen wie. deutschen Dichtern beliebt: Mann und Frau sprechen Strophe um Strophe; ${ }^{105}$ doch findet auch ein rascherer Wechsel statt, so dass jeder Redende mitunter nur ein paar oder eine Zeile spricht.

${ }^{87} 4,18 . \quad{ }^{88} 12,44 . \quad{ }^{89} 7,150.8,179.14,264 . \quad 9011,33.18,125 . \quad{ }^{91} 98$, 59. 139. ${ }^{92} 1,56 .{ }_{93}^{93}, 1 .{ }_{94} 2,39 . \quad{ }^{95} 2,45 ;$ vgl. noch $15,43.18,97$. ${ }^{86} 15,280 . \quad{ }^{97} 15,310 . \quad{ }_{88}^{83}, 182.176 .{ }^{99} 1,4 .{ }_{100}^{87}, 1 .{ }_{101}^{10} 37,1 .{ }^{102} 80$, 8. ${ }^{103} 61,1$ u. Anm. 98, 159. ${ }^{104} 15,280 .{ }^{105} 15,1.15,544.21,661$. 
Sehr geschickt und zierlich haben die Dichter von diesem Mittel Gebrauch zu machen gewusst; so Albrecht von Johansdorf ${ }^{100}$ and der Truchsess von St. Gallen. ${ }^{101}$ Namentlich in den neidhartischen Liedern ist die Gesprächsform häufig. Durch eine Erzählung leitet das Gepräch Wintersteten ein. ${ }^{108}$

Die dramatische Form findet ihren eigentlichen 8chwerpunkt in einer besonderen Gattung der Liebespoesie, dem Tageliede, mhd. tageliet, tagewốse, ${ }^{100}$ das das Scheiden der Liebenden nach heimlichem $\mathrm{Zu}$ sammensein beim anbrechenden Morgen schildert. ${ }^{110}$ Die einfachste und ursprünglichste Art desselben ist die, dass die Liebenden durch den Tag geweckt sich zum Scheiden rüsten: ein Vöglein auf der Linde ist der einzige Wächter and Wecker in dem ältesten Tageliede, das wir besitzen. ${ }^{111}$ Auch 98, 107 ist die Situation, wie es scheint, die, dass der Ritter die Nacht bei der Geliebten gewesen und am Morgen fortreitet. Heinrich von Morungen "1s lässt ebenfalls die Liebenden erwachen und Strophe nm Strophe mit dem Refrăn 'da tagte es' klagen, ohne dass ein antlerer um ihr Geheimniss weiss. Dem weckenden Wächter begegnen wir bei Wolfram von Eschenbach, dessen Beispiel von entscheidendem Einflusse anf diese Gattung war: ${ }^{113}$ er lässt den Wächter mit seinem Rufe beginnen; daran knüpft sich im ersten Liede ein Zwiegespräch der Fran mit ihm; im zweiten folgt Erzählung wic im ersten schliesslich anch, und nur wenige Worte spricht der Ritter. Das Wechselgespräch zwischen Wächter und Fran hat der mit Wolfram etwa gleichzeitige Markgraf von Hohenburg, ${ }^{14}$ aber ohne erzählendes Element. Ebenso ist nur dramatisch das Tagelied Botenlaubens, ${ }^{115}$ während der Ungenannte ${ }^{116}$ nach einem Gespräch zwischen Frau und Wächter erzählend abschliesst. Episch hebt Frauenberg an, ${ }^{117}$ worauf der Wächter seinen Ruf erklingen lässt und ein Dialog zwischen ihm und der Liebenden folgt. Liechtenstein nahm an der Mitwissenschaft des Wächters Anstoss und lässt ihn durch eine Dienerin ersetzen; ${ }^{118}$ sein Beispiel scheint den Markgrafen von Lüenz beeinflusst zu haben. ${ }^{119}$ Die ironische Kehrseite zeigt uns ein Lied Steinmars, der den Knecht und seine Dirne durch den Hirten wecken lässt: ${ }^{190}$ dieselbe Ironie also, die den Dichter anch das Minnelied verspotten macht. •

Der niederen Minne neben der hohen sahen wir die vorztiglichsten Dichter huldigen. Bei den Romanen baben solche Verhăltoisse ritterlicher Liebhaber und ländlicher Schönen eine besondere Gattung, die

$10011,33 . \quad 10780,13.80,31 . \quad{ }^{108} 38,191 . \quad{ }^{109} 29$, 4. 22, 60 . ${ }^{110} \mathrm{~V}$ gl. auch

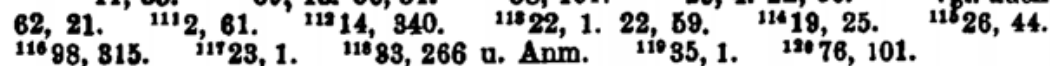


Pastourelle, pror. pastorela, pastoreta, veranlasst. Vereinzelte Beispiele liefert auch die deutsche Poesie. So gehört hierher das reizende Lied Walthers ${ }^{121}$ und mehrere Lieder Neifens, der bald mit einem Garn windenden Mädchen, ${ }^{122}$ bald mit der am Brunnen schöpfenden Magd, ${ }^{123}$ bald mit der flachsbrechenden Schönen ${ }^{124}$ Gespräche und Scherze anknüpft. Steinmar hat sich eine süeze selderîn erwählt, die nach Gras auf die Wiese geht, ${ }^{125}$ und eine kluge Dienerin, die hinterm Pfluge her schreitet. ${ }^{126}$ Der Anfang einer Pastourelle ist in einer namenlosen Strophe ${ }^{127}$ erhalten; an Walthers Lied erinnert eins von Hadloub, ${ }^{128}$ wiewohl hier der Dichter nicht eine bäuerliche Geliebte meint.

Der Zug zum realistischen, im Gegensatz zu dem übertriebenen Idealismus der eigentlichen Minnepoesie, tritt am schärfsten in der von Neidhart begründeten höfischen Dorfpoesie hervor. Angeregt durch die romanische Pastourelle, gestaltete er das lange vor ihm im Volke vorhandene Tanzlied zu einer Unterhaltung der höfischen Kreise um, in denen er selbst lebte; und welchen Beifall diese neue Gattung fand, sieht man am besten aus der zahlreichen namentlich österreichischen Nachfolgerschaft. Neidharts Lieder zerfallen in Reigen und Tänze oder Sommerlieder und Winterlieder: mhd. reie ${ }^{129}$ oder reige ${ }^{130}$ (das Verbum reien ${ }^{131}$ oder reigen ${ }^{132}$ ) und tanz. ${ }^{183}$ Auch hovetanz $(98,500)$, hovetenzel (25, 440), tanzwîse $\left(33,1\right.$. 73), tanzliet $(29,4)$ kommt vor. Liechtenstein nennt ein Lied ${ }^{134}$ vrowen tanz, auch sincwîse ${ }^{135}$ ist wohl ein Tanzlied. Namen von bestimmten Tänzen sind govenanz, ${ }^{186}$ vom französ. convenance, eigentlich also Zusammenkunft, und da bei geselligen Zusammenkünften der Tanz eine grosse Rolle spielte, auch eine Art Tanz bezeichnend; hoppaldei ${ }^{137}$ von hoppen, hüpfen, abgeleitet; ridewanz, ${ }^{\mathbf{1 3 8}}$ vom böhmischen radowa, einem noch heute lebenden Tanze; trei, ${ }^{139}$ nicht näher zu bestimmen. Auch die stampen $\hat{\imath} e^{140}$ ist vielleicht ein zur Begleitung des Tanzes gesungenes Lied. Der Tanz wird getreten, der Reigen gesprungen ; $^{141}$ einer tanzt vor, der voretanzer, ${ }^{142}$ wie auch den Gesang beim Tanze ein Vorsänger anstimmt. ${ }^{143}$ Neidharts Lieder führen uns lebendig mitten in die bäuerliche Welt ein, die mit feinem Humor behandelt wird. Eine sehr häufige Form der Einkleidung ist, wie schon bemerkt, das Gespräch, entweder erzählend oder durch eine Naturbetrachtung eingeleitet. Gewöhnlich unterhalten sich die alte Bäuerin und ihre Tochter, welch

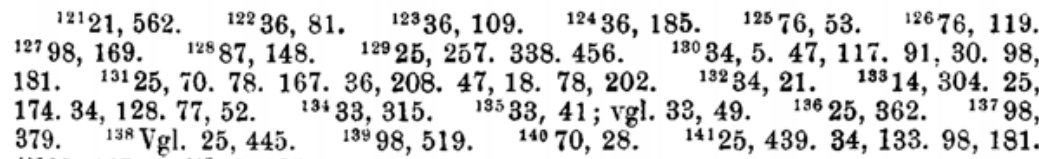
14:25, 437. 143.25, 405 . 
letztere den von Reuenthal (den Dichter) liebt und an seiner Hand zum Tanze möchte, wogegen die Mutter vor den gefährlichen Folgen warnt. Aber auch die Alte ist oft von Tanzlust erfillt und wetteifert mit dem Mädchen. ${ }^{144}$ Zwei Gespielinnen werden nach einer einleitenden Strophe redend eingefuhrt und klagen sich ihr Leid. ${ }^{14 s}$ Mitunter tritt nach dem Eingange nur der Dichter erzählend hervor. ${ }^{140}$ Auch ernstere Töne lässt er hindurchklingen und berührt die trüben Zeitverhältnisse ${ }^{167}$ in einem Tanzliede bekennt er, wie lange er seiner Geliebten, der Weltsüsse, gedient, um deren willen er achtzig neue Weisen gesungen. ${ }^{148}$ Die Winterlieder, wo in der Stube getanzt wird, entwickeln andere Scenen. Da versammeln sie sich bei dem, der die grösste Stube hat; aber der Raum ist doch zu enge, als dass nicht zuweilen Zank und Schlägerei daraus entstünde. ${ }^{149}$ Zugleich nimmt der Dichter hier Gelegenheit den üppigen Kleiderprunk der reichen Banern zu schildern, die sich ganz wie Ritter gebärden.

Die Hauptzüge haben Neidbarts Nachahmer sich angeeignet, namentlich das Gespräch zwischen Mntter und Tochter; 80 Scharpfenberg ${ }^{130}$ nd Geltar, ${ }^{151} 80$ wie ein Ungenannter ; $^{152}$ zwischen zwei Gespielinnen, Burkart von Hohenvels. ${ }^{158}$ Anch das Lied Ulrichs von Wintersteten, ${ }^{154}$ in welchem Mutter und Tochter redend eingeführt werden, und jene den Dichter, dessen Sang man auf den Gassen singt, vor dem liebenden Mädchen herabzusetzen sucht, ist wohl ein Tanzlied. Ein Nachahmer Neidharts benutzt das Ballspiel zum Gegenstande; ${ }^{10 b}$ ein anderer lässt den auch bei Neidhart vorkommenden Zank von einer Blase ansgehen, die durch den Kreis der Tanzenden geschlagen wird ; ${ }^{158}$ ein dritter nimmt sich der von Neidhart verspotteten Bauern an und lässt einen derselben in Neidharts Melodie antworten. ${ }^{157}$ Doch finden wir auch Tanzlieder ohne Beziehung auf Schilderungen des bänerlichen Lebens: 80 bei Burkart von Hohenvels, der den Winter in der Stube zu empfangen auffordert $;^{138}$ in einem andern, worin der Name stadelwîse begegnet, kommt man in der Scheuer (dem Stadel, daher der Name) zusammen. ${ }^{130}$ Einen volksmässigen Charakter anderer Art trägt ein Lied Neifens, ${ }^{160}$ worin die junge tanzlustige Mutter der Amme das Kind ubergibt, um zum Reigen zu eilen. Bruchstícke von volksthümlich gehaltenen Tanzliedern stehen unter den namenlosen Strophen. ${ }^{101}$ Ganz im höfischen Tone ist das Lied Hildbolds von Schwangau, ${ }^{16 s}$ aus dessen Refrän man allein die Be-

144 Vgl. 25, 1. 22. 83. 113. 120. ${ }^{145} 25,161.250 . \quad{ }^{146} 25,50.65 . \quad{ }^{147} 25$, 307. 672. 10825,588 . 149 Vgl. 25, 347. 417. 509. ${ }^{180} 54,1 . \quad 16157,20$. 16298, 435. 15834, 21. 161. 16438, 1. ${ }^{155} 98,345 . \quad{ }^{156} 98,475 .{ }^{157} 98,454$. 158 34,1 . $16934,111.16036,203$. $16198,181.202$. 256. 263. 10220,51 . 
stimmung zum Tanze entnehmen kann; im übrigen ist es ein Minnelied wie alle andern. Nicht minder die Lieder Liechtensteins ${ }^{163}$ und Sachsendorfs, ${ }^{184}$ während das von Wizlav ${ }^{18 s}$ ein wenig populärern Beigeschmack hat. Wintersteten ${ }^{180}$ knüpft an das Tanzlied Klagen über den Verfall der Minne und der Sitten an, was schon Neidhart gethan. In das Volksleben hinein greift das Emtelied Hadloubs, ${ }^{137}$ während die zum Preise des Herbstes gedichteten Esslieder Steinmars ${ }^{108}$ and Hadloubs ${ }^{169}$ mehr die Kehrseite des idealen Minnedienstes als das volksthümliche Element zur Anschaung bringen. Ganz in die Weise des Volksliedes tritt hinüber Neifens Lied vom Büttner ${ }^{170}$ and desselben Bruchstück vom Pilgrim, ${ }^{71}$ die sogar wirkliche Volkslieder sein könnten. ${ }^{37}$ Auch das lateinisch-deutsche Liedchen ${ }^{173}$ ist rein episch. Sonst ist die epische Einkleidung, gewisse Gattungen abgerechnet, selten: der Dichter tritt dann meist als Erzähler auf, wie in dem volksthümlich gehaltenen an die Pastourelle streifenden Liedchen Johanns von Brabant," ${ }^{11}$ der in einem Baumgarten drei Jungfrauen findet; oder bei Walther, der seinen Traum und die Deutung des alten Weibes erzählt. ${ }^{17 s}$ Eine liebliche Erinnerung an die längst entschwundene Kinderzeit kleidet Meister Alexander ebenfalls in erzählende Form. ${ }^{176}$ In die bänerliche Welt führt wiederum Hadloub, der sich als Zeugen eines Zwistes zwischen zwei Banern darstellt. ${ }^{17}$

Eine Gattung lyrischer Gedichte nennt Reinmar der Fiedler hügeliet, ${ }^{178}$ was Freudengesang bedeutet, ohne dass wir durch den Namen einen näheren Einblick in das Wesen derselben erhielten.

Die dramatische Form sahen wir im eigentlichen Liebesliede wie im Tanzliede mehrfach auftreten. $\mathrm{Zu}$ einer besonderen Gattung, wie die Tenzone der Provenzalen ist, hat sie sich nicht entwickelt; man könnte Walthers $\mathrm{Z}$ wiegespräch ${ }^{170}$ beinahe so nennen, doch fehlt das eigentlich streitende Element, auch stehen sich nicht zwei Dichter mit ibren Ansichten gegenüber. Dies findet erst in der letzten Periode der mhd. Lyrik statt; so, wenn ein Dichter dem andern ein Räthsel aufgibt. ${ }^{180}$ Die Räthsel waren in der zweiten Hälfte des 13. Jahrhunderts sehr beliebt; ein Beispiel gibt Raumsland. ${ }^{181}$ Einen Anklang an die Liebestenzone der Provenzalen enthält eine Strophe Rubins, ${ }^{18 s}$ worin eine Frau zu entscheiden aufgefordert wird.

In die heitere Welt des Liebesliedes klingen die ernsteren Töne der

${ }^{168} 33,1.73 .815 . \quad 16439,1 . \quad{ }^{108} 84,1 . \quad{ }^{108} 38,136 . \quad{ }^{107} 87,321 . \quad{ }^{108} 76,1$. $18087,256 . \quad{ }_{110} 36,148.17136,173 . \quad{ }^{17 n}$ Uhland, der feinste Kenner des Volksliedes, hat letzteres wirklich unter seine Sammlung aufgenommen (8. 235). 17698 , 7. $1782,37 . \quad{ }^{175} 21,507 . \quad 17671,145 . \quad 1787,223$; vgl. 30, 123.

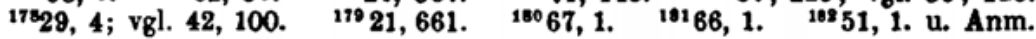


Zeit, die Verhältnisse des Lebens hinein. Die Verbindung ron Liebe und Leben bildet den Hauptstoff des Kreuzliedes, mhd. kriuzliet. ${ }^{18 s}$ Die feurige Begeisterang provenzalischer Dichter vermissen wir allerdings in den deutschen Liedern dieser Art, aber sie thun wohl durch die Innigkeit der religiösen Empfindung und die sanfte Schwermuth, die ans ihnen athmet. Herz und Leib sind mit einander im Streite : während dieser zur Fahrt gegen die Heiden bereit ist, wird jenes ron süssen Banden zurückgehalten. ${ }^{104}$ Der Dichter meint, er hätte wohl Ursache gehabt, in der Heimath zu bleiben, aber die Pflicht des Glaubens hat den Sieg davongetragen. ${ }^{18 s}$ Erzählend und dramatisch führt den Abschied von der Geliebten Johansdorf vor, ${ }^{186}$ der den Wunsch ausdrückt, er möge, wenn er heimkehre, die Geliebte treu wiederfinden. ${ }^{187}$ Im Wechselgespräch beim Scheiden stellt sich Botenlouben dar. ${ }^{\text {ss }}$ Bei Friedrich von Leiningen, der im Begriff steht, eine Fahrt nach Apulien zu machen, und nur die fün Worte 'fahr hin zu guter Stunde' von der Geliebten $\mathbf{z u}$ hören verlangt, ist dieser die letzte Strophe zugetheilt. ${ }^{180}$ Nicht unpassend spricht ein anderer Dichter seinen Entschluss, an Christi Grab zu ziehen, am Ende eines Tageliedes aus, welches das letzte Beisammensein der Liebenden vor der langen Trennung schildert. ${ }^{100}$ Seinen Freunden vererbt seine Liebe Hildbold von Schwangau, ${ }^{191}$ während Rubin beim Abschied jenen einen Gruss an die Geliebte aufträgt. ${ }^{108}$

Aber das Kreuzlied stimmt auch anderen Ton an. Der Ritter, der dem göttlichen Dienste sich weiht, fühit die Nothwendigkeit aller irdischen Liebe zu entsagen: 'nun will ich dienen dem der lohnen kann,' sagt Friedrich von Hausen, ${ }^{198}$ nachdem er lange, ohne Gnade zu finden, einer Frau sich geweiht. Hartmann rühmt die Gottesminne, von der sein Herz erfültt ist, gegen die weltliche. ${ }^{104}$ Noch ist das Herz im Kampfe mit der Lust der Welt, noch nicht ausschliesslich dem Dienste Gottes gewidmet; ${ }^{108}$ aber das Trügerische der Welt hat der gottbegeisterte Sänger erkannt ${ }^{106}$ und erblickt in der Kreuzfahrt die Rettung vor der Sünde, die uns umfangen hält. ${ }^{107}$

Dem Fernen aber erwacht die Sehnsucht nach der verlassenen Heimath, auch wenn es nur die Berge (die Alpen) sind, die ihn von der Geliebten trennen. ${ }^{108}$ Sein Herz jubelt, wenn er durch einen Pilgrim von ihr vernommen, ${ }^{199}$ und von Wien her, wo er mit dem Heere des Königs liegt, sendet der Schenk von Landegg der Geliebten in Schwaben

${ }^{188} 29$, 5. $1848,109 . \quad{ }^{185} 8,141 . \quad{ }^{186} 11,9 . \quad{ }^{197} 11,1 . \quad{ }^{188} 26,30$.

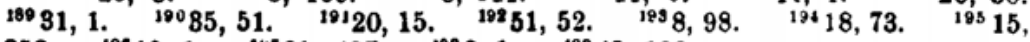
352. ${ }^{196} 18,1 .{ }^{167} 21,427 .{ }^{199} 8,1 .{ }^{199} 43,188$. 
seinen Gruss. 300 Beim Ausziehen auf ritterliche Fahrten singt der Dichter eine ûzreise ${ }^{\text {yot }}$ zum Lobe der Frauen im allgemeinen. Der Tanhanser dichtet ein Lied auf der Seefahrt, ${ }^{203}$ worin aber das minnigliche Element nicht hervortritt.

Religiöse Lieder ansser den Kreuzliedern haben wir nur wenige; zwischen Spruch und Lied mitten inne stehen Spervogels Strophen über Weihnachten, ${ }^{209}$ Ostern, ${ }^{206}$ Himmel and Hölle. ${ }^{206}$ Die Allmacht Gottes feiert eine schōne Strophe desselben. ${ }^{208}$ Die Mariendichtung war in Deutschland nicht so verbreitet wie in Frankreich; eine Probe geben wir in Sigeher. ${ }^{107}$ Im vierzehnten Jahrhundert, wo die trüber sich gestaltenden Zeitverhältnisse den weltlichen Sinn ernster stimmten, dichtete man beliebte weltliche Weisen in geistlichen Inhalt um: so warde Steinmars Lied zum Preise der Sommerzeit ${ }^{208}$ geistlich gewendet und aufs Himmelreich bezogen, ${ }^{200}$ und wahrscheinlich ist auch das folgende, ${ }^{210}$ das dieselbe Handschrift enthält, Umdichtung eines weltlichen, und zwar eines Tanzliedes: wie sonst die Tochter gegen den Willen der Mutter zum Tanze eilt, so geht sie hier fröhlich ins Kloster, ein rechtes Gegenstück zu dem Klageliede der Nonne, ${ }^{211}$ die mit schwerem Herzen ihr junges Leben in die Klostermauern eingesargt sieht. Den Schluss unserer Sammlung bilden $z$ wei tiefinnige religiöse Lieder, ${ }^{213}$ die den Geist der Mystik des 14. Jahrhunderts athmen.

Die Nichtigkeit alles Irdischen klingt aus ihnen nieder; schon viel früher haben Dichter in ähnlichem Grundton gesungen. Heinrich von Rugge klagt wie die Freude aus der Welt schwinde, "ts und ähnliche Klage erbebt Walther, ${ }^{\text {"4 }}$ wenn er sich der frohen Vergangenheit erinnert. Der von Kolmas weist von den trügerischen Freuden der Welt auf den Himmel und dessen Gnade hin, ${ }^{\text {11s }}$ und ein Ungenannter mahnt wie alle Freude mit Leid zergeht." 18 Walther lässt einen Meister sagen, dass alle Weltlust zerbrechlich wie Glas und flüchtig wie ein Traum sei." Er nimmt Abschied von der Welt, der er sein Leben lang gedient, ${ }^{\text {918 }}$ wie sein Nachahmer, der Truchsess von St. Gallen, auch thut." Der Guter führt uns in 'erzählender Form das Bild der Fran Welt vor, die einem kranken Ritter erscheint, und knüpft daran ernste Betrachtungen. ${ }^{330}$

Zu solchen musste namentlich dann der Dichter Anlass finden, wenn der Tod ihm einen Gönner entriss, dessen Freigebigkeit sein Leben ver-

20072 , 1. 20133,98 u. Anm. ${ }^{202} 47,193 . \quad{ }^{203}$ 3, 91. ${ }^{2043,15 . ~} 2053$ 97. 103. ${ }^{2063} 3,163 .{ }^{207} 63,1 .{ }^{208} 76,51 . \quad 20098,641 . \quad 21098,671 . \quad 21198$, 581. 212 98, 695. 716. ${ }_{213} 10,23 . \quad{ }^{214} 21,895.2_{215} 13,1 . \quad 21698,297$. ${ }^{217} 21,859 . \quad 21821,946 . \quad 21930,135 . \quad 22089,1 \mathrm{ff}$. 
schönte. Diese Klagelieder um Todte, mhd. klageliet, ${ }^{221}$ haben zumal die Provenzalen gepflegt und zu einer besondern Gattung, plank, ausgebildet. Das älteste Lied der Art sind Spervogels Strophen auf den Tod Wernharts von Steinberg. ${ }^{\text {s" }}$ Reinmar widmet, indem er die Welt redend einführt, seinem Gönner Herzog Leopold von Oesterreich einen tief empfundenen Nachruf, 2 ss und ein Ungenannter beklagt Ottakers von Böhmen Tod." Auch dem geschiedenen Kunstgenossen wird ein Wort der Erinnerung geweiht, so Reinmarn zwei schöne Strophen von Walther; "1 diesem von dem Truchsessen von St. Gallen; ${ }^{236}$ Konrad von Würzburg durch Franenlob."s7 Mit wehmüthigem Hinblick auf die Vergangenheit klagen nm die geschiedenen Meister der Kunst, in denen die Herrlichkeit der Poesie lebte, der Marner, ${ }^{38}$ Reinmar von Brennenberg "s" und Herman der Damen; ${ }^{\text {s0 }}$ doch sind das nicht eigentliche Klagelieder, sondern einzelne Strophen, ${ }^{231}$ die demnach dem Bereiche der Spruchpoesie angehören.

Wenn Walther den Verfall der höfischen Sangeskunst, das Eindringen unhöfischer Töne beklagt, ${ }^{\text {sss }}$ wenn derselbe ein anderes dem Leben entnommenes Thema, die Erziehung der Kinder, in Liedesform behandelt, ${ }^{238}$ so streift er damit an die Grenze desjenigen Gebietes, welches die zweite Hauptgattung der Lyrik, die Spruchdichtung, umfasst. Im Bau sich von den eigentlichen Liedern wenig unterscheidend, nur in der Wahl der Verse die längeren vor den kurzen bevorzugend, aber nicht in Strophen sich aufbauend wie das Lied, sondern nur je eine Strophe enthaltend, geht die Spruchdichtung neben der Liederpoesie einher; auch sie uralt und gleich am Beginne unserer Lyrik durch ein trefliches Beispiel, Spervogel, vertreten. Er berührt die verschiedensten Seiten des Lebens, die Freundschaft, die Ehe, die Standesverhältnisse, nur die eigentliche Minne schliesst er aus. Die Einkleidung ist wie auch bei den ältesten Liederdichtern zum Theil episch, Fabeln mit kurzer Nutzanwendung, und darin sind ihm spätere Dichter gefolgt, wie der Marner, "' Konrad von Würzburg, "sss und der letzte Dichter unserer Sammlung, Heinrich von Muglin, ${ }^{\text {ss }}$ den wir auch im Liede mit dem ältesten Lyriker sich berūhren sahen. Aehnliches Inhalts wie die des alten sind die Strophen des jungen Spervogels. ${ }^{237}$ Episches Gewand wie die Fabel trägt das Lügenmärchen, das auch uralten Ursprunges ist, ${ }^{988}$ bei Reinmar von Zweter ${ }^{299}$ und dem Marner; ${ }^{140}$ das mhd. spel

"2129, 4; in allgemeinerem Sinne 98, 345; klagesanc $60,25 .{ }^{222} 3,7$.

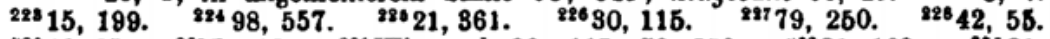
${ }^{220} 46,65$. ${ }^{220} 78,18$. ${ }^{281}$ Wie auch 30,115 . 79, 250. ${ }_{282}^{21}, 163$. ${ }^{283} 21$,

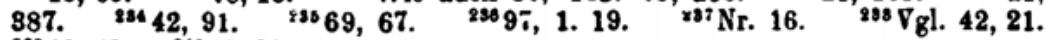
${ }^{389} 40,48.24042,39$. 
bedeutet Lüge und Märchen zugleich." "11 Bald von diesem, bald von jenem Dichter werden die manichfaltigsten Gegenstände behandelt. Gott, dessen Huld zu erringen des Menschen hōchstes Streben sein muss; ${ }^{\text {262 }}$ das Gebet, eine Umdichtung des Vaterunsers; ;"s die Sündhaftigkeit des Menschen. "s4 Den Lügner und Meineidigen straft der Marner, ${ }^{24 s}$ während Friedrich von Sunburg dem Armen, dem Freigebigen und Liebenden zu lügen erlaubt $;^{326}$ gegen den Schmeichler wie gegen den Geizigen wendet sich der Marner, ${ }^{247}$ gegen den Verschwender Herman der Damen. ${ }^{248}$ Die Macht des Geldes als die höchste in der Welt bezeichnet Boppe; von Ehre und Glück handelt Frauenlob. ${ }^{\text {sto }}$ Die Stände, namentlich Ritter- und geistlichen Orden, vergleicht Reinmar von Zweter ${ }^{281}$ und Frauenlob; $;^{252}$ Pfaffen, Ritter und Bauern Regenbogen; ${ }^{2 s s}$ dem jungen Herrn gibt Stolle ironisch gemeinte Lehren. ${ }^{24}$ Von Frazen und Minne wird auch in der Spruchpoesie viel geredet, namentlich schön von Reinmar von Zweter, der das Wesen der Liebe treffend zeichnet, ${ }^{285}$ das Weib dem Grale vergleicht ${ }^{256}$ und die Minneschule als die höchste hinstellt. ${ }^{257}$ Die Macht der Minne an Beispielen der alten und mittleren Zeit veranschaulicht Frauenlob, ${ }^{238}$ der in begeistertes Lob der Frauen öfter ausbricht. ${ }^{39}$ Die Tugenden eines reinen Weibes stellt Regenbogen zusammen. ${ }^{360}$ Von Freundschaft handelt Heinrich von Rugge ${ }^{361}$ und Walther. ${ }^{203}$ Auch die Vergänglichkeit des Irdischen wird ebenso wie in den Liedern ausgesprochen ${ }^{265}$ die unablässige Reise, die der Mensch dem Tode entgegen macht; ${ }^{304}$ die Thorheit der Menschen, die meinen, man könne in Wahrheit der Welt entsagen, ${ }^{365}$ die die Gefahr der Sünde kennen und doch in ihre Stricke gehen.9os Das unnultze Thun vergeblicher Dinge verspottet Frauenlob ${ }^{\mathbf{3 6 7}}$ in einer später vielbeliebten Form, der Priamel, lat. prceambulum, die eine Reihe von Vordersätzen durch einen den Gedanken enthaltenden Nachsatz vereinigt. Auch diese Form ist sehr alt; das früheste Beispiel gewährt der junge Spervogel. ${ }^{208}$

Von den ewig sich erneuernden allgemeinen Verbältnissen des Lebens wendet der Dichter seinen Blick auf bestimmtere seiner Zeit; auf die Sitten der Rheinländer, die französischem Geschmacke huldigen; ${ }^{209}$ auf den Verfall der Kunst; ; $^{870}$ auf die trübe Lage der Dinge im allgemeinen ${ }^{271}$ und insonderheit auf die Zustände des Reiches und der

\footnotetext{
$24142,131.87,340.2470,1.2430,97 . \quad 24421,243 . \quad 2432,91 . \quad 24662$,

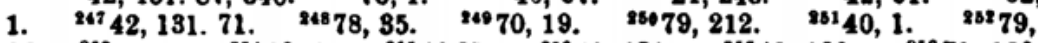

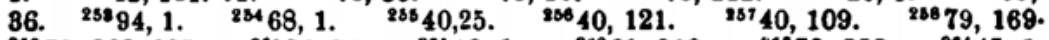
2ง9 79, 268. 285. 20094, 14. 261 $10,1 . \quad 26821,313 . \quad 26879,353 . \quad 26445,1$.

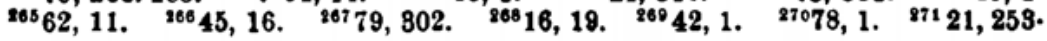


Kirche."12 Seine persönlichen Beziehungen und Erfahrungen namentlich den Grossen gegentuber veranlassen den Dichter $2 u$ Lob und Tadel: 2wei besondere Abarten bilden sich darans, das lobeliet "s und das rüegliet, "1" vielleicht auch schimpfliet, ${ }^{378}$ was jedoch Scherzlied bedeutet. Das Rügelied kommt dem sirventes der Provenzalen am nächsten. Wichtige Ereignisse im Leben des Gönners feiert der ihn begleitende Sänger." ${ }^{30}$ Er ermahnt zur Freigebigkeit" ${ }^{37}$ und spendet sein volles Lob, wo er Tugend und zumal Freigebigkeit, die dem fahrenden Dichter am höchsten erscheinende Tugend, findet. ${ }^{378}$ Seit der $\mathbf{z w e i t e n}$ Hälfte des dreizehnten Jahrhunderts werden die Lobsprüche häufiger, aber auch geschmackloser und plumper. Gegen nngerechtfertigtes Lob schmeichelnder Sänger richten sich die Strophen Bruder Wernhers. ${ }^{270}$ Der karge Grosse wird ebenso scharf getadelt wie der Freigebige begeistert gepriesen. ${ }^{260}$ Sehr beissend äussert sich Walther aber die ungastliche Aufnahme in dem reichen Tegernsee. ${ }^{281}$ An den Gönner richtet der bedürftige Dichter die Bitte um eigenen Besitz, ${ }^{282}$ da er das Glück des eigenen Heerdes nicht gekannt, sondern wandernd die Welt durchziehen muss, ${ }^{288}$ oder er fügt diese Bitte am Schlusse eines Liedes in einer besonderen Strophe an, ${ }^{284}$ wie namentlich romanische Dichter ähnliches lieben. Jubelnd bricht er nach Gewährung der Bitte in wärmsten Dank aus ; ${ }^{285}$ aber das Geschenk reicht nicht hin, die Abgaben sind zu gross, um ihn and seine Familie ernähren zu können. ${ }^{288}$

Ueberhaupt findet im Spruche der Dichter am häufigsten Anlass, seine persönliche Lage zu berühren, seine Standesverhältnisse zu schildern. Ein eigenes Lied hat darüber Hadloub gedichtet ${ }^{287}$, worin er die Haussorgen eines verheiratheten armen Dichters uns vorführt. Der eigenen Armuth gedenkt schon Spervogel, der seinen Kindern nicht Lehen noch Eigen hinterlassen kann. ${ }^{88}$ Die meisten Dichter, auch wenn sie ritterliches Standes waren, befanden sich in ärmlichen Verhältnissen und waren auf die Freigebigkeit der Grossen angewiesen; eine Ausnahme ist es, wenn der Truchsess von St. Gallen Gott dankt, dass er nicht wie sein Meister von der Vogelweide von Anderer Gnade leben müsse. ${ }^{280}$ Namentlich seit der Mitte des 13. Jahrhunderts, wo die politische Lage der Dichtkanst mehr und mehr ungünstig wurde, hãufen sich die Klagen ; ${ }^{990}$ freilich muss sich Herman der Damen selbst vorwerfen, dass er verschwenderisch gelebt und nichts erspart habe. 291 Dem auf das ver-

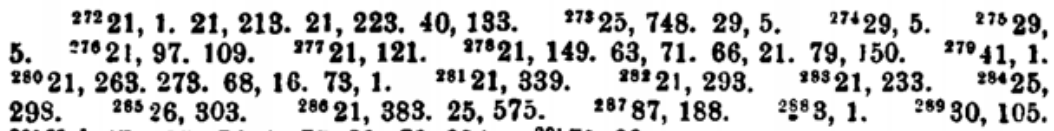

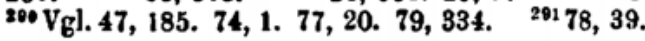


schiedenste gerichteten Geschmack des Publikums kann der Dichter nicht nachkommen, ${ }^{292}$ wenn auch seine ausgebreiteten Kenntnisse ihm allen möglichen Stoff zuführen. ${ }^{293}$ Die Spielleute, die durch erbärmliche Gaukeleien und Sittenlosigkeit sich ihren Unterhalt suchen, sieht er mehr berücksichtigt als wahre Kunst, ${ }^{264}$ und daher zieht er es vor, wiewohl alle Arten des Minnesanges ihm bekannt sind, keine Lieder zu singen, weil Weiber beim Weine zu schelten den jungen Herrn lieber geworden, als der Frauen Lob zu hören. ${ }^{296}$

Mit der Abnahme der Gunst der Grossen steigt der Neid unter den Sangesgenossen, indem noch landschaftliche und sprachliche Unterschiede hinzutreten; ${ }^{298}$ doch sind auch schon früher spottende Bemerkungen der Dichter über einander üblich gewesen. ${ }^{297}$ Der allzu zärtlich und ideal liebende Minnesänger muss sich den Spott seines realistischer denkenden Sangesbruders gefallen lassen. ${ }^{298}$. Den jüngern Dichter sehen wir von dem älteren in die Kunst eingeführt werden; jener huldet ihm als seinem Herm und wird wie ein Ritter in den Orden der Poesie aufgenommen. ${ }^{299}$ Doch ist die bestimmte Gestaltung des Verhältnisses zwischen Meister und Schüler erst ein Ergebniss später Zeit, die den Uebergang in die Kunst der Meistersänger bildet.

Anderer Art sind die persönlichen Angriffe Walthers auf Gerhard Atze, die auf einem Streit um ein erschossenes Pferd beruhen. ${ }^{200} \mathrm{Er}$ entschliesst sich zu 'scharfem Sange', weil er gesehen, dass man Herren Gut und Weibes Gruss nicht auf die höfische wohlerzogene Weise wie er bisher gethan erwerben könne. ${ }^{301}$

Die Spruchpoesie von meiner Sammlung auszuschliessen schien unthunlich, wiewohl der Titel nicht genau den Inhalt ausdrückt. Ohne sie würde die Entwickelung der deutschen Lyrik eine unvollständige gewesen sein; denn wir fanden, dass sie sich ebenso im Inhalt mit der eigentlichen Liederdichtung berührt, wie die Form eine in allen Hauptpunkten übereinstimmende ist.

Ueber die Form seien noch einige Bemerkungen gestattet. Die Strophe, mhd. gewöhnlich liet ${ }^{302}$ hat natürlich die grösste Manichfaltigkeit, was Wahl und Verbindung der Versarten, Verkettung der Reime betrifft. Wir unterscheiden den Text, mhd. wort, und die Melodie, wise oder dôn, auch gedone. ${ }^{303}$ Der Dichter war in der Regel auch Componist der begleitenden Melodie. Schon im zwölften Jahrhundert sehen

\footnotetext{
${ }^{202} 42,111 . \quad{ }^{203} 42,131 . \quad 29477,1 . \quad{ }^{295} 63,21 . \quad{ }^{206} \mathrm{Vgl} .42,20.66,1$. 11. $69,82.78,52 . \quad 29729,1 . \quad{ }^{298} 56,1 . \quad 29979,131 . \quad{ }^{300} 21,323.348 . \quad{ }^{301} 21$, 203. ${ }^{302} 58,20$; demin. liedel 39, 2. 98, 359. liedelîn 38, 99; doch hat liet daneben schon die heutige Bedeutung, 84, 57. $\quad{ }^{303} 21,244.1,17.25,648.39,3$. 11, 53. $39,1.37,6$.
} 
wir das Gesetz zwar nicht ansgesprochen, aber in Wirklichkeit durchgeführt, dass kein Dichter den von einem andern erfundenen Ton (Strophenform und Melodie) sich aneignen durfte. Wer das that, hiess ein dornediep. ${ }^{304}$ Daher jene Fülle von Tōnen, von der unsere moderne Lyrik kaum eine Vorstellung hat. Wenn manche Formen sich sehr nahe berühren, manche vielleicht anch in der Wahl der Versarten und Verkettung der Reime übereinstimmen (und das konnte bei einfachen Formen leicht geschehen, weil es in der Zeit breiterer Entwickelung unmöglich war, alle schon dagewesenen Verbindungen zu kennen und zu vermeiden), so ist daraus auf eine Nachahmung oder Aneignung noch keineswegs zu schliessen, denn die begleitende Melodie konnte verschieden sein. Die Provenzalen fanden von Anfang an nichts darin, in der Weise eines andern Dichters zu singen, and behielten dann nicht nur seine Melodie, sondern auch dieselben Reime bej.

In Deutschland war bis zur Mitte des 13. Jahrhunderts die Anwendung der Form eines andern nur in besonderen Fällen gestattet, z. B. wenn man gegen eines Dichters Ausspruch sich wandte, so brauchte man dieselbe Form, wie Walther ein paar Mal Reinmar gegenüber; der Truchsess von St. Gallen, wenn er über Walthers Armuth scherzt, braucht den Ton, in dem Walther über seine Dürftigkeit klagte; und der Vertheidiger der Bauern gegen Neidhart wendet die Form an, in der der Dichter den Kleiderschmuck jener verhöhnt. Von der zweiten Hälfte des 13. Jahrhunderts an, wo die Erfindungskraft an Form und Inhalt schwächer zu werden beginnt, kommen auch andere Fälle vor, und bei den Meistersăngern galt es für ganz unanstössig, in Tönen älterer oder gleichzeitiger Dichter zu singen.

Das allgemeine Gesetz der deutschen Strophenbildung ist der dreitheilige Bau; die Strophe besteht aus zwei einander gleichen (Stollen) und einem von jenen verschiedenen gewöhnlich längeren Theile (Abgesang). In meiner Sammlung sind die drei Theile durch grosse Buchstaben kenntlich gemacht. Doch fügen sich keineswegs alle Strophen diesem Gesetze; namentlich die Tanzlieder Neidharts zum Theil, auch eine Anzahl Spruchformen, z. B. Walthers, kennen es nicht. Eine besondere Beziehung zwischen Stollen und Abgesang braucht nicht zu walten; erst in späterer Zeit wird es üblich in dem Schlusse des Abgesanges den Stollen ganz oder theilweise zu wiederholen. Dagegen haben die älteren Dichter die Eigenthümlichkeit, die Reime durch alle drei Theile der Strophe hindurchgehen zu lassen, während sonst gewöhnlich im Abgesange neue Reime eintreten. Dass diese Wiederholung nicht 20442, 35. 
ursprünglich deutsche Art ist, zeigen die ältesten Dichter; sie beginnt erst mit der Nachahmung romanischer Formen, und bei den Romanen war diese Art die herrschende. Fast nur Dichter, die entschieden romanischen Einfluss verrathen (Veldeke, Hausen, Johansdorf, Neuenburg, Horheim, Schwangau), zeigen auch die Durchreimung von Stollen und Abgesang.

Die Anwendung dactylischer Verse findet sich am häufigsten im 12 . Jahrhundert und hängt gleichfalls mit der romanischen Poesie zusammen. Der am häufigsten vorkommende dactylische Vers von vier Hebungen ist genau der zehn - oder elfsilbige Vers der Romanen, der wie alle romanischen Verse kein festes Mass, sondern wie noch heutzutage im allgemeinen den geflïgelten Charakter von Anapästen und Dactylen an sich trägt. Indem die deutschen Dichter ihn herübernahmen, ahmten sie die Zahl der Silben (den Auftakt abgerechnet, der stehen und fehlen darf) und den rhythmischen Klang nach. So finden sich die dactylischen Vierfüssler rein gebraucht bei Johansdorf, ${ }^{305}$ Horheim, ${ }^{306}$ Bligger von Steinach, ${ }^{307}$ Hartmann von Aue, ${ }^{308}$ dem Markgrafen von Hohenburg, ${ }^{309}$ Hildbold von Schwangau, ${ }^{310}$ Walther, ${ }^{311}$ dem Herzog von Anhalt ${ }^{312}$ und einem ungenannten Dichter, ${ }^{313}$ doch hier theilweise durch innere Reime unterbrochen, die die Romanen bei dieser Versart ebenfalls häufig haben; derselbe Fall bei Heinrich von Rugge. ${ }^{314}$ Mit kürzeren dactylischen Versen gemischt bei Hausen ${ }^{315}$ und dem tugendhaften Schreiber $;^{316} \mathrm{mit}$ mehr als vierfüssigen bei dem von Kolmas, ${ }^{817}$ Kristan von Hamle, ${ }^{\text {s18 }}$ Ulrich von Liechtenstein ${ }^{319}$ und Burkart von Hohenvels, ${ }^{320}$ iiberall zugleich mit inneren Reimen versehen. Nur längere Verse hat der von Weissensee; ${ }^{321}$ mit andern (trochäischen und jambischen) Versen mischen den dactylischen Vierfüssler Veldeke, Morungen und Buwenburg. ${ }^{\text {s22 }}$

Am Schlusse der Strophe begegnet nicht selten der Refrän: entweder als ein Jodelruf, wie Walthers tandaradei, das zwischen die beiden letzten Strophenzeilen eingeschoben ist, ${ }^{823}$ und ähnliche kürzere und längere Rufe bei Neidhart, ${ }^{324}$ Stretelingen, ${ }^{325}$ Johann von Brabant, ${ }^{326}$ einem Namenlosen ${ }^{327}$ und einem Nachahmer Neidharts $;^{328}$ auch wâfen, das an der Spitze der Schlusszeile jeder Strophe bei Steinmar wiederkehrt, gehört hierher. ${ }^{329}$ Oder es sind wirklich bestimmte sich wiederholende Worte und Verse, namentlich im Tanzliede, wo sie das vom

${ }^{305} 11,9 . \quad{ }^{306} 12,28 . \quad{ }^{307} 17,1 . \quad{ }^{308} 18,115 . \quad{ }^{309} 19,1 . \quad{ }^{310} 20,1.15 .81$. 31121, 552; mit Veränderunz des zweiten Fusses nachgeahmt 98,176. $\quad{ }^{12} 27,1$. ${ }^{313} 98,281 . \quad{ }^{314} 10,23 . \quad{ }^{315} 8,19 . \quad{ }^{316} 24,1 . \quad{ }^{317} 13,1 . \quad{ }^{318} 32,1 . \quad{ }^{319} 33,73$ ${ }^{320} 34,1 . \quad{ }^{321} 93,1 . \quad{ }^{322} 7,129.14,208.88,1 . \quad{ }^{323} 21,569 . \quad{ }^{32+} 25,7 . \quad{ }^{325} 61$, 8. ${ }^{3: 6} 82,43 . \quad{ }^{327} 98,17 \jmath . \quad{ }^{328} 98,442 . \quad{ }^{329} 76,10$. 
Chore gesungene bezeichnen; ${ }^{330}$ aber auch sonst im Liebesliede, ${ }^{331} \mathrm{im}$ Tageliede, ${ }^{832}$ beim Markgrafen von Hohenburg am Schlusse der Stollen und des Abgesanges, je nach der redenden Person wechselnd. ${ }^{383}$ Diesen Wechsel je nach dem sprechenden hat Strophe um Strophe auch Wintersteten. $^{334}$ Der Umfang des Refräns ist sehr verschieden; er umfasst eine Zeile; ${ }^{335}$ gewöhnlich zwei Verse, ${ }^{886}$ seltener drei, ${ }^{337}$ vier, ${ }^{338}$ fünf, ${ }^{339}$ sechs; $;^{340}$ eine höhere Anzahl kommt in unserer Sammlung nicht vor.

Provenzalische Dichter pflegen am Schlusse des Liedes ein Geleit anzufügen, welches meist persönliche Beziehungen enthält und die letzten Verse der vorhergehenden Strophe in der Form wiederholt. Der Art, aber ohne persönliche Beziehung, die ausserhalb des Inhalts des Liedes stände, ist bei Morungen die dreizeilige Strophe, 14, 294-296, die dem Abgesang der vorhergehenden gleich ist. Und wie romanische Dichter mehrere Geleite anhängen, so hat Walther ${ }^{\mathbf{3 4 1}}$ den Abgesang der letzten Strophe mit Veränderung eines Reimwortes und Variation des Gedankens zweimal wieder aufgenommen.

Der strophischen Form wiederstrebt nur eine Dichtungsart, die die dritte Hauptgattung bildet, der leich, ${ }^{\mathbf{3} 2}$ von dem wir im Ganzen nur fünf Belege geben konnten. Seinem Inhalte nach kann der Leich sehr verschieden sein: dem Lobe der Geliebten ist der Liechtensteins ${ }^{3+3}$ und der Rotenburgs ${ }^{344}$ gewidmet; vom Wesen des Gottes Amor handelt der wilde Alexander, ${ }^{\mathbf{3 4 5}}$ und Tanhauser erzählt nach Art der Pastourelle in launigen, absichtlich mit Fremdwörtern stark gemischtem Stile sein Liebesabenteuer mit einer ländlichen Schönen. ${ }^{346}$ Der letztere Leich zeigt die Bestimmung, beim Tanze gesungen zu werden, wie denn der Dichter nach Beendigung seiner Erzählung in die übliche Weise des Tanzliedes übergeht. Aber es gibt auch religiöse Leiche; einen zur Theilnahme an den Kreuzzügen auffordernden Leich dichtete nach dem Tode Friedrichs I. Rugge $;^{347}$ in andern werden Bezüge auf Gönner, auf Erlebnisse des Dichters (namentlich beim Tanhauser) niedergelegt; die meisten jedoch haben die Minne zum Gegenstande. Den regclmässigsten Bau zeigt Liechtensteins Leich: er zerfällt in zwei grosse sich vollkommen gleiche Absätze, die durch grössere Anfangsbuchstaben kenntlich gemacht sind $;^{348}$ ihnen folgt ein kürzerer, ${ }^{340}$ der dieselben Melodien noch einmal,

${ }^{330} \mathrm{Vgl} .20,51.34,29.34,111.36,209$.

${ }^{331} 8,196.38,81 . \quad 33214,348$. 26, 54. ${ }^{333} 19,27$; wecke in frouve, der Wächter, sîtf geselle, die Frau. ${ }^{334} 38,191 . \quad{ }^{335} 14,348.26,54.19,27 . \quad{ }^{336} 8,196.20,51.34,29.34,111.38$, 13. $38,145.38,256.44,14.59,6.76,59.98,267 . \quad{ }^{337} 36,209.38,336.38,81$; hier weicht der Refrän der letzten Strophe ab. ${ }^{338} 82,9.64 .{ }^{349} 38,191$.

1. ${ }^{347} 10,44 .{ }^{348} 33,139-173.174-208 .{ }^{349} 33,209-220$. 
aber nur zur Hälfte wiederholt. Einige einleitende Verse (33, 133-138) und die Schlusszeilen (227-229) stehen in keiner nahen Verbindung und bilden eine Art musikalischen Vor- und Nachspiels. Bei Rugge sind die einzelnen Absätze zweitheilig, die meisten haben unter sich keine Verwandtschaft; ganz gleich sind nur die Absätze 113-122 und $151-160$; und ebenso $161-168=169-176$. Rhythmisch ist aber auch der Abschnitt 123-130 den an erster Stelle erwähnten beiden gleich, da man die beiden kurzen Zeilen (115 f. etc.) als eine mit Inreim (=125) nehmen kann, und wieder unterscheiden sich von den an zweiter Stelle erwähnten beiden Absätzen diese drei nur durch die Verschiedenheit des Reimgeschlechtes in der Schlusszeile beider Hälften. Auch der Absatz 79-84 zeigt nahe rhythmische Verwandtschaft mit 123-130 so wie 113-122. 151-160, indem in den drei letzten nur Erweiterungen jeder Hälfte um einen viersilbigen Vers eingetreten ist. Nicht zweitheilig sind die Absätze 131-150, wegen deren meine Anmerkung zu vergleichen ist. Freier gebaut ist der Leich Rotenburgs, wo nur die Zweitheiligkeit jedes einzelnen Leichabsatzes fest gehalten zu werden pflegt, die manchmal auch viertheilig auftritt, und gewisse Formen sich aufs neue mit derselben Melodie wiederholen. So kommt der sechszeilige Abschnitt 43, 21-26 noch sechsmal vor. ${ }^{350}$ Beim Tanhauser, wo die Zweitheiligkeit fast gar nicht begegnet, kehrt eine Form (47, 5-9) ebenfalls mehrfach wieder. ${ }^{351}$ Der wilde Alexander hat durchgehends zweitheiligen Bau der Absätze, und ausserdem Wiederholung einer grösseren Parthie: so. sind die vier Absätze 71, 67-84 vollkommen gleich den vier folgenden 85-102. Der dichterischen Freiheit war hier ein ziemlicher Spielraum gegeben, und die Lyriker des 13. Jahrhunderts haben davon den ausgedehntesten Gebrauch gemacht. Gegen Ende desselben wurde es Brauch, jedem Absatze, in sich zweitheilig, eine eigene Melodie zu geben, die nicht wiederholt wurde.

Vorstehenden Bemerkungen über Inhalt und Form unserer mhd. Lyrik lasse ich folgen, was über Zeit, Heimath und Leben der in meine Sammlung aufgenommenen Dichter bisher ermittelt worden ist. Eine so reiche Quelle wie für die Troubadours in den provenzalischen Biographien derselben besitzen wir leider bei unsern mhd. Dichtern nicht; die geringen Anhaltspunkte in ihren Liedern wie urkundliche Nachweise und Form und Charakter ihrer Poesie sind fast das einzige, worauf wir unsere Kenntniss bauen. Dennoch würde eine Darstellung des Lebens und Wirkens der deutschen Liederdichter in der Weise von Diez' Leben und

${ }^{350} 39-44.51-46.63-68.90-95.104-109.118-123 .{ }^{351} 47,10-14$. $29-33.45-49.81-85$. 
Werken der Troubadours eine dankenswerthe Aufgabe sein und ein anschauliches Bild vom mittelalterlichen deutschen Sängerleben liefern, da die Abhandlungen Hagens im vierten Bande seiner Minnesinger weder kritisch genug den Stoff behandeln, noch eine klare Entwickelung der einzelnen Dichter wie der gesammten Lyrik geben.

\section{Der von Kürenberc.}

Urkundlich sind mehrere dieses Geschlechtes, dessen Burg an der Donau eine Stunde westlich von Linz bei dem Kloster Wilhering lag, seit dem Anfang des zwölften Jahrhunderts nachgewiesen. Es erscheinen Burchard und Markward in einer Urkunde zwischen 1100-1139; Magnes 1121; Konrad 1140 und 1147; Heinrich 1150; Gerold 1155-60; Walther 1191; Otto und Burchard zwischen 1160-90; Heinrich zwischen 1190-1217. Die vier letztgenannten können nicht in Betracht kommen. Ob einer der früheren der Dichter ist, lässt sich nicht entscheiden: aber dem Geschlechte gehörte er an, und im Breisgau haben wir ihn nicht zu suchen. Seine Lieder, meist einzelne Strophen, habe ich alle aufgenommen. Ausgabe in 'Kiurenbergii et Alrammi Gerstensis poetarum theotiscorum carmina carminumque fragmenta recensuit G. Wackernagel. Berolini 1827' (wiederholt in Hoffmanns Fundgruben 1, 263-267); 'Minnesinger, deutsche Liederdichter des 12. 13. und 14. Jahrhunderts, von F. H. von der Hagen (MSH). Leipzig 1838' (4 Theile $4^{\circ}$ ) 1, 97; und 'des Minnesangs Frühling (MF) herausgegeben von Karl Lachmann und Moriz Haupt. Leipzig 1857' 8. 2. Ausgabe 1875. S. 7-10. Vgl. dazu die Recension von K. Bartsch und Fr. Pfeiffer, Germania 3, 481-508, und Haupts Erwiderung, Zeitschrift 11, 563-593, so wie Germania 4, 232-237. Die urkundlichen Nachweise MF. S. 229 fg. Germania 2, 492 fg. Vgl. Hagen 4, 109. Scherer in der Zeitschrift f. d. Alterth. 17, $561 \mathrm{ff}$. versuchte die Autorschaft des K. zu widerlegen und die ihm beigelegten Strophen als Produkte verschiedener nachzuweisen. Vgl. dazu Fischer, Die Forschungen über das Nibelungenlied (Leipzig 1874) S. $257 \mathrm{ff}$. Scherer in der Zeitschrift 18, 150; Bartsch in der Germania 19, $356 \mathrm{ff}$., Fischer ebenda 20, $118 \mathrm{ff}$. und Paul in seinen Beiträgen 2, $406 \mathrm{ff}$. Dem Dichter hat, auf die Uebereinstimmung der strophischen Form gestützt, Franz Pfeiffer das Nibelungenlied zugeschrieben: 'Der Dichter des Nibelungenliedes. Ein Vortrag, Wien 1862.' Vgl. dazu K. Vollmöller, Kürenberg und die Nibelungen Stuttgart 1874; Bartsch in der Germania 19, $352 \mathrm{ff}$. und dessen Untersuchungen über das Nibelungenlied (Wien 1865) S. $352 \mathrm{ff}$. 


\section{Hêr Dietmâr von Aiste.}

Der Familienname lautet in Urkunden des 12. Jahrhunderts Agast, Agist, Aist; B bat Aste, C Ast. Das Geschlecht war im Lande ob der Ens, in der Riedmark, ansässig und leitete den Namen von dem Bache Agist, jetzt Aist. Dietmar erscheint in Urkunden seiner Heimath nicht selten. Zuerst in einer zu Lorch ansgestellten Urkunde von 1143, in eincm Gütertausch der Probstei Berchtesgaden um 1144, in einer Urkunde Herzog Heinrichs, Wien 1158, in einer Urkunde des Bischofs Konrad von Passau 1159, in der Bestätigung des Privilegiums von $1158 \mathrm{im}$ Jahre 1161. Im Salbuche des Klosters Aldersbach findet sich eine um 1170 angesetzte Urkunde über eine Schenkung Dietmars. Im Jahre 1171 war er sicher schon todt: eine Urkunde Herzog Heinrichs ans diesem Jahre gedenkt seiner Schenkungen an das Kloster Garsten und bezeichnet ihn als verstorben. Auch dem Kloster Baumgartenberg machte er Schenkungen, die 1209 Herzog Leopold VI. bestätigte. Seine Lieder tragen nicht alle das alterthümliche Gepräge, das in Form und Ausdruck der Zeit vor 1170 zukommt. Daher ist Wackernagels Vermuthung, es seien unter seinem Namen zwei Dichter gemischt, nicht unwahrscheinlich; aber nicht zwei dieses Geschlechtes, denn mit Dietmar starb dasselbe aus. Sein Erbe gieng vermuthlich an seine Schwester Sophia über, die mit Engilbert von Schonheringen vermählt war. Ich habe nur die alterthïmlicheren Strophen ausgehoben. Vgl. Scherer, deutsche Studien II. (Wien 1874), 473 ff.; Paul in seinen Beiträgen 2, 457 ff., Lehfeld ebenda 2, 371 ff. - Seinen Tod beklagt Heinrich vom Türlein (um 1220) in der Krone 2438 ouch muog ich klagen den von Eist, den guoten Dietmâren, an der Spitze von andern Lyrikern des 12. Jahrhunderts. - MF. 32-41. MSH. 1, 98-102. Die arkundlichen Nachweise MF. 245 (247) und Germania 2, 493; vgl. 3, 505. Hagen 4, 111.

\section{Spervogel.}

Die Handschriften unterscheiden einen Spervogel und einen jungen Spervogel, weisen also auf zwei Dichter hin, wenngleich sie die Strophen beider vermischen. Die Unterscheidung bestätigt Metrik und Reimgebrauch. Nach Simrock (Lieder der Minnesänger 8. IX und Paul 2, 127) hiess der ältere Dichter Herigêr, was aus $\mathbf{3 8}$ gefolgert werden kann, aber nicht muss. Er war ein wandernder Sänger von bürgerlichem Stande, dessen Zeit namentlich durch die in 8-12 erwähnten Persönlichkeiten sich bestimmt. Wernhard von Steinberg erscheint in einer 
Wormser Urkunde Lothars III. vom 27. December 1228 und könnte der vom Dichter beklagte sein. Steinberg ist Gräfensteinberg bei Gunzenhausen, wo die Fürsten von Oettingen noch im 18. Jahrhundert Besitz hatten. Er müsste aber lange gelebt haben, wenn 8pervogel seinen Tod zugleich mit dem Walthers von Husen beklagen konnte (8); denn dieser, der Vater des Dichters Friedrich von Husen, in Urkunden seit 1159, lebte noch im Jahre 1173. Heinrich von Giebichenstein ist noch nicht nachgewiesen; Heinrich von Staufen ist wahrscheinlich der Burggraf von Regensburg, denn die Steveninger Burggrafen nannten sich auch von Regenstauf oder von Stauf. Baiern war vermuthlich die Heimath des Dichters. Seine Strophen habe ich sämmtlich aufgenommen. Sie stehen hinter denen des jüngern Dichters im MF. 25-30. MSH. 2, 374-377. Lieder und Sprüche der beiden Meister Spervogel. Heransgegeben von H. Gradl. Prag 1869; vgl. Germania 15, 237 ff. Schneider, Spervogels Lieder. Halberstadt 1876. Die urkundlichen Nachweise MF. 237 (238 f.). Haupt, Hartmanns Lieder S. XVI. Pfeiffer, Germania 2, 494. Hagen 4, 685-692. Vgl. noch Scherer, deutsche Studien I. Wien 1870; Paul in seinen Beiträgen 2, $427 \mathrm{ff}$.

\section{Hêr Meinlôh von Sevelingen.}

Die von Sevelingen, jetzt Söflingen, bei Ulm waren Truchsessen der Grafen von Dillingen. Nur ein jüngerer Meinlôh de Sevelingen ist in einer Urkunde des Klosters Kaisersheim von 1240 nachgewiesen (Stälin, wirtembergische Geschichte 2, 761); wahrscheinlich ein Enkel des Dichters. Derselbe hat nur gepaarte, keine überschlagenden Reime: die Strophenform seiner Lieder ist eine Erweiterung der Nibelungenstrophe. MF. 11-15; vgl. S. 231 (232). MSH. 1, 219 fg. 4, 156-158. Vgl. Paul, Beiträge 2, 418 f. 452 f.

\section{v. Der burcgr\&̊v von Regensburc.}

Die Burggrafschaft Regensburg war bis zum Jahre 1184 in dem Geschlechte der Grafen von Steveningen und Rietenburg erblich: daher die von Hagen (4, 155) ansgesprochene Vermuthung, es sei der Burggraf von Regensburg und der von Rietenburg eine und dieselbe Person, manches für sich hat. Demselben Geschlechte haben beide Dichter sicher angehört. Der Zeit nach würde am besten passen Heinrich von Stevening und Rietenburg, der 1161-1176 Burggraf von Regensburg war. MF. 16-17; vgl. S. 232 (233 f.) MSH. 1, 171. 4, 480-484. 


\section{Der burcgrâve von Rietenburc.}

Formell unterscheidet er sich von dem vorigen durch künstlichere Strophenformen und überschlagende Reime, während jener in seinen einfachen an die Nibelungenstrophe sich anlehnenden Weisen nur gepaarte kennt. Daher vielleicht der Sohn des vorigen, Friedrich, von 1176 bis um 1181 Burggraf von Regensbarg. MF. 18-19. 232 (234). MSH. 1, 218. 4, 155 fg. Vgl. Paul Beiträge 2, 419 f. 455 f. Lehfeld ebenda 2, $365 \mathrm{f}$.

\section{Hêr Heinrich von Veldeke.}

Stammt aus einem ritterlichen Geschlechte, das in der jetzigen belgischen Provinz Limburg heimisch war. Bis jetzt ist nur eine bei dem Dorfe Spalbecke gelegene Mühle namens Veldeke and um 1235 ein Heinrich ron Veldeke, wahrscheinlich ein Nachkomme des Dichters nachgewiesen. In seiner Heimath fand er einen Gönner an Grafen Ludwig von Loz († 1171) und dessen Gemahlin, Agnes, der einzigen Tochter des Grafen von Reineck: auf ihren Anlass dichtete er nach lateinischer Quclle die Legende von S. Servatius, dem Schutzheiligen von Mastricht. Am Hofe von Cleve wurde vor 1175 der grösste Theil seines Hauptwerkes, der Eneide, bei dem er dem Roman d'Eneas von Benoît de Sainte More folgte, geschrieben, allein das Manuscript durch einen Grafen Heinrich von Schwarzburg dem Dichter entführt, der sein Werk etwa zehn Jahre später auf der Neuenburg an der Unstrut im Dienste des Landgrafen Hermann von Thüringen, damals noch Pfalzgrafen, vollendete. Zu Pfingsten 1184 war der Dichter bei dem Feste zu Mainz anwesend, welches Friedrich I. zu Ehren der Schwertleite seiner Söhne veranstaltete. Seinen Ruhm rerdankt Heinrich hauptsächlich der Eneide; als Lyriker nennt ihn der Marner (XIII, 58) und ein Meistergesang des vierzehnten Jahrhunderts (m. Meisterlieder 24, 41). Bei ihm zuerst finden wir den Einfluss französischer Lyrik auf die deutsche im Strophenbau, in einzelner Nachbildung und im ganzen Geiste. Ausgabe des Servatius: Sinte Servatius Legende van Heynrijck von Veldeken, uitgegeven door $\mathbf{J}$. H. Bormans. Maestricht, 1858 (8. 285 SS.); vgl. daza K. Bartsch, Germania 5, 406-431. Eneide und Lieder in Heinrich von Veldeke herausgegeben von Ludwig Ettmïller. Leipzig 1852 (8. XX, 476 SS.); tiber die französische Quelle: A. Pey, essai sur li romans d'Eneas. Paris 1856, und derselbe in Eberts Jahrbuch fur romanische und englische Literatur 2, 1-45. Die Lieder im MF. 56-68. MSH. 1, 35-40; vgl. 4, 72-79. Vgl. noch Braune in Zachers Zeitschrift 4, 249-304; Paul, Beiträge 2, 421 f. $471 \mathrm{ff}$. 


\section{Hêr Friderich von Hûsen.}

Der Sohn Walthers von Husen, dessen Tod Spervogel (III) beklagt. Mit seinem Vater zugleich erscheint er 1171 als Zeuge in einer Urkunde des Mainzer Erzbischofs Christian I. (Baur, hessische Urkunden. Darmstadt 1860. 2, 23). Im Jahre 1175 war er in Italien: in Pavia bezeugt Fridericus filins Waltheri de Husen eine Urkunde desselben Bischofs aus diesem Jahre (Baur 2, 24). Nochmals war er 1186 mit Heinrich VI. in Italien und bezengt am 30. April des genannten Jahres in Borgo San Domino eine Urkunde Heinrichs für Lucca (Haupts Zeitschrift 14, 134), am 6. October einen Schutzbrief des Königs zu Bologna (Stälin 2, 768) und am 28. Januar 1187 in Foligno eine Urkunde zu Gunsten der Camaldulenser (Haupt a. a. O.) Im December 1187 war er bei dem Gespräche Friedrichs I. und Philipp Augusts zwischen Mouzon an der Mass und Yrois, sowie anf dem Rückwege bei einer Verhandlung zu Virton gegenwärtig. 1188 geleitete er den Grafen Balduin V. von Hennegau und bezengt zu Weihnachten 1188 in Worms die Belehnung Balduins mit Namur. 1189 zog er mit Friedrich I. ins heilige Land, und kam am 6. Mai in einem Gefechte bei Philomelium, von seinen Genossen lebhaft beklagt, um. Seiner gedenken Dichter des 13. Jahrhunderts mehrfach rühmend, so Heinrich von dem Türlin (Krone 2443), Reinmar von Brennenberg (unten XLVI, 73) und der von Gliers (MSH. 1, 107 ). Seine Lieder tragen rheinfränkische Färbung und lehnen sich wie die Veldekes an romanische Vorbilder an: bis jetzt sind nur provenzalische Belege nachgewiesen (zu VIII, 68. 170). Die Reime zeigen noch viele Freiheiten; ganz rein gereimt sind nur MF. 52, 37-53, 14 (nur in C) und 53, 15-30 (in BC), die auch keine Spur mundartlicher Abweichung zeigen. - MF. 42-55. MSH. 1, 212 bis 217. 3, 321. Die urkundlichen Nachweise MF. 249. 251 (251. 252). MSH. 4, 150-154. Haupt, Hartmanns Lieder S. XVI. Stälin 2, 768. Vgl. noch Mullenhoff in Haupts Zeitschrift 14, 133-143. Lehfeld in Panl-Braunes Beiträgen 2, 345-405. Panl ebenda 2, 422 ff. 443 ff. Spirgatis, die Lieder F's. v. H. Tübingen 1876.

\section{Grâve Ruodolf von Fênis.}

Es ist Rudolf II., Graf von Neuenburg in der Schweiz, der in Urkunden 1158-1192 erscheint und vor dem 30. August 1196 starb. Seine Lieder sind meist Nachbildungen provenzalischer Originale, die bis jetzt aus Peire Vidal und Folquet von Marseille nachgewiesen sind. Und zwar müssen ihm die Originale bald nach ihrer Enstehung bekannt 
geworden sein, denn das dem Peire Vidal nachgedichtete Lied fält ins Jahr 1189 (s. meinen Peire Vidal S. XL) und in die achtziger Jahre auch die Lieder Folquets. Seine Heimath erklärt die rasche Verbreitung. Unter verstorbenen Liederdichtern nennen ihn der Marner (unten XIII, 57) and Reinmar von Brennenberg (XLVI, 71). MF. 80-85. MSH. 1, 18-20. Urkundliche Nachweise MF. 262 (263). MSH. 4, 47-52. Ueber das Verhältniss zur provenzalischen Poesie: Bartsch in Haupts Zeitschrift 11, 145-162. Vgl. noch Branner im Berner Taschenbuch für 1873; Pfaff in der Zeitschrift für dentsches Alterthum 18, 44-58; Scherer, deutsche Studien 2, 35. Paul, Beiträge 2, 433 fr. 450 f.

\section{Hêr Heinrich von Rngge.}

Er erscheint als Zeuge (Heinricus miles de Rugge) in einer zwischen 1175-1178 ausgestellten Urkunde des Abtes Eberhard von Blaubeuren. Seine Lieder haben noch hin und wieder Assonanzen, während sein Leich, der eine Ermahnung zur Theilnahme am Kreuzzuge enthält und im Spätjahr 1191 geschrieben ist, als die Trauerkunde von Friedrichs I. Tode (10. Juni 1190) nach Deutschland gekommen war (44-176), mit einer einzigen Ansnahme, nur reine Reime hat. Daher müssen seime Lieder früher fallen. Als Leichdichter ist er nach Ulrich von Gutenburg (MF. 69-77) der älteste, denn von Friedrich von Husen sind ans keine Leiche erhalten, und als solchen rühmt ihn neben andern der von Gliers (MSH. 1, 107 ), als Liederdichter Heinrich von dem Türlin (Krone 2442) und Reinmar von Brennenberg (unten XLVI, 72). MF. 96-111. MSH. 1, 220-222. 3, 468. Der arkundliche Nachweis durch Pfeiffer, Germania 7, 110. Vgl. noch E. Schmidt, Reinmar von Hagenan und Heinrich von Rugge. Strassburg 1874. Vgl. Paul, Beiträge 2, 487 ff. 531 ff.

\section{Hêr Albreht von Jôhansdorf.}

Ans einem bairischen ritterlichen Geschlechte. Albertus et frater ejus Eberhardus de Jahenstorf in einer Urkunde des Bischofs Hermann von Bamberg, Osterhofen 1172, unter den Ministerialen; Albert allein als Ministeriale desselben Bischofs 1188. In einer Urkunde des Klosters S. Nicolaus zu Passau (um 1185) Albert und sein Bohn Adalbert Der Sohn ist wahrscheinlich der unter Ministerialen des Bischofs Wolfker von Passau 1201 und 1204, des Bischofs Manegold 1209 vorkommende. Ich halte den 1185-1209 orscheinenden fir den Dichter. Er nahm an einem Krenzzuge Theil, wahrscheinlich dem Friedrichs I. (1189); auf denselben beziehen sich mehrere Strophen. Das Gesprăchslied 
(33-34) gehōrt wohl seiner spätern Zeit an. Rühmend gedenkt seiner Reinmar von Brennenberg (XLVI, 73). MF. 86-95. MSH. 1, 321-325. 3, 329. Urkundliche Nachweise MF. 267 (268).

\section{Hêr Berngêr von Horheim.}

Vermuthlich im Enzgau (Wirtemberg) heimisch, wo es Herren von Horheim gab. Er war an der Heerfahrt nach Apulien betheiligt, die im Frühling 1190 Heinrich VI. nach dem Tode Wilhelms II. ron Sicilien sendete; Heinrich selbst folgte am Ende desselben Jahres nach. Seine Lieder verrathen französischen Einfluss; bestimmte Nachahmung ist an einem Liede dargethan (1-27). MF. 112-115. MSH. 1, 319-321. Die historischen Nachweise MF. 275 fg. (276 f.)

\section{Der von Kolmas.}

Aus einem thüringischen Geschlechte, aus dem ein Henricus de Kolmas in Eisenacher Urkunden von 1274, 1277 und 1279 nachgewiesen ist. Von ihm kennen wir nur das eine tiefempfundene Lied, dessen Ton und Rhythmus mehr als die Reime für die Zeit, in der er lebte, zeugen. MF. 120-121. MSH. 3, 468 . Altd. Blätter 2, 122. Urkundliche Nachweise MF. 277 f. $(278$ f.)

\section{Hêr Heinrich von Môrangen.}

Auch er ist ein thüringischer Ritter aus der Gegend von Sangerhausen, wo ein Geschlecht seines Namens, doch nicht der Dichter selbst nachgewiesen ist. Ein jüngerer Heinricus miles de Morungen begegnet 1276. Zu dieser Heimath stimmt seine Mundart, über welche Pfeiffer, Germania 3, 503, zu vergleichen ist. Auch in Meissen hat Bech einen Henricus de Morungen um 1213-21 nachgewiesen. Unter den Lyrikern vor Reinmar und Walther ist Heinrich von Morungen an Tiefe und Manichfaltigkeit unbestritten der bedeutendste. Auffallend ist, dass keiner der spätern Lyriker seiner gedenkt. Als Dichter von Tageliedern erwähnt ihn Seifried Helbling 1, 759; als Dichter überhaupt Hugo von Trimberg (Renner S. 20). Er war ein gebildeter Dichter, dem auch das klassische Alterthum nicht fremd war (MF. S. 284). Seine Zeit bestimmt sich 'nicht aus äusseren Beziehungen, auch nicht aus den Reimen, denn diese sind, das mundartliche abgerechnet, durchaus rein, sondern aus dem ganzen Charakter seiner Lieder, der Durchreimung von Stollen und Abgesang, der Anwendung des daktylischen Rhythmus und der Nachahmung provenzalischer Dichter, die ich Germania 3, 304 
gezeigt habe. MF. 122-147; vgl. 278 (279 f.) MSH. 1, 120-131. 3, 317. 4, 122-126. Die urkundlichen Nachweise durch Bech, Germania 19, 419; Zurborg in der Zeitschrift f. d. Alterthum 18, 319. Vgl. noch Germania 8, 54. 15, 375; Paul, Beiträge 2, 475. 546 ff.

\section{Hêr Reinmâr.}

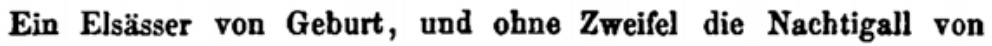
Hagenau, deren Tod (um 1207) Gottfried von Strassburg beklagt. Hauptsächlich scheint er sich am österreichischen Hofe aufgehalten zu haben, wo er auf Walthers Entwickelung nicht unwesentlich einwirkte. Er schloss sich dem Krenzzuge Herzog Leopolds VI. (1190) an (352-381) und widmete diesem seinem Gönner, als derselbe Ende des Jahres 1194 starb, ein schōnes Klagelied (199-234). Sein Verhältniss zu Walther muss nicht immer freundlich geblieben sein; dennoch klagt Walther mit aufrichtigem Schmerze um seinen Tod (XXI, 361-386). Reinmar neben Hartmann wird von Heinrich von dem Türlein (Krone 2416 ff.) beklagt. Der Beiname 'der Alte', den er in der Handschrift $\mathbf{C}$ hat, soll ihn von dem jüngern Reinmar von Zweter unterscheiden, mit dem zusammen (zwêne Regimâr) der Marner ihn nennt (XLII, 57). Er ist unter den eigentlichen Liederdichtern nächst Walther der fruchtbarste. MF. 150 bis 204. Hagen 1, 174-201. 3, 318-321. 468. 4, 137-144. Lachmann zu Walther 82, 24. E. Schmidt (vgl. zu X); E. Regel, Germania 19, 149-182; Bötticher, ebd. 22, 70-93. 195-225. Paul, Beiträge 2, 487 ff. $535 \mathrm{ff}$.

\section{Der junge Spervogel.}

Von dem älteren Dichter (III) wohl um 20-30 Jahre abstehend, aber noch dem Schlusse des 12. Jahrhunderts angehörend, da er, wenn auch wenige, Reimungenauigkeiten hat und hin und wieder die Senkungen auslässt. Seine Strophen stehen MF. 20-25 vor denen des ältern Dichters; vgl. Germania 2, 494. 3, 482. MSH. 2, 371. 374. 375-376. Paul, Beiträge 2, 427. Den Spruch 55 ff. citirt mit Spervogels Namen die Zimmernsche Chronik 4, 414.

\section{Hêr Bliggêr von Steinach.}

Ein rheinpfälzischer Ritter, dessen Stammburg am Neckar noch heute in Trümmern sichtbar ist. Er und sein Bruder Konrad erscheinen mit ibrem Vater Bligger bereits 1165 in Urkunden, 1184 er mit Konrad als Zeuge einer Schönauer Urkunde des Pfalzgrafen Konrad; 1196 in einer Urkunde Heinrichs VI. in Worms, obne den Bruder; 1198 mit 
Konrad und Ulrich bei dem Kanfe des Gutes Lochheim, und Bligger noch 1209 als Vermittler eines Streites zwischen dem Kloster Eberach und Eberhard Waro von Hagen. Er war 1194 mit Heinrich VI. in Italien: in Piacenza bezeugt er eine Urkunde Heinrichs, eine Schenkung an das Bisthum Brixen betreffend. Er dichtete schon vor 1193, da er Saladins († 3. März 1193) als eines lebenden gedenkt (XVII, 38). Sein Sohn Bligger, urkundlich seit 1211, und 1228 gestorben, den Hagen (MS. 4, 256) für den Dichter hält, ist zu jung. Als Gottfried seinen Tristan schrieb (um 1207), lebte er noch: Gottfried hebt preisend seinen 'Umhang' hervor, ein episches Gedicht, das novellenartige Erzählungen vermuthlich des klassischen Alterthums unter dem Bilde eines Wandteppichs an einander reihte. Nicht minder rūhmt ihn Rndolf von Ems im Willehalm und Alexander. Von dem verloren geglaubten 'Umhang' hat Franz Pfeiffer (zur deutschen Literaturgeschichte, Stuttgart 1855. S. 1-18) mit grosser Wahrscheinlichkeit ein anonym überliefertes Bruchstück nachgewiesen. Benutzt scheint der Umhang in des Pleiers Meleranz (S. 365 meiner Ausgabe, vgl. Germania 8, 61). Von den Liedern sind nur die beiden von mir ausgehobenen (1-39) echt: das dritte (MF. 119, 13-27), das nur $C$ hat, verräth strophischen Bau, wie er zur Zeit des Dichters nicht üblich war. Es könnte einer der jüngern Bligger der Verfasser sein. - MF. 118-119. MSH. 1, 326. 4, 254-260. Vgl. noch Ritsert im Archiv f. hessische Geschichte Bd. 12, 1 (1868).

\section{Hêr Hartman von Onwe.}

Ein Dienstmann der Herren von Aue, in Schwaben, aus der Gegend von Rottenburg, etwa zwischen 1160-1170 geboren, dichtete etwa von 1190-1204. Er war noch am Leben, als Gottfried den Tristan dichtete (um 1207); um 1220, wo Heinrich von dem Turlein um ihn klagt (Krone 2348), bereits todt. Eines seiner Lieder ist in Franken (XVII, 88) nach Saladins Tode (3. März 1193) gedichtet. Er nahm an einem Kreuzzuge Theil, wahrscheinlich dem von 1197, wenn nicht, was aus mehreren Gründen nicht unwahrscheinlich, an zweien, dem von 1189 und 1197. Hartmann stand bei seinen Zeitgenossen in hohem Ansehen und wird von ihnen und spätern Dichtern oft gepriesen, am schönsten wold von Gottfried in der bekannten Stelle des Tristan. Doch bezieht sich dies Lob fast ausschliesslich auf seine epischen Dichtungen: nur die Stelle der Krone nennt ihn neben Reinmar und andern Lyrikern; und der von Gliers (MSH. 1, 107') erwähnt ihn unter Leichdichtern. Leiche von ihm haben sich nicht erhalten. Hartmanns erzahlende Dichtungen (Erec, Gregor, Iwein, armer Heinrich) so wie die beiden 
Büchlein können wir hier übergehen. Seine Lieder im MF. 205-218, in 'die Lieder und Büchlein und der arme Heinrich von Hartmann von Aue herausgegeben von Moriz Haupt, Leipzig 1842', wo S. X. fg. die Nachrichten über Hartmanns Leben zusammengestellt sind, und in Bech's Ausgabe von Hartmanns Werken Bd. 2 (2. Auflage, Leipzig 1873). MSH. 1, 328-334. 3, 468". 4, 261-278. Stälin 2, 762. Vgl. noch E. Sambaber, die innere Chronologie der Lieder H. v. A. (Programm) Freistadt 1873; H. Schreyer, Untersuchungen über das Leben und die Dichtungen H's v. A. Naumburg 1874. H. L. Schmid, des Minnesängers H. v. A. Stand, Heimath und Geschlecht, Tubingen 1874. Wilmanns in Haupts Zeitschrift 14, 149-155; Heinzel ebd. 15, 125-140; Paul, Beiträge 2, 172 ff. 476 ff.

\section{Der marcgrafve von Hôhenburc.}

Nach dem Charakter der Lieder kann dies nur der Markgraf Diepold von Vohburg sein, der 1212 die Wittwe Friedrichs Grafen von Hohenburg, Mathilde, eine Gräfin von Andechs, heirathete und 1212-1225 in Urkunden den Titel eines Markgrafen von Hohenburg fübrt. Er ward von Heinrich VI. mit der Grafschaft Acerra in Sicilien belehnt, führte nach dem Tode Heinrichs (1197) den Oberbefehl des deutschen Heeres und die Statthalterschsft, und besiegte, nachdem er selbst mehrmals Niederlagen erlitten und gefangen worden, 1205 den Grafen Walther von Brienne, der als Gatte der ältesten Tochter Tancreds, Albinia, Anspruch auf Sicilien erhob. Mit Friedrich II. kehrte 1212 Diepold nach Deutschland zurück und starb 1226. Dass er, nicht sein Sohn Berthold, der Dichter ist, zeigt der daktylische Rhythmus mehrerer Lieder (1-24 bei mir und Hagen 1, 34 $4^{\circ}$, der alterthümliche Reim verlat: gedaht $\left(1,3^{\mathrm{b}}\right)$, das Durchreimen in Stollen und Abgesang nach romanischer Weise $\left(1,33^{\circ}\right)$. Das Lied $1,34^{b}$ hat $\mathrm{C}$ allerdings nochmals unter Hildbold von Schwangau, aber A hiln die Autorschaft des Hohenburgers bestätigen, indem es diese Strophen dem Markgrafen von Rotenburg beilegt. Der König $\left(1, \mathbf{3}^{\mathrm{b}}\right)$ ist daher nicht Konrad, sondern Friedrich II. vor seiner Kaiserkrönung. MSH. 1, 33-34. 3, 317. 4, 68-72.

\section{Hêr Hiltbolt von Swanegou.}

Ein schwäbischer Ritter: am linken Ufer des obern Lechs, jetzt zu Baiern gehörend, stand das Schloss, wo jetzt, Hohenschwangau genannt, eine neu erbaute Burg steht. Er kann weder der Hiltbolt sein, der 1146 eine Schenkung des Herzoga Welf bezengt, noch derjenige, 
der von 1221-1254 in Urkunden vorkommt, vermuthlich ein Enkel des erstern, sondern der Vater des zweiten, der auch Hiltbold geheissen haben wird, aber in Urkunden nicht nachgowiesen ist. Denn seine Zeit fält, wie der Charakter seiner Lieder zeigt, in das Ende des 12. und den Anfang des 13. Jahrhunderts. Daranf weist bestimmt der häufige daktylische Rhythmus seiner Lieder, die Beibehaltung der Stollenreime im Abgesange nach romanischem Muster, in einem Liede die ebenfalls romanische Umstellung der Reime in den Stollen (XX, 15-50), die einreimigen Strophen (45-46 C), die zweistrophigen (XX, 1-14. C 14-15. 19-20. 22-23. 43-44) and vierstrophigen Lieder $(1-4$. 7-10 C). Doch können leicht zwei Dichter desselben Geschlechtes gemischt sein, denn C 11-13 (=XX, 51-80) und 33 stimmen nicht zu der Art der übrigen. Er machte eine Kreuzfahrt mit, auf die sich XX, 15-50 bezieht und von der er glücklich heimkehrte; vermuthlich ist der Zng Leopolds VII. von Oesterreich 1217 gemeint, wenn nicht ein früherer. Hiltbold mag um 1220 gestorben sein, denn von 1221 erscheint der dritte Hiltbold in Urkunden. - MSH. 1, 280-284. 4, 190 bis 192. B's von Schwangau Minnelieder übersetzt und herausg. von J. Schrott. Augsburg 1871.

\section{Hêr Walther von der Vogelweide.}

Von den vielen Vermuthungen über seine Heimath hat diejenige die meiste Wahrscheinlichkeit für sich, die ihn in Tirol, auf der Vogelweide am Layener Ried im Eisackthale, geboren sein lässt. Walther kam frühe nach Oesterreich, wo er nach seiner eigenen Aussage singen und sagen lernte. Nach dem Tode Herzog Friedrichs in Palästina (Mitte April 1198) verliess er Oesterreich (XXI, 85-96) und gieng nach einem kurzen Aufenthalte am thüringischen Hofe, von wo ihn der lästige Zusammenfluss von Begehrenden verscheuchte (73-84), nach Mainz, wo er der Krönung Philipps von Schwaben am 8. September 1198 beiwohnte (97-108). Die nächste Zeit blieb er in Philipps Gefolge; er besang die Weihnachtsfeier des Königs zu Magdeburg 1199, aber nicht mehr als Augenzeuge (109-120), denn schon Ende 1199 war er wieder in Oesterreich, wo er am 12. Nov. vom Bischof Wolfker von Passau einen Pelzrock geschenkt erhielt. Zu Pfingsten 1200 finden wir ihn bei der Schwertleite Leopolds zu Wien; aber nur vorübergehend. Zwischen dem September 1204 und dem Sommer 1211 hielt der Dichter sich eine Zeit lang am thüringischen Hofe auf (322-338. 348-360), wo er Wolframs Bekanntschaft machte. Im Jahre 1212 erscheint er im Dienste des Markgrafen Dietrich von Meissen (149-162), bei dem er jedoch längstens 
bis Herbst 1213 verweilte. Demnächst folgt der Dienst bei Otto IV., der dem Dichter die gegebenen und ernenten Versprechungen nicht hielt und dadarch sich ihn entfremdete (263-272. 273-282). Er verliess ihn und begab sich zu Friedrich II., der jhm den lang gehegten Wunsch eines eigenen Heerdes durch Ertheilung eines kleinen Lehens erfiillte (283-312). Allein auch jetzt hörte sein Wanderleben nicht auf: er gieng im Frühjahr 1217 nach Oesterreich, als Herzog Leopold gerade zum Kreuzzuge sparte, den er im Sommer 1217 wirklich antrat. In diese Zeit fältt auch sein Aufenthalt beim Herzog Bernhard von Kärnten (163-212). Um 1220 finden wir Walther in der Umgebung des Sohnes Friedrichs II., König Heinrichs, zu dem er in einem schwerlich mit Sicherheit aufzuklärenden Verhältnisse stand. Nach der Lösung dieses Verhältnisses lebte er in Würzburg, vielleicht auf dem ihm ertheilten Lehen, ohne jedoch dem öffentlichen Leben seine Theilnahme zu entziehen. Den besten Beleg dafür gibt der von ihm mitgemachte Kreuzzug im Jahre 1227 (427-506). Er kehrte von demselben zurück: seine letzten poetischen Spuren fallen um 1230. In Würzburg wird er gestorben sein; er wurde im Kreuzgange des ehemaligen Collegialstifts zum neuen Münster begraben und hinterliess der Sage nach ein Vermächtniss, nach welchem täglich auf seinem Leichensteine die Vögel gefüttert werden sollten: eine offenbar aus dem Namen gefolgerte Erzählung. - Die Schriften ïber diesen fruchtbarsten und bedgutendsten Lyriker des deutschen Mittelalters sind bereits zu einer stattlichen Reihe herangewachsen. Die Gedichte Walthers von der Vogelweide herausgegeben von Karl Lachmann. Berlin 1827. 1843. (5. Ausg. 1875). Walther von der Vogelweide nebst Ulrich von Singenberg und Leutold von Seven herausgegeben von W. Wackernagel und M. Rieger. Giessen 1862. Walther von der Vogelweide herausgegeben von Fr. Pfeiffer. Leipzig 1864 (5. Auflage 1877). Walther von der Vogelweide herausg. von W. Wilmanns. Halle 1869. Walther von der Vogelweide herausg. von K. Simrock. Bonn 1870. Walther von der Vogelweide. Schulausgabe von $\mathrm{K}$. Bartsch. Leipzig 1875. MSH 1, 222-279. 3, 321-325. 451. $468^{\mathrm{c}} .468^{\mathrm{dd}}$. Hornig, Glossarium zu den Gedichten Walthers von der Vogelweide. Quedlinburg 1844. Gedichte Walthers von der Vogelweide, ubersetzt von Karl Simrock und erläutert von $K$. Simrock und W. Wackernagel. 2 Bde. Berlin 1833. (6. Aufl. 1876). Andere Ueberzetzungen von F. Koch, Halle 1848; G. A. Weiske, Halle 1852; K. Pannier, Leipzig 1876. Zur Texteskritik: Fr. Pfeiffer in seiner Germania 5, 21-44' 2, 470-472. 6, 365-368. K. Bartsch, Germania 6, 187-214. Paul, Beiträge 2, 550 ff. 5, 447 f. Zum Leben des Dichters: L. Uhland, 
Walther von der Vogelweide, ein altdentscher Dichter. Stuttgart 1822 (In Uhlands Schriften Bd. 5). MSH. 4, 160-190. Böhmer, Fontes rerum germanicarum 1, XXXVL. W. Grimm in Haupts Zeitschrift 5, 381-384. O. Abel, uber die Zeit einiger Gedichte Walthers von der Vogelweide ebd. 9, 138-144. Karajan, über zwei Gedichte Walthers von der Vogelweide in den Sitzungsberichten der Wiener Akademie 1851. Daffis, zur Lebensgeschichte Walthers von der Vogelweide, Berlin 1854. G. A. Weiske, die Minneverhältnisse Walthers von der Vogelweide im Weimar. Jahrbuch 1 (1854), 357-371. Fr. Pfeiffer, Germania 5, 1-20. Opel, mîn guoter kJôsenære, Halle 1860. Max Rieger, das Leben Walthers von der Vogelweide. Giessen 1863. Ueber Walthers von der Vogelweide Herkunft und Heimath von Dr. Heinrich Kurz. Programm der Aarganischen Kantonsschule 1863. R. Menzel, das Leben Walthers von der Vogelweide. Leipzig 1865. W. Wackernagel, Leben und Wirken W's v. d. Vogelweide, in Herzogs Realencyclopädie für protestant. Theologie. K. Lucae, Leben und Dichten W's v. d. Vogelweide. Halle 1867. M. Lexer, über W. v. d. Vogelweide. Würzburg 1873. K. Meyer, W. v. d. Vogelweide. Basel 1875. Zingersle, zur Heimathfrage Walthers, Germania 20, 257-270; vgl. 22, 280. J. E. Wackernell, W.v. d. Vogelweide in Oesterreich. Innsbruck 1877. W. Wilmanns in Haupts Zeitschrift 13, 217-288. Paul, Beitrăge 2, 482 fi.

\section{Hêr Wolfram von Eschenbach.}

Aus einem ritterlichen aber armen Geschlechte im baierischen Nordgau, Eschenbach bei Ansbach, wahrscheinlich ein jüngerer Sohn. Er stand einige Zeit im Dienste von Herren seiner engern Heimath, so der Herren von Wertheim in Unterfranken, bis er eine dauernde Stätte am Hofe des Landgrafen Hermann von Thüringen fand. Er tiberlebte seinen Gönner, der im Jahre 1216 starb, und scheint dann sich in seine Heimath zurückbegeben zu haben, da er in Eschenbach begraben liegt. Anch Wolfram verdankt wie Hartmann den besten Theil seines Ruhmes seinen epischen Dichtungen (Tschionatulander, Parzival, Willehalm), von welchen nur die 2 weite vollendet wurde. Unter seinen Liedern nehmen die Tagelieder eine bedeutende Btelle ein. Dass er jedoch der Erfinder der Gattung gewesen, dass wenigstens die Einführung des Wächters von ihm herrïhrt, lässt sich nicht beweisen. Wolfram von Eschenbach von Karl Lachmann. Berlin 1833 (3. Ausg. 1872), enthält 8. 3-10 die Lieder. MSH. 1, 284-287. Ueber sein Leben: Leben und Dichten Wolframs von Eschenbach von San Marte 2 Bde. Magdeburg 1836-41. 2: Ausg. Leipzig 1858. Schmeller, uber Wolframs von 
Eschenbach Heimath, Grab und Wappen in den Abhandlungen der Münchener Akademie (philos. philol. Classe) 1837, 2, 189. MSH. 4, 192-230. Frommann, das Wappen Wolframs von Eschenbach im Anzeiger für Kunde der deutschen Vorzeit 1861，355-359. Vgl. Paul, zu Wolframs Liedern: Beiträge 1, $202 \mathrm{ff}$.

\section{Hêr Heinrich von Frowenberc.}

Den schweizerischen Frauenbergern angehörig, da er eine Reihe schweizerischer Dichter in C beschliesst. Auch in Baiern gab es ritterliche Frauenberger (vgl. die Stammburg der Frauenberger von Dr. M. A. Vogel im oberbayrischen Archiv 9, 202-210). Seine Zeit ist spätestens der Anfang des 13. Jahrhunderts; der H. miles de Frouenberch 1257 (Hagen 4, 918) ist entschieden zu jung. Dafür spricht das Subst. holde 'Geliebter' 24; der Reim gelouben: ougen $16 \mathrm{C}$ und der daktylische Rhythmus des zweiten Liedes. MSH. 1, 95-96. 4, 108.

\section{Der tugenthafte Schrîber,}

der im Wartburgkriege auftritt, und dem spätere Chroniken den Vornamen Heinrich geben, ist wahrscheinlich der Henricus Notarius oder Henricus Scriptor, der in thüringischen Urkunden von 1208-1228 erscheint. Zwei seiner Lieder, unter welchen das letzte, das Streitgedicht zwischen Kai und Gawan, von der Jenaer Handschrift dem Stolle beigelegt wird, in dessen Alment es gedichtet ist, und demnach dem Schreiber nicht zukommt, haben daktylischen Rhythmus 1-5 C und bei mir 1-35; ein anderes (29-31 C) das Durchreimen aller drei Theile der Strophe, daher wir ihn in den Anfang des 13. Jahrhunderts zu setzen berechtigt sind. Auffallen muss, dass seine Lieder gạr keine Spur thüringischer Mundart zeigen. MSH. 2, 148-153. 4, 463-468. Haupts Zeitschrift 6, 186-188.

\section{Hêr Nîthart.}

Ein baierischer Ritter, der sich nach einem von seiner Mutter ererbten Gute von Reuental nannte. Er hatte schon um 1215 dichterischen Ruf, denn um diese Zeit bezieht sich Wolfram im Willehalm $(312,11)$ auf seine Lieder. 1217-1219 nahm er an dem Kreuzzuge Herzog Leopolds VII. von Oesterreich Theil: ein Lied ist während des Krieges, ein anderes auf der Heimreise gedichtet. Um 1230 verliess er, durch Umtriebe eines Ungenannten aus der Gunst des Herzogs von Baiern vertrieben, seine Heimath und scheint nicht mehr dahin zurück- 
gekehrt zu sein. Er begab sich nach Oesterreich, wo er bei Friedrich dem Streitbaren gute Aufnahme fand; derselbe ertheilte ihm auf seine Bitte (736-749) eine Wohnstätte in Medlick (bei Wien), wo er aber ähnlich wie Walther über grosse Ausgaben (Zins) und kleine Einnahmen zu klagen hatte, die zur Erhaltung seiner Familie nicht ausreichten (575-587). Ueber 1236 hinab können wir seine Spuren nicht verfolgen. Neidhart nimmt eine bedeutsame Stellung in der Lyrik ein als Schöpfer der volksmässigen Lyrik der Höfe, die im Gegensatze zu der ritterlichen das Leben und Treiben der Bauern zum Gegenstande sich wählte und in Oesterreich auch nach Neidhart hauptsächlich gepflegt wurde. Seine Lieder, deren Zahl bedeutend war, die aber nicht alle auf uns gekommen sind (er selbst gibt achtzig Weisen an 648), scheiden sich in Frühlings- und Winterlieder, jene zum Reigen im Freien, diese in der Stube zum Tanze gesungen. Die spätere Zeit, die seinen Namen allegorisch deutete, hat auf ihn eine Menge unechter zum Theil höchst roher Lieder gehäuft, von denen die namenlosen Lieder (XCVIII, 305-518) Proben geben. Neidhart von Reuenthal herausgegeben von Moriz Haupt. Leipzig 1858; vgl. Germania 4, 247-250; Haupt in seiner Zeitschrift 13, $175 \mathrm{ff}$. Paul, Beiträge 2, $554 \mathrm{ff}$. Germania 15, $431 \mathrm{ff}$. MSH. 2, 98-125. 3, 185-313. 468 - 468 . W. Wackernagel in MSH. 4, 435-442. Liliencron in Haupts Zeitschrift 6, 69-117. K. Schröder, die höfische Dorfpoesie des Mittelalters, in Gosches Jahrbuch 1 (1864), 45-98. O. Richter, N. v. R. als Hauptvertreter der höfischen Dorfpoesie, im N. Lausitz. Magazin 45. Bd. E. Tischer, über N. von R. Leipzig 1872. H. Schmolke, Leben und Dichten N's von R. Potsdam 1875 (Programm).

\section{Grâve 0tte von Botenlouben.}

Ein Graf von Henneberg, geboren zwischen 1175-1180, des Grafen Poppo VI. jüngerer Sohn, der nach der vielleicht von ihm erbauten, noch heut in Trümmern sichtbaren Burg Botenlauben bei Kissingen in Unterfranken (vgl. XXXVI, 100) genannt ist. Er erscheint als Graf von Henneberg urkundlich 1196 und öfter; meist im Gefolge Heinrichs VI., den er nach Italien begleitete. Der Kreuzzug, an dem er Theil nahm und auf den sich 30-43 bezieht, ist wahrscheinlich der von 1197. Er blieb in Syrien bis gegen 1220 und vermählte sich mit Beatrix, der Tochter Joscelins IV. von Courtenay, des Seneschalls von Jerusalem. Im Jahre 1234 verkaufte er Botenlauben an den Bischof Hermann von Würzburg, und starb vor dem 7. Februar 1245 in dem von ihm und seiner Gemahlin gestifteten Kloster Frauenrode bei Kissingen, in welchem er mit seiner Gemahlin, die ihn etwas überlebte, begraben liegt. Seiner 
Lieder, deren letzte Spuren auf das zweite Jahrzehnt des 13. Jahrhunderts weisen, gedenkt Hugo von Trimberg (Renner S. 20). MSH. 1, 27-30. 4, 62-68. L. Bechstein, Geschichte und Gedichte des Minnesängers Otto von Botenlauben Grafen von Hennenberg, Leipzig 1845. 4. Wegele, Graf Otto von Hennenberg-Botenlauben und sein Geschlecht (1180-1250). Würzburg 1875.

\section{Der herzoge von Anehalt.}

Ohne Zweifel ist Heinrich I. gemeint, der mit Irmengard, einer Tochter des gesangliebenden Landgrafen Hermann von Thüringen rermählt war. Er war ein Anhänger der Staufer, stand 1199 auf Philipps Seite, war nach Philipps Ermordung Otto's IV. Parteigänger, später Friedrichs II., machte also dieselben politischen Wandlungen durch, die wir an Walther u. a. wahrnehmen. Seinem Vater Bernhard I. folgte er 1212 und starb 1252, nachdem er bereits um 1245 die Regierung niedergelegt hatte. Seine Lieder fallen in seine Jugendzeit: das eine derselben, in daktylischem Rhythmus und mit Durchreimung von Stollen und Abgesang (1-24) zeugt bestimmt für den Anfang des dreizehnten Jahrhunderts. Von der heimischen Mundart haben sich noch Spuren erhalten, ich habe sie deshalb hergestellt. MSH. 1, 14-15. 4, 36-38.

\section{Hêr Liutolt von Savene.}

Ein jüngerer Zeitgenosse und Nachahmer Walthers, aus einem ritterlichen Geschlechte in Tirol (Säben) im Eisackthal. Seine Zeit bestimmt sich ungefähr durch die Beziehung auf den byzantinischen Kaiser Robert von Courtenay (1221-1228), der unter dem künec von Kriechen (Wackern. Walther 261, 141) gemeint ist. Die Zahl seiner Lieder muss nach der Angabe Reinmars des Fiedlers (XXIX) viel grösser gewesen sein als die uns erhaltene. Leutold entzückt uns 'durch die anmuthige Beziehung, in welche er die Liebe zum Leben der Natur bringt, durch eine eigene Schlichtheit und Einfalt der leichthinschreitenden Rede, durch schmelzenden Wohllaut des Vers- und Strophenbaues, zumal durch einen süssen melodischen Reiz der Abgesänge.' Ausgabe seiner Lieder im Anhange zu Wackernagel-Riegers Ausgabe Walthers S. 259-270. MSH. 1, 305-306. 3, 327. 451. 468 ${ }^{\text {c }} 4$, 239-243. Wackernagel S. XX-XXIV. Leutolds von Säben Gedichte. Innsbruck 1876 . 


\section{Hêr Reimâr der Videler.}

Das ihm von C gegebene Prädikat Hêr weist auf ritterliche Herkunft. Er wird derselben Gegend wie der vorige angehören, wenngleich die Autorschaft fur die mitgetheilte Strophe (1-10), die in einem Tone Walthers gedichtet ist und den von Seven erwähnt, nicht sicher ist, weil in $\mathbf{A}$, die sie allein enthält, Strophen vorausgehen, die andern Dichtern angehören. Aeussere Merkmale der Unechtheit liegen ebensowenig vor, als sich die Echtheit beweisen lässt. MSH. 2, 161-162. 3, 330. 4, 474-475.

\section{Der truhsæze von Sant Gallen.}

Ulich von Singenberg mit Namen: wie Leutold ein jüngerer Zeitgenosse und Schüler Walthers, den er ausdrücklich als seinen Meister bezeichnet, den er parodiert, dem er vieles in Worten und Gedanken entlehnt. Urkundlich begegnet er von 1209-1230. Er scherzt über Walthers Armuth (105-114) und preist im Gegensatze dazu die eigene behagliche Lage. Walthern hat er eine schöne Strophe (115-122) nach dessen Tode (nach 1230) gewidmet. Ebenso widmete er dem Abt Ulrich VI. von Banct Gallen (1204-1219) einen Nachruf (Wackern. Walth. 215, 4-15). Auch der politischen Dichtung wandte er wie sein Meister sich zu: ein paar Sprüche, die um 1230 fallen, beziehen sich auf Heinrich, Friedrichs II. Bohn, und greifen denselben, der unter schädlicher Umgebung 'aus dem ungezogenen Knaben von ehemals zum fertigen Wüstling geworden' (Rieger, Walther S. 51) heftig an. Ansgabe seiner Lieder in Wackernagel-Riegers Walther S. 209-256. MSH. 1, 288-299. 3, 325-327. 4, 231-235. Wackernagel S. XIV bis XX. Rieger, Leben Walthers $\mathrm{S}$. $52 \mathrm{fg}$.

\section{Grâve Friderich von Liningen.}

In ihm den Grafen Friedrich zu erblicken, der mit Landgraf Ludwig V. von Thüringen 1190 nach dem heiligen Lande zog, wie Hagen (MS. 4, 60) und Holtzmann, (Pfeiffers Germania 1, 254) annehmen, denselben, der dem Landgrafen Hermann das französische Trojerlied brachte (Herbort 95) liegt kein Grund vor. Das einzige von ihm in C erhaltene Lied trägt nicht die Weise des 12. Jahrhunderts; dasselbe gilt von dem strophischen Baue, der Wiederholung der Stollen am Schluss des Abgesanges, der Kürzung mei für meie u. a. Der Dichter scheint Wolframs Parzival gekannt za haben. Ich halte ihn daher 
für den Grafen Friedrich von Leiningen, der in elsässischen Urkunden 1214-1239 vorkommt. Zu Fahrten nach Apulien (37) war in dieser Zeit oft Anlass, ohne dass wir die vom Dichter gemachte, vor der er sich von seiner Fraue verabschiedet, näher bestimmen könnten. MSH. 1, 26. 4, 59-61.

\section{Hêr Kristân von Hamle.}

Kein alemannischer Dichter, wie Hagen annimmt, sondern, wie die apokopierten Infinitive u. a. zeigen, dem mittleren Deutschland, wahrscheinlich Thüringen, angehörig. Die Zeitbestimmung Hagens (um 1225) mag annähernd richtig sein, eher möchte er noch etwas früher fallen. MSH. 1, 112-114. 4, 118.

\section{Hêr Uolrich von Liehtenstein.}

Aus einem steirischen Rittergeschlechte. Urkundlich erscheint er zuerst 1239, 1. December zu Wien, und von da an häufig, zuletzt am 27. Juli 1274. Nicht lange darauf, am 6. Januar 1275 oder 1276 starb er, nachdem seine Gattin Bertha schon vor ihm gestorben; ibn tiberlebte sein Sohn Otto. Seine dichterische Laufbahn begann er 1223, im Dienste einer adelichen Dame, der ihn zu den abenteuerlichsten und tollsten Streichen im Stile eines Ritters der Tafelrunde veranlasste, wie er dies Leben selbst in seinem 'Frauendienst' (verfasst 1255) beschrieben hat. Seine Erzählungsweise ist nicht unangenehm, mitunter freilich roh und in der Form ungelenk; aber anziehend und wichtig ist der Frauendienst durch die treue Schilderung des damaligen Lebens. Die Lieder, die er in den Frauendienst einschaltet, sein Leich (83-179) and die Büchlein, stechen vortheilhaft durch Melodie und Wohlklang von dem erzählenden Theile ab. Im 'Frauenbuche' (verfasst 1257), worin sich der Dichter mit einer Dame redend einfuihrt, zeigt er sich von einer ernsteren und würdigeren Seite als im Frauendienst, wenngleich er auch hier uber ein änsserliches Erfassen des Verhältnisses zwischen Mann und Weib nicht hinauskommt. Ulich von Liechtenstein mit Anmerkungen von Theodor von Karajan herausgegeben von Karl Lachmann. Berlin 1841. Das Frauenbuch gedruckt durch J. Bergmann in den Wiener Jahrbüchern 1840, Band 41. Frauendienst, bearbeitet von L. Tieck. Stuttgart 1812. MSH. 2, 32-62. 4, 321-404. Die urkundlichen Nachweise durch Karajan bei Lachmann S. 661 ff. Abbildung seines Siegels (1250) im Sphragistisch. Album von Furst von Hohenlohe-Waldenburg. 1. Heft. Frankf. a. M. 1863; vgl. Anzeiger f. Kunde der deutschen Vor- 
zeit 1865, Sp. 9. J. Falke, Geschichte des fürstlichen Hauses Liechtenstein I. (Wien 1868), 57-124. Beckh-Widmannstetter, U's von L Grabmal in den Mittheilungen des historischen Vereins für Steiermark 19, 199 ff. (1872): vgl. 20, 93. K. Lind in den Mittheilungen der K. K. Centralcommission 17. Jahrgang. A. W. Schopf, die Töne Uolrichs von Liechtenstein. Programm des katholischen Gymnasiums zu Pressburg 1854. 4. K. Knorr, über U. von L. Strassburg 1875 ; vgl. Germania 21, 434 f.

\section{Hêr Burkart von Hôhenvels.}

Die Burg Hohenfels am Bodensee in der Nähe von Ueberlingen, deren Thurm sich bis auf die Gegenwart erhalten hat, ist das Stammschloss dieses Sängers, der zuerst in Weingarten am 6. November 1226 bei König Heinrich urkundlich erscheint, ausserdem in Urkunden des Klosters Wettingen 1228 und 1229 vorkommt. Ein jūngerer Burkardus de Hohenvels in einer Ueberlinger Urkunde vom 17. März 1296 (im germanischen Museum) kann daher nicht wohl der Dichter sein. Seine Lieder zeigen eine Vorliebe fur Bilder aus dem Jagdleben, die er in den Minnegesang hineinträgt, und auf der andern Seite die Neigung zur volksmässigen Lyrik im Sinne Neidharts. MSH. 1, 201-210. 4, 145-147. Stălin, wirtemberg. Geschichte 2, 765. Bader, Burghart von Hohenfels der Minnesänger, seine Familie und Heimath in Badenia 3. Band, Heidelberg 1866. Barack, uber den Minnegesang am Bodensee und den Minnesänger B. von H., in 'Schriften des Vereins für Geschichte des Bodensees' 2. Heft. Lindau 1870. O. Richter, B. von H., im N. Lausitz. Magazin XLVII, 1 (1870).

\section{Der barcgrâve von Lüenz.}

Wahrscheinlich der Burggraf Heinrich von Lüenz in Kärnten (an der Drau), der zuerst in einer Urkunde des Grafen Meinhard von Görz in Brixen 1231 als Zeuge erscheint, ebenso in Urkunden desselben Grafen von 1237, 1241, 1249 und 1256, in letzterer zugleich mit seinem Sohne Konrad, der allein 1263 und 1265 vorkommt. Des Burggrafen Heinrich gedenkt mehrfach Ulrichs Frauendienst, zuerst bei dem Turnier in Frisach (1224), bei welchem auch Graf Meinhard von Görz war $(89,26)$; dann 1227 bei der Fahrt Ulrichs als Frau Venus $(191,5.11)$ und 1240 bei der von Ulrich veranstalteten Tafelrunde, wo Heinrich den Namen Parzival fuhrte $(490,11)$. Er nahm an einer Kreuzfahrt Theil (vgl. 51-60), entweder schon der Leopolds VII. (1217-19) oder 
Friedrichs II. (1227-28). Das erste seiner beiden Wächterlieder, dem die Kreuzfahrtsstrophe angefügt ist, unterscheidet sich von den gewöhnlichen durch die erzählende Einkleidung. MSH. 1, 211. 212. 4, 149. 150.

\section{Hôr Gotfrit von NIfen.}

Ein schwäbischer Dichter aus ritterlichem Geschlechte, dessen Burg, jetzt Hohenneufen, in stattlichen Ruinen noch sichtbar ist, der jüngere Sohn Heinrichs von Neifen (1213-1246), kommt urkundlich 1234-1255 vor: 1234 und 1235 zu Wimpfen in der Umgebung König Heinrichs, 1241 in Blankenhorn in einer Schenkung an das Kloster Wald mit seinem Vater und seinem ältern Brader Heinrich, 1246 am 15. März zu Ulm mit denselben in einer Schenkung an das Kloster Salem; am 6. Februar 1253 stiftete er mit seiner Gattin Mathilde an das Kloster Maulbronn Wein und Weizen von dem Zehnten in Güglingen; endlich 1255, am 23. April in einer Urkunde des Klosters Rechenzhofen als Zeuge. Mit seinem Bruder Heinrich kämpfte er am S. Albanstage (21. Juni) 1245 gegen den Bischof Heinrich von Constanz im Schwiggersthale, ein Kampf, in welchem der Bischof den Sieg behielt und die beiden Brüder gefangen nahm; doch kamen sie nach kurzer Zeit frei. Seine Lieder zeigen die Ausbildung der Form auf dem Höhepunkte und zeugen von ungemeiner Beherrschung der Sprache, in andern tritt die einfache Weise des Volksliedes hervor, so dass man manche gradezu Volkslieder nennen könnte und genannt hat; wahrscheinlich sind es von ihm überarbeitete Volkslieder. Er hat neben der höfischen Minne auch eine niedere, ein Verhältniss zu einem Landmädchen, das wahrscheinlich in Winnenden (84), einer den Neifern gehörigen Burg, wohnte. Von spätern Lyrikern wird er mehrfach genannt und gerạhmt: von Friedrich von Sunburg, Hugo von Trimberg u. a. Die Lieder Gottfrieds von Neifen herausgegeben von Moriz Haupt. Leiprig 1851. MSH. 1, 41-62. Die urkundlichen Nachweise bei Stälin, wirtembergische $\mathrm{Ge}$ schichte 2, 582-585. 576. 765. MSH. 4, 80-83. 754. Vgl. O. Richter, G. von N. als volksthümlicher Dichter, im N. Lausitzischen Magazin 44. Band. G. Knod, G. von N. und seine Lieder. Tübingen 1877.

\section{Der Taler.}

Ein Zeitgenosse und Landsmann des von Neifen, den er in einem seiner Lieder $(8 \mathrm{C})$ nennt: vielleicht aus dem adelichen Geschlechte derer von dem Tal, die in Schwaben vorkommen. Doch ist Taler auch 
bürgerlicher Name: Jacob der Taler z. B. in Urkunden vom 27. April 1340 und 8. December 1348 zn Brixen (im germanischen Museum). Auch er neigt wie Neifen in dem von mir ausgehobenen Liede zum derben volksthümlichen Tone. Seine Lieder, an deren Spitze ein Leich steht, MSH. 2, 146-148. Vgl. 4, 461-463.

\section{Schenk Uolrich von Wintersteten.}

Ein schwäbischer Ritter, schwerlich ein Bruder des Schenken Konrad von Wintersteten, der unter der Regierung Friedrichs II. eine bedeutende Rolle spielte und der Gönner der Dichter Rudolf von Ems und Ulrich von Türheim war, erscheint um 1239 als Zeuge in einer Urkunde, in welcher Schenk Konrad zwischen den Aebten von Kempten und Isny vermittelt, nicht neben diesem, anch nicht als Schenke bezeichnet, sondern einfach als Ulricus de Winterstetten. Da der Dichter jedoch sich selbst als Schenken bezeichnet, Bo ist an eine andere Linie des Geschlechtes zu denken; in der Schmalneckischen Linje begegnet ein Ulrich, ein Sohn Konrads von Smalnecke, 1241 und 1244.1258 war dieser Ulrich Kanonikus zu Augsburg und wird als solcher noch 1265 und 1269 erwähnt. Dazu stimmt dass das Wappen der Pariser Handschrift das schmalneckische ist. Die meisten seiner Lieder und Leiche mögen in die Jugendzeit fallen; aber auch als er Domherr geworden, entsagte er dem Gesange nicht, wie ein Lied bezeugt, das den Tod eines Bruders beklagt und demnach nach 1258 entstanden sein muss. Neben der ausgelassenen Fröhlichkeit, die sich in den meisten seiner zahlreichen Lieder and in den funf Leichen findet, klingen doch anch ernstere Töne, die an den Verfall der Sitte und Zucht mahnen, und das Absinken der Poesie bezeichnen. Seine Lieder müssen sehr verbreitet gewesen sein: auf allen Gassen wurden sie gesungen (10), wozu sie sich wegen ihrer leichten Formen und Melodien, in welchen der volksthümliche Refrän eine grosse Rolle spielt, gut eignen mochten. MSH. 1, 134-174. 4, 132-137. Stälin 2, 615. 765. Vgl. J. Graf von Oeynhausen, die Schenken von Winterstedt, in Vierteljahrsschrift for Heraldik, Sphragistik und Genealogie 1876. 1. Heft. Baumann, der Minnesinger Schenk U. v. W. in: Korrespondenzblatt des Vereins für Kunst and Alterthum in Ulm II, 3 (1877).

\section{Der von Sahsendorf.}

Vermuthlich ein Oesterreicher, wenn auch nicht sicher identisch mit dem von Liechtenstein $(472,17)$ erwähnten Ulrich von Sachsendorf. 
Seine Zeit lässt sich durch nichts näher bestimmen. Der von Sahsendorf. Carmina quot supersunt recognovit emendavitque F. G. P. Storck. Monasterii 1868. (Vgl. Germania 15, 251 f.) MSH. 1, 300-302. 4, 236.

\section{Hêr Reinmâr von Zweter.}

Er war ritterlicher Abkanft, am Rheine geboren, in Oesterreich aufgewachsen (145 fif.). Einen Theil seines Lebens verbrachte er am böhmischen Hofe, bei Wenzel I. (1229-1252) und war wie dieser anch ein eifriger Anhänger Friedrichs II., dessen Lobe als Kaiser (seit 1220, † 1250) er mehrere Strophen gewidmet hat. Damit hängt von selbst zusammen, dass er ein Gegner des Pabstes war: er richtet heftige Angriffe besonders gegen Gregor IX. (Hugolinus, 1227-1241); allein um 1245, als Innocenz IV. Friedrich zu Lyon entsetzt hatte, scheint anch Reinmar des Kaisers Parthei aufgegeben za haben. Unter denen, die er als der Reichskrone würdig bezeichnet, nennt er Wenzel I. und Erich VI. von Dänemark (1242-1250): mōglich dass ihn seine Wanderungen auch nach Dänemark führten. Später kehrte er in seine Heimath an den Rhein zurück. Nach einer Nachricht des 14. Jahrhunderts liegt er zu Essfeld in Franken begraben. Wir besitzen von ihm ausser einem Leiche religiösen Inhalts ein paar hundert Sprüche, in welchen alle Fragen des Lebens erörtert werden, und die mit wenigen Ausnahmen in ein und derselben Strophenform (Frau-Ehren-Ton) verfasst sind. In allen verräth sich ein ernster männlicher Charakter, der in mancher Hinsicht an Walther erinnert. Der Gedanke überwiegt aber bei ihm die Form, während bei Walther beide in schöner Harmonie stehen; daher sind seine Verse oft hart, und dass er eben das verschiedenartigste, auch die Minne, in einer und derselben Form überall abhandelt, bezeugt die Vernachlässigung der formellen Seite am besten. Seinen Tod beklagt der Marner, der ein jüngerer Zeitgenosse war, da er ihn in einer Strophe angreift, was doch nur auf den noch Lebenden gehen kann. Die spätere Zeit vermischt ihn vielfach mit dem ältern Reinmar: bei den Meistersängern, die den Frau Ehren Ton vielfach anwendeten (m. Meisterlieder B. 159) stand er in hohem Ansehen. MSH. 2, 175-221. 3, 332. 468 ${ }^{8}$. 4, 587-510. De Reinmaro de Zweter. Von Oberlehrer B. Hüppe. Programm des Gymnasiums zu Cœesfeld 1861. K. Meyer, Untersuchungen über das Leben Reinmars von Zweter und Bruder Wernhers. Basel 1866. W. Wilmanns in der Zeitschrift f. d. Alterthum 13, 434-463. 20, 250-254. Tschiersch, Beurtheilung der von Goedeke aufgestellten Behauptung, dass R. von Z. und der Marner identisch seien. Görlitz 1872. 


\section{Broder Wernher.}

Vermuthlich ein Oesterreicher, wenigstens hauptsächlich in Oesterreich lebend, anch er wie Reinmar ein ausschliesslich lehrhafter Dichter, dessen erste Strophen bereits um 1220 (Lachmann Walther S. 198) fallen. Auch er war ein Anhänger Friedrichs II., an den er warnend und rathend, ein Nachahmer Walthers, mehrere Strophen gerichtet hat. Nicht minder bezieht er sich auf König Heinrich, Friedrichs unglücklichen Sohn, so wie auf Friedrichs jüngern Sohn, König Konrad IV. Er klagt über den Tod des Fürsten von Baierland $\left(3,19^{b}\right)$ d. h. Herzog Isudwig, der im September 1231 ermordet wurde, und rühmt den Grafen Poppo von Henneberg in Osterfrankenland $\left(3,15^{b}\right)$. Auch am Rhein und in Schwaben hat er sich aufgehalten, so dass die Erklärung seines Titels 'Bruder' als 'wallender Pilger' annehmbar erscheint und auf geistlichen Stand nicht geschlossen zu werden brancht; vielleicht war er Laienbruder in einem Kloster. Am längsten aber weilte er doch in Oesterreich, wohin auch die meisten persönlichen Beziehungen, auf den von Ort in Steiermark $\left(3,233^{\mathrm{b}}\right)$ Graf Wilhelm von Honesburg $\left(3,14^{\mathrm{b}}\right)$, den Grafen von Ortenberg (wie nach Hagen statt Osterberc 3, 19* zu lesen ist), Herzog Leopold VII. $\left(2,2^{\circ} 3^{\circ}\right)$ und Friedrich den Streitbaren von Oesterreich $\left(2,234^{\circ} .3,12^{b}\right)$ hinweisen. Unter Gestorbenen beklagt ihn Rubin (Hagen 3, 31 ) $)$. MSH. 2, 227-235. 3, 11-20. 4, 514-524. Lachmann zu Walther 84, 20. K. Meyers (bei XLI) erwähnte Schuift. R. Schröder in der Zeitschrift für deutsche Philologie 2, 302 ff., wo die von K. Schröder und Meyer behauptete Identität von Bruder Wernher und Wernher dem Gartenære, dem Dichter des Helmbrecht, wohl mit Recht bezweifelt wird.

\section{XuII. Der Marner.}

Ein schwäbjscher Dichter, (vgl. LXVI, 17) von bürgerlichem Stande, nach der Ueberlieferung der Meistersänger und nach Andeutungen von Zeitgenosssen $\left(3,101^{b}\right)$ Konrad geheissen. $\mathrm{Da}$ er Walthern seinen Meister nennt (55. 56), so muss er schon vor 1230 gedichtet haben. Er besingt einen Grafen von Henneberg, vermuthlich Hermann, der nach Heinrich Raspes Tode (1247) zur Königswahl stand: das Lob des Dichters sollte wohl günstig auf die Stimmung wirken (XV, 4 Strauch). Von dem unglücklichen Konradin $(+1268)$ hegte er grosse Erwartungen, die leider durch das traurige Ende des letzten Staufers nicht erfüllt wurden $(\mathbf{X V}, 5)$. Ein fahrender Sänger, durchwanderte er 
das Land, war am Rhein (1-19), wo er über die gezierten und hochmüthigen Sitten der Rheinländer sich ărgerte, und anderwärts. Er überlebte von Zeitgenossen Rubin, Wachsmut und Reinmar von Zweter, den er nebst ältern Dichtern beklagt (55-70). Eine Strophe (20-37) greift Reinmar heftig an und zeigt bereits jene gehässige Anfeindung der Sänger unter einander, die mit dem Verfall der Kunst und dem abnehmenden Interesse der Herren zunimmt. Dass er von Selbstüberschätzung nicht frei war, lehrt die Strophe eines jüngern Zeitgenossen, Raumlands von Sachsen (LXVI, 11-20), der ein heftiges Räthsel (LXVI, 1-10) gegen den hochmïthigen Schwaben dichtete. Auch von Seiten des Meisners erfuhr er Tadel und Missbilligung (3, 100. 101). Er ward während des Interregnums vor Konrads von Würzburg Tode (1287) als alter Mann erschlagen '(gegen 1270), wenn eine Strophe Raumlands $(3,53)$ mit Recht auf ihn gedentet wird. Hermann der Damen nennt ihn unter Verstorbenen (LXXVIII, 23), als Konrad von Würzburg noch lebte. Mit hohem Lobe gedenkt seiner Hugo von Trimberg als Verfassers von lateinischen und deutschen Gedichten (Renner S. 20): mehreres lateinische von ihm hat sich erhalten; ein lateinisches Lied (1231) besingt den Prälaten Heinrich von Maria Saal. Er hat Lieder, doch vorzugsweise Sprüche geistlichen und weltlichen Inhalts gedichtet, an Formen reicher und gewandter als Reinmar von Zweter, aber an männlichem Charakter ihm nicht zu vergleichen. MSH. 2, 236-258. 3, 332-334. 451. 468 ${ }^{\text {h }}$ 4, 524-536. Der Marner herausgegeben von Ph. Strauch, Strassburg 1876; vergl. Germania 22, 95 ff.; Anzeiger f. d. Alterthum 3, 118 ff. F. Meyer, über Leben und Dichten des Marner. Berlin 1873 (Giessener Dissertation). B. Schneider, de vita et carminibus Marneri. Mühlberg 1873 (Leipziger Dissertation). Fischer Beiträge zur Litteratur, Kritik und Erklärung des Marner. Berlin 1876 (Programm). Bech in Germania 22, 385 ff.

\section{XIIII. Hêr Ruodolf von Rôtenbarc.}

Aus einem ritterlichen Geschlechte in der Schweiz, in der Gegend von Luzern, wohin ihn schon seine Stellung in der Pariser Handschrift mitten unter Schweizer Dichtern weist. Rudolf von Rotenburg bezengt mit seinem Brader Wernher 1257 in Lazern eine Urkunde, die den Streit zwischen Arnold und Markward von Rotenburg und dem Kloster Murbach schlichtet. Auf eine Fahrt ausser Landes weisen die mehrfachen Andentungen, dass er fern von der Geliebten ist, der er Boten und Lieder sendet, von der ein fremder Pilger (188) ihm erzăhlt. Die Leiche, deren dritten ich mittheile, bilden den grösseren Theil seiner 
Dichtungen. Unter verstorbenen Leichdichtern wird er von dem von Gliers (MSH. 1, 107 ${ }^{\circ}$ ) gerühmt. MSH. 1, 74-90. 4, 105-107.

\section{Der Schenke von Limparc.}

Seinen Vornamen nennt $C$ nicht: am bekanntesten ist der Schenke Konrad, der von 1230 an häufig in Urkunden erscheint (Stälin 2, 603 ff.). Er war 1241 mit Friedrich II. in Italien, wo er im Oktober zu Cremona eine Urkunde des Kaisers bezengt. Er starb zwischen 1237-53, ist also wohl für den Minnesänger, dessen Vorbild zunächst Ulrich von Wintersteten scheint, zu alt. Sein jüngerer Sohn Konrad (der ältere hiess Walther)erscheint in Urkunden: 801263 im Februar in einer Schenkung an das Kloster Lichtenstern; im Mäne desselben Jahres in einer Schenkung an das Hospital zu Hall, immer mit seinem Bruder $W$ alther zusammen. Er begleitete Konradin auf seinem Zuge nach Italien, und bezeugt zu Verona am 27. December 1267 eine Urkunde Konradins, und am 14. Juni 1268 eine andere desselben für Pisa. In Italien mögen die Strophen 9-11 C entstanden sein, in denen er sagt, dass er durch Gebirge von der fernen Geliebten getrennt Bei. Als Dichter erwähnt ihn Hugo von Trimberg (Renner S. 20). MSH. 1, 131-134. 4, 126-132. Stälin 2, 602. 767. A. Bauer, der Hohenstaufen und die Schenken von Limburg, Zeitschrift des Vereins f. d. wirtemb. Franken VII, 1 (1865).

\section{Der Hardegger.}

Nach Hagen und Lassberg aus dem Geschlechte der Edlen von Hardegge in der Schweiz, wo namentlich Heinrich 1227-1264 in Urkunden erscheint. In der ersten Urkunde (1227) zugleich mit Ulrich von Singenberg, dem Truchsessen von St. Gallen, auf dessen Lied (zu XXX, 135) er $\left(2,136^{b}\right)$ anspielt. Auch die historischen Beziehungen seiner Lieder stimmen dazu : in dem einen $\left(2,136^{\circ}\right)$ bittet er die Himmelskönigin um Gnade für den Kaiser und den König, dass jener gegen diesen seinen Zorn fahren lasse, und um Hülfe für König Konrad, dass er Vogt von Rom werde, im Hinblick auf die Absetzung König Heinrichs durch Kaiser Friedrich II. (1235) und die 1237 erfolgte römische Kōniggwahl Konrads. Er muss aber lange gedichtet haben, denn Stolle, der auf eine seiner Strophen antwortet und in dessen Tone er dichtete, lebte noch im letzten Viertel des 13. Jahrhunderts. Auch tragen seine Strophen (eigentliche Lieder hat er nicht gedichtet) mehr den Charakter der bürgerlichen lehrhaften Poesie, so dass die Annahme adelicher Herkunft zweifelhaft erscheint. MSH. 2, 134-137. 4, 445-447. 


\section{Hêr Reinmâr von Brennenberc.}

Aus einem adelichen Geschlechte in der Nähe von Regensburg, urkundlich 1238 mit seiner Mutter Adelheid nachgewiesen. Er wurde aus unbekanntem Anlasse von den Regensburgern erschlagen: im Jahre 1276 wurde seinem Bruder, dem Kanonikus Bruno, noch beim Leben der Mutter, von dem Bischof von Regensburg Sühne fär den Mord verheissen, und wie es scheint auch geleistet. Ob er oder ein früherer des Geschlechtes der im Volksliede gefeierte Brennenberger ist (eine spätere Chronik verlegt die Sage ins 12. Jahrhundert), muss unentschieden bleiben. Der 1238 vorkommende, vor 1276 Erschlagene ist ohne $\mathrm{Z}_{\text {weifel }}$ der Dichter, nicht der jüngere Reinmar, der 1295-1325 ứrundlich erscheint; denn in der ihm gehörenden Strophe $(65-76)$ nennt er als verstorben nur Dichter, die vom Ende des 12. Jahrhunderts bis in die Mittte des 13. reichen. MSH. 1, 335-338. 3, 329. 334. 4, 278-284.

\section{Der Tanhuser.}

Er gehörte zu dem edlen Geschlechte derer von Tanhusen, die im Salzburgischen und in Baiern urkundlich vorkommen. Ein unstätes Wanderleben fuhrte ihn weit in der Welt, auch taber die Grenzen des deutschen Reiches hinaus, herum. In seinen Leichen, die er, was vor und nach ihm kein andrer gethan, zum Preise der Gönner verwendet, ruhmt er Friedrich den Streitbaren von Oesterreich $(2,81)$ Herzog Otto VI. von Baiern und eine Menge andrer Fürsten, aus deren Anfährung sich als die Zeit seines Dichtens etwa die Jahre 1240-1270 ergeben. Er war auch zur See, worauf sich das letzte der von mir mitgetheilten Gedichte (193-247) bezieht. Seine Leiche verrathen eine ungewōhnliche geographische und Sagenkenntniss: doch ist in Bezug auf letztere zu bemerken, dass er die Sagenelemente willkürlich zu mischen liebt. Thm wird, jedoch mit Unrecht, anch eine Hof- und Tischzucht (Zeitschrift 6, 188) beigelegt. Wie andere seiner Sangesgenossen, der Morunger, der Brennenberger, ging er in das Volkslied aber und lebte in solcher Gestalt durch Jahrhunderte fort. Anlass zu der Tanhauser-Sage mochte das Busslied (Hagen 3, 48) geben, das allerdings nur $\mathbf{J}$ enthält, das aber keinen Anstoss bietet. Seine Leiche, deren wir sechs besitzen, behandeln die verschiedensten Gegenstände, Minne, Zeitgeschichte, Länderkunde und Sage. Im Liede zeigt sich bei ihm die Parodie des Minneliedes and Minnedienstes. MSH. 2, 81-97. 3, 48. 4, 421-434. Robert v. Raab, die Thannhansen in Mittheilungen der Gesellschaft für Salzburger Landeskunde XIII (1872). 


\section{XLVIIL. Grave Kraft von Toggenbura.}

Ans dem thurganischen Grafengeschlechte. Der Sohn von Diethelm dem Brudermörder and Gertrud von Nenenburg, urkundlich seit 1243. Eine unstäte wilde Natur, führte er mit seinen Brüdern vereint mehrfache Fehden gegen St. Gallen (1249), bis er von einem Edelknechte, Namens Locher, in einem Hohlwege (vor 1260) erschlagen ward. Er scheint als junger Mann gestorben zo sein. Doch kann man auch an den jüngern Kraft denken, der 1309-1321 Propst in Zürich war. MSH. 1, 20-23. 4, 52-55. Drei Schweizerdichter ans dem 13. Jahrhundert von Dr. A. Rochat. Heidelberg 1856.

\section{XIIX. Hồr Hîc von Werbenwâc.}

Ein schwäbischer Ritter (in Baden), der als Zeuge in einer Hohenberger Urkunde 1258, in einer andern zu Ettlingen 1263 und noch 1268 und 1279, erscheint. Seine Zeit bestimmt sich durch das von mir ausgehobene Gedicht (49), in welchem er der Geliebten, die einen Franken ihm, dem Schwaben, vorzog, droht, er werde sie beim König Konrad verklagen, und wenn dieser ihm nicht Recht verschaffe, sich an den jungen König aus Thüringenland (Heinrich Raspe 1246), ja sogar an den Pabst wenden. Er scheint im KJoster sein Leben geendet zu haben; wenigstens wird 1292 ein 'frater Hugo de Werbenwag monachus in Salem' erwähnt. MSH. 2, 67-69. 4, 409-410. Stälin 2, 767. Birlinger in der Germania 16, 83. Vgl. noch Staiger, das schwäbische Donauthal. Sigmaringen 1866, 3. Anhang.

\section{Hêr Walther von Metze.}

Ein ritterlicher Dichter, eher aus Tirol, wo Herren von Metz nachgewiesen sind, als aus der Rheinpfalz, wo es ein Geschlecht desselben Namens gab (zu MF. 4, 1. Bertoldus et Godilmannus de Methis in Flersheim betreffenden Urkunden von 1249 und 1253, Baur, hessische Urkunden 2, 117), weil er in $\mathrm{C}$ unter Dichtern Tirols steht. Er war um 1270 bereits gestorben, da der vor 1276 erschlagene Reinmar von Brennenberg ihn unter verstorbenen Dichtern nennt (XLVI, 75). Mit dem französischen Dichter Gautier de Metz, der 1245 seine Mappemondo dichtete, hat er in keinem Falle etwas zu thun. MSH. 1, 307-310. 3, 328. 468 ${ }^{\circ}$. 4, 243-248. Vgl. Schönbach in der Zeitschrift für deutsche Philologie 5, 159-165. 


\section{Hêr Rubin.}

Wie der Vorige ans einem tirolischen Adelsgeschlechte, dessen Stammburg noch steht. Unter bereits verstorbenen Dichtern wird er vom Marner (XLII, 58) rom Brennenberger (XIVI, 75) und von Hermann Damen (LXXVIII, 18) beklagt. Schwerlich ist er eins mit dem Robin der Jenaer Sammlung, der den Tod Reinmars, Walthers, Stolles, Nitharts beklagt und Bruder Wernher unter den noch Lebenden nennt, denn Robin reimt sêre : klagebære (Hagen $3,31^{\circ}$ ), was einem tirolischen Dichter um 1250 nicht zukommt. Er nahm an einer Kreusfahrt Theil, auf die sich 55-75 bexieht; vermuthlich ist der Kreuzzug Friedrichs II. 1228 gemeint, so dass schon damals der Dichter gesungen hätte. Seine Lieder verrathen in Form und Gedanken Walthers Schule. MSH. 1, 311-319. 4, 249-251. Rubins Gedichte kritisch bearbeitet von J. Zupitza. Oppeln 1867. Gedichte Rubins. 8. Bozen o. J.

\section{Hêr Wahsmnot von Mülnhtên.}

Hagen sucht ihn im Oberelsass, wogegen aber seine Spracheigenthümlichkeiten sprechen, die ihn vielmehr dem Niederrhein zuweisen (zu 52, 4). Ungewiss ist, ob er oder Wachsmut von Künzich der von dem Marner (XLII, 58) und Brennenberger (XLVI, 75) beklagte Wachsmut ist. MSH. 1, 327-328. 4, 260. Vgl. Germania 9, 147.

\section{Marcgrâve Beinrich von Mîssen.}

Es kann nur Heinrich III. der Erlauchte (illustris) gemeint gein, der, 1218 geboren, als eweijähriges Kind seinem Vater Dietrich IV. nachfolgte. Er vermählte sich 1234 mit Constanze, der Tochter Leopolds VII. von Oesterreich, nach deren Tode (1243) mit Agnes, der Tochter Wenzels I. von Böhmen, die $1268 \mathrm{starb}$, und rum drittenmale mit Elisabeth von Miltitz. 1237 machte er eine Preussenfahrt, nahm später an den Kriegen Ottakers von Böhmen gegen Rudolf I. Theil, hielt prachtvolle Turniere zu Nordhansen (1263), Meissen (1265) und Merseburg (1268), und starb 1288. Wahrscheinlich ist er im Kloster Altenzelle begraben. $\mathrm{Er}$ war wie schon sein Vater ein Dichterfreund: ihn rühmt der Tanhauser (Hagen 2, 90*). Andere Erwähnungen gelten nicht ihm, sondern dem bürgerlichen Meisner, einem Zeitgenossen Konrads von Würzburg (Vgl. LXIX, 82). Anch Componist war er; er componierte einige Stücke der Messe und legte seine Arbeit Innocenz IV. vor, der durch Bulle vom 23. Januar 1253 ihre Einfuhrung in die Kirche ge- 
stattete. MSH. 1, 13-14. 4, 29-35. Codex diplom. Saxon. reg. v. Gersdorf, 1. Band.

LIV. Der von Scharpfenberc.

Wie die ihm unmittelbar in $\mathbf{C}$ voransgehenden Dichter ein Oesterreicher, dessen Vormame nicht ẗberliefert ist: mehrere des Geschlechtes, das in Kärnten ansăssig war, kommen seit 1250 in Urkunden vor. Seine Lieder schliessen sich an Neidhart an, dem er eine Strophe (8 C) beinahe wörtlich entlehnt. MSH. 1, 349-350. 4, 302-307.

\section{Hêr Wahsmnot von Kunzich.}

So lautet der Name in B, welche Form durch LVI, 1 bestätigt wird: C nennt ihn von Künzingen. Wohl ein schwäbischer Dichter, weshalb er bein Marner and Brennenberger, die einen Wachsmut unter den verstorbenen Dichtern beklagen (XLII, 58. XLVI, 75), eher gemeint ist, als Wachsmut von Mülhausen. Seine Zeit wird die Mitte des 13. Jahrhunderts sein. Er muss mehr gedichtet haben als wir von ihm besitzen: ein andrer Dichter (LVI, 1 ff.) verspottet ihn wegen seiner überzarten Minne, mit Bezug auf ein uns verlorenes Lied. MSH. 1, 302-303. 4, 237.

\section{Gedrat.}

Ein Frauenname, unter welchem A meist Strophen verschiedener Dichter enthält, so dass die Autorschaft nicht sicher ist. An eine Dichterin haben wir, wie der Inhalt des einzigen Liedes zeigt, nicht zu denken. Die Beziehung auf Wachsmut von Künzich zeigt, dass er derselben Zeit und Heimath angehört. Auffallend für seine Zeit ist der Reim schiede : liebe 12, weniger unsich 13, was ich ergănzt habe und was noch bei Hadlaub vorkommt. MSH. 3, 332. 4, 758.

\section{Hôr Geltâr.}

Ein ritterliches Geschlecht dieses Namens (C gibt ihm das Prädikat 'Herr') ist nicht nachgewiesen: aber die Beziehung auf Mergersdorf (in Oesterreich unter der Ens) stellt die Heimath ausser Zweifel. Darum kann er auch nicht Verfasser der unter Gedrut mitgetheilten Strophen sein, unter welchem Namen A die in C Geltar beigelegten hat. Auch er gehört 20 der Schule Neidharts und bezeichnet die realistische Richtung des Minnegesanges, die in Oesterreich hauptsächlich heimisch war (zu 
LVII, 17). Eine Beziehung auf die Dichter Alram von Gresten (MF. 4, $1 \mathrm{Anm}$.) und Friedrich den Knecht hat Hagen mit Unrecht in der ersten Strophe (4) erblickt. MSH. 2, 173. 4, 485. 758.

\section{Der von Wildonje.}

Vermuthlich Herrand von Wildonje, der als Novelleńdichter bekannter ist, aus einem steirischen Adelsgeschlechte, ein jüngerer Zeitgenosse Ulrichs von Liechtenstein, den er als Gewährsmann einer seiner Erzählungen anführt. Ottaker ist für seine und seines Geschlechtes Geschichte eine reiche Quelle. Sein Leben lässt sich darnach und nach Urkunden von 1251-1277 verfolgen. Hugo von Trimberg nennt ihn unter andern namhaften Lyrikern (Renner S. 20). Seine vier Erzählungen (diu getriuwe kone, der blosse Kaiser, die Katze, der verkehrte Wirth) hat Jos. Bergmann (Wien 1841) herausgegeben. MSH. 1, 347-348. 4, 294-301.

\section{Der von Suonegge.}

Ein kärntischer Ritter, ebenfalls ein Zeitgenosse Ulrichs von Liechtenstein, möglicherweise der von ihm genannte Konrad von Sounecke, der 1224 beim Turnier von Frisach zugegen war. Er folgt in C unmittelbar auf den von Wildonje und theilt mit ihm demnach wohl Zeit wie Heimath. MSH. 1, 348-349. 4, 301-302. K. Tengl, die Freien von Suneck. Mittheilungen des histor. Vereins für Steiermark 12. Heft. 1863.

\section{Meister Heinrich Teschler.}

Ein bürgerlicher Dichter der Schweiz, der eine von Rüedeger Manesse ausgestellte Urkunde von 1252 bezeugt. Er war, wie man aus dem Eingange des von mir ausgehobenen Liedes sieht, ein nicht unberühmter und unbeliebter Dichter. MSH. 2, 125-130. 4, 442. Haupts Zeitschrift 7, 168.

\section{Hêr Heinrich von Stretelingen.}

Von der Burg seines Geschlechtes am Thuner See in der Schweiz sind noch Ruinen erhalten. Heinrich II. selbst erscheint in Urkunden seiner Heimath von 1252-1263. Sein Wohnsitz war Laubegg. Sein Sohn, Heinrich III. tritt urkundlich 1258-1294 auf, und Bächtold ist mehr geneigt, in diesem den Minnesänger zu erblicken. Mancherlei 
Sagen von dem Geschlechte enthält die Stretlinger Chronik. Eine Sage hat in poetischer Form und mittelhochdeutscher Sprache ein Freund (Franz Pfeiffer) bearbeitet: Heinrich von Stretelingen. Ein altdeutsches Gedicht. 1854. MSH. 1, 110-111. 4, 116-117. Die urkundlichen Nachweise Germania 9, 147. Die Stretlinger Chronik herausgegeben von J. Bæchtold. Frauenfeld 1877, wo S. VII-XXVI des Dichters Lieder nebst Abhandlung über ihn und sein Geschlecht.

\section{Meister Friderich von Sunburc.}

Schwerlich aus einem edlen Geschlechte, da er nur als 'Meister' bezeichnet wird. Seine Heimath ist wohl Sonnenburg (Suoneburc) im Pusterthale in Tirol; in jedem Falle ist er ein oberdeutscher Dichter, und die nur in der Jenaer Hs. stehenden Strophen mit niederdeutschen Anklängen sind schwerlich echt. Sein Wanderleben als Begehrender brachte er haupstsächlich in Baiern zu, wo er nach einander Otto II. $(\dagger$ 1253) und Heinrich von Niederbaiern ( $\dagger$ 1290) verherrlichte. Aber auch im mittleren und niederen Deutschland hat er gelebt: er rühmt den Grafen Friedrich III. von Beichlingen ( + 1275) und den König Ottaker von Böhmen († 1278). In Friedrichs II. Dienste hat er wohl nicht gestanden: die Strophe auf dessen Tod (1250) deutet auf keine näheren Beziehungen. Dagegen verherrlicht er durch einen Spruch Rudolfs I. Krönung zu Aachen (October 1273). Ereignisse, die über 1274 hinabgehen, werden in seinen Liedern nicht berührt. In jedem Falle starb er vor 1287, da er zur Zeit, als Konrad von Würzburg noch lebte, von Hermann dem Damen als todt beklagt wird (LXXVIII, 19). Er hat nur Sprüche, keine Lieder gedichtet. Friedrich von Sonnenburg. Herausgegeben von 0 . Zingerle. Innsbruck 1878. 8. MSH. 2, 352-360. 3, $69-78$. 4, 647-660.

\section{Meister Sigehêr.}

Ein fahrender Sänger bürgerlicher Abkunft, der meist am böhmischen, in der zweiten Hälfte des dreizehnten Jahrhunderts vielbesuchten Hofe lebte. Er dichtete bereits vor 1253, da er Wazlav (Wenzel I.) von Böhmen ( + 1253) preist $(71-83)$; ebenso diente er dem Nachfolger desselben, Ottaker, und widmete ihm mehrere Strophen. In andern berührt er die politischen Verhältnisse Deutschlands und Europas während des Interregnums, deutet auf die Eroberung Constantinopels (1261) durch die das lateinische Kaiserthum aufhörte, und fordert 1272 Ottaker auf, das Reich zu erstreiten, ohne jedoch auf Rudolf Bezug zu nehmen, so dass wohl anzunehmen ist, dass mit 1272 seine dichterische Lauf- 
bahn schliesst. Das Marienlied ist als ein Beleg der nicht zahlreich vertretenen Mariendichtung ausgehoben. MSH. 2, 360-364. 4, 661 bis 664.760 .

\section{Hêr Walther von Klingen.}

Aus einem ritterlichen Geschlechte im Thurgau. Bei dem Tode seines Vater, Ulrich (1250 oder 1251) theilten die drei Brüder Ulrich, Walther und Ulrich Walther die Besitzungen. Walther erhielt die Güter im Aargau und im Schwarzwald mit der Burg Klingnau. Reich beschenkte er Kirchen und Klöster: 1252 stiftete er und Ulrich ein Kloster, das sie 1259 mit Gütern im Werthe von 50 Mark Silber begabten. Walther allein gründete 1256 das Kloster Klingenthal bei Basel, 1269 zu Klingnau das Wilhelmiterkloster Syon. Seine Gattin Sophia hatte ihm drei Söhne und fünf Töchter geboren, alle drei Söhne aber und eine Tochter fanden einen frühen Tod. Der Mangel eines Erben mochte zu seinen frommen Werken beitragen. König Rudolf stand er nahe und begleitete ihn mehrfach auf Kriegszügen. Er starb am 1. März 1284 und ist entweder im Predigerkloster zu Basel oder in Klingenthal begraben. Seine Frau überlebte ihn und setzte die Mildthätigkeit ihres Gatten fort: sie starb wahrscheinlich 1291. Walthers dichterisches Vorbild ist Gottfried von Neifen. W. Wackernagel, Walther von Klingen, Stifter des Klingenthals und Minnesänger. Basel 1845. Die Klosterkirche Klingenthal in Basel von Dr. C. Burckhardt und C. Riggenbach (Mittheilungen der Gesellschaft für vaterländische Alterthümer in Basel. VIII). Basel 1860. J. A. Pupikofer, Geschichte der Freiherrn von Klingen zu Altenklingen, Klingnau und zu Hohenklingen: Thurgauische Beiträge zur vaterländischen Geschichte 10. Heft. Derselbe, Walther III. Freiherr von Klingen zu Klingnau. Schriften des Vereins f. Geschichte des Bodensees 2. Heft (1870). MSH. 1, 71-74. 4, 100-105. Vgl. Germania $9,148$.

\section{Künic Kuonrât der junge.}

Bekannter in der Geschichte unter dem ihm in Wälschland gegebenen Namen Konradin, der Sohn Konrads IV. geboren am 25. März 1252. Mit einem Heere nach Italien gezogen (im Sommer 1267), um das sicilische Reich seinem Hause wieder zu erobern, mit Jubel in Rom empfangen, wurde er bei Tagliacozzo (23. August 1268) von Karl von Anjou geschlagen, in Astura auf der Flucht gefangen genommen, und mit Friedrich von Oesterreich am 29. Oktober, erst $16^{1 / 2} \mathrm{Jahr}$ alt, enthauptet. Die ihm beigelegten Strophen sind wohl noch in Deutschland, also in 
sehr jugendlichem Alter entstanden. Lebend wie nach dem Tode, der allgemeine Entrüstung hervorrief, wurde er von deutschen und romanischen Sängern gefeiert und beklagt. MSH. 1, 4. 4, 8-11. Stälin, wirtemb. Geschichte 2, 208--227.

\section{Meister Rûmzlant.}

Ein jüngerer Zeitgenosse des Marner, den er wegen seines Hochmuthes verspottet, dem er aber doch ein Klagelied nachsendet, als er, ein alter Mann, ermordet wurde: von Geburt ein Sachse, wie er selbst (17) sagt, und wie seine Sprache ausserdem bezeugen würde, unterschieden von Rumelant von Swaben (Hagen 3, 68). Er war bürgerlicher Herkunft und führte ein wanderndes Leben hauptsächlich in Norddeutschland. Er besingt die Krönung Rudolfs I. zu Aachen (24. October 1273), rühmt den Fürsten Barnam von Stettin (1222-1278), Herzog Albrecht von Braunschweig (1252-1279), Guncelin von Schwerin (gestorben vor 1276) und König Erich von Dänemark, über dessen Mord (1286) er Klage erhebt. Von süddeutschen Fürsten rühmt er Ludwig von Baiern (1253-1294) $(21-30)$, so dass sich daraus die Grenzen seiner Wanderungen und seines Dichtens (etwa 1260-1290) ergeben. In einem Spruche $\left(3,65^{b}\right)$ nennt er Konrad von Würzburg ( $\dagger$ 1287) unter den lebenden Meistern neben dem Meisner, dem Unverzagten und Höllefeuer. An dem Streitgedichte zwischen Frauenlob und Regenbogen, über Frau und Weib, nahm er Theil; das dichterische Kämpfen und Befehden war zu seiner Zeit schon Mode geworden. Auch mit dem nachfolgenden Singuf finden wir ihn im literarischen Streite. MSH. 2, 367-371. 3, 52-68. $4,671-685$.

\section{Meister Singûf.}

Derselben Zeit und Heimath wie der vorige Dichter angehörig, und wie er ein bürgerlicher. Er erscheint mit Ausnahme zweier Strophen lehrhaften Inhalts nur in dem Streitgedichte mit Rûmzlant, dem er ein von diesem leicht gelöstes Räthsel aufgibt; wesshalb sich dieser in ein paar andern Strophen $(3,65)$ unter Beziehung auf seinen Namen über ihn lustig macht. MSH. 3, 49. 4, 714.

\section{Meister Stolle.}

Ein jüngerer Zeitgenosse des Hardeckers, auf dessen einen Spruch er antwortet. Seine Heimath möchte man, nach einigen Spuren seiner Sprache (steit im Reime für stât, wille im Accusativ statt willen, êre: wære usw.) in Niederdeutschland suchen, jedesfalls müsste er dann frühe 
nach Süddeutschland (ein Heinricus Stollo 1191 [vgl. Germania 20, 262], Christan der Stolle in einer Urkunde vom 9. December 1323 aus Brixen, im germanischen Museum) gekommen sein, da seine Sprüche (Lieder hat er nicht gedichtet) durch ihre geschichtlichen Beziehungen nur nach Oberdeutschland weisen. Einer seiner Sprüche rügt scharf die Hinrichtung der Gemahlin Ludwigs von Baiern, Maria von Brabant (1256). Ein andrer ist an Herzog Meinhard von Kärnten (1285-1296) gerichtet; ein dritter (16-30) tadelt Rudolf I. (1273-1292) wegen seiner Kargheit gegen die Sänger, die auch andere (LXXIII, 1-13 und Hagen $3,45^{\mathrm{a}}$ ) in ähnlicher Weise rügten. Dadurch ergeben sich als Grenzen seiner Thätigkeit die Jahre 1256 bis nach 1285. In seiner Almentweise, die auch bei den Meistersängern oft angewendet wurde (m. Meisterlieder S. 164) und die doch wohl von ihm erfunden ist, haben Dichter, die zum Theil älter scheinen als er, z. B. der Hardecker, gedichtet. MSH. 3, 3-10. 4, $706 \mathrm{f}$.

\section{Meister Kuonrât von Würzeburc.}

Ein bürgerlicher Sänger, in Würzburg geboren, aber frühe aus seiner Heimath ausgewandert und später in Basel ansässig, wo, wenige Jahre nach seinem Tode, 1290, ein domus quondam magistri Cunradi the Wirzeburg vorkommt. Auf Basel weisen die meisten seiner Gönner, deren er in seinen erzählenden Dichtungen erwähnt. Johannes von Bermeswil und Heinrich Isenlin im Alexius (urkundlich 1294); Johannes von Arguel im heil. Pantaleon (urkundlich 1297), Leutold von Rœtelen im Silvester (1256-1295); Dietrich von dem Orte (Canonicus 1271, Cantor 1281) im trojanischen Kriege; Peter der Schaler (Patricier 1236-1292 in Urkunden vorkommend), Heinrich Marschant (urkundlich 1273-96) und Arnold der Fuchs (urkundlich 1253) im Partenopier. Ausserdem nur noch zwei Strassburger, ein Liehtenberger (wahrscheinlich Bischof Konrad III. von Strassburg 1273-1289, der ein Liechtenberger war), den ein Spruch $(32,361-375)$ preist, und ein Domprobst von Thiersberg, auf dessen Bitte er den Otte dichtete. Am 31. August 1287 starb er an einem Tage mit seiner Frau Berchta, seinen Töchtern Gerina und Agnes, wahrscheinlich an einer ansteckenden Krankheit, und wurde mit ihnen in der Magdalenenkapelle des Basler Münsters begraben. Seine zahlreichen erzählenden Dichtungen übergehe ich hier. In lyrischer Form hat er Leiche, Lieder und Sprüche gedichtet; die Form ist sorgfältig und kunstvoll bis zur Ueberküinstelung (ein Gedicht, in dem jedes Wort reimt, Nr. 26 meiner Ausgabe), aber die Liebeslieder sind ziemlich inhaltsleer und immer allgemein, nie mit Bezug auf ein bestimmtes Liebes- 
verhältniss gehalten. Er huldigte damit also nur dem Geschmack der Mode ohne inneres Bedürfniss. Seine Hauptbedeutung liegt auf dem Gebiete der erzählenden Poesie. Er genoss hohes Ruhmes bei seinen Zeitgenossen und in der Folgezeit: als Lebenden preisen ihn Ranmsland und Hermann der Damen, nach seinem Tode Boppe, Franenlob (250-267), Hugo von Trimberg (Renner 8. 20), dieser jedoch mit Tadel wegen seiner oft gekünstelten Ansdrucksweise. Von seinen Beziehungen zu Zeitgenossen gibt die Strophe 82-96 Zeugniss, in der er den Meisner, einen mitteldeutschen fahrenden Sänger, der, wie es scheint, sich in ähnlicher Weise wie der Marner tiber die oberdeutschen Sanger erboben hatte, erst übermässig lobt, aber am Schlusse durch die epigrammutische Wendung einem Bänkelsănger gleichstellt, der auf Jahrmärkten von Eggen singt. Konrads von Würzburg Partenopier und Meliur, Turnei von Nantheiz, Sant Nicolans, Lieder und.Spriche herausgegeben von K. Bartsch. Wien 1871. W. Wackernagel in Pfeiffers Germania 3, 257-266. Archiv des histo. rischen Vereins in Unterfranken 1852. 2. Heft; Germania 4, 113-115. MSH. 2, 310-335. 3, 334-344. 453. 4, 723-730. Germania 9, 148. Vgl. noch G. Scheibler, za den lyrischen Gedichten Konrads ron Würzburg I. Breslau 1874 (Dissertation).

\section{Heister Boppe.}

Wahrscheinlich ein Baseler und derselbe starke Boppe, den die Kolmarer Annalen zum Jahre 1270 erwähnen. Seine persönlichen Beziehungen zu Bischof Konrad III. von Strassburg(1273-89), Rudolf I. Markgrafen von Baden (1242-88) und dessen Sohne Hermann VII. († 1291) so wie auf Rudolf I. von Habsburg begrenzen seine Thätigkeit anf das südwestliche Deutschland und die siebziger und achtziger Jahre des 13. Jahrhunderts. Er tberlebte seinen Landsmann Konrad von Würzburg ( $†$ 1287), dem er ein Klagelied widmete $\left(2,383^{\text {b }}\right)$. Er hat fast nur Sprüche, daneben ein Lied parodischer Art $\left(2,385^{\circ}\right)$ gedichtet. Die mehrfach wiederkehrende Beziehung auf die Nichtigkeit körperlicher Kraft macht wahrscheinlich, dass der Dichter, wie sein Beiname 'der Starke' zeigt, von ungewöhnlicher Stärke gewesen. W. Wackernagel in Haupts Zeitschrift 8, 347. MSH. 2, 377-386. 3, 405 bis 408. 4, 692-699.

LXXI. Der wilde Alerander.

So nennt ihn die Pariser Handschrift, die Jenaer Meister Alexander, einen bürgerlichen Stand bezeichnend. Schon nach seiner Stellung in 
der Pariser Handschrift muss er den jüngern Dichtern beigezăhlt werden, und ich glanbe, dass die Deutung einiger răthselhaften Strophen, wie sie Hagen annimmt, ihn $2 n$ frühe setzst. Ein sülddeutscher Sänger war er, das zeigt seine Sprache: die Erwähnung von Burgan, ewischen Angsburg und Ulm $\left(3,30^{*}\right)$ weist darauf hin und meint wohl den 1282 gestorbenen Markgrafen Heinrich von Burgau. Sein Leich (1-144) ist im Stile Kronrads von Würzburg gedichtet; das Lied (145-193) gibt ein anmuthiges Bild von dem Glücke der längst entschwundenen Kindheit, mit Anknüpfung einer allegorischen Deutung. MSH. 2, 364-367. 3, 26-31. 4, 665-670.

\section{Hêr Knonrat der Schenke von Landegge.}

Sein Geschlecht bekleidete das Schenkenamt von St. Gallen, wie die Singenberger Truchsessen waren. Konrad kommt urkundlich zuerst 1271 zugleich mit seinem Bruder Leutold vor; 1280 in Rorschach als Zenge; 1281 verpfändete ihm König Rudolf zum Lohne für geleistete Kriegsdienste die Vogtei Scheftenau im Toggenburgischen für 30 Mark Silbers. Zuletzt erscheint er 1304 in einer Urkunde für das Kloster Tenikon. Die Kriegsdienste bei Rudolf bestätigt ein Lied $(1-50)$, welches er vor Wien sang, als Rudolf die Stadt belagerte (1276). Auch sonst scheint er in der Welt herumgekommen 20 sein; in einem andern Liede (103 bis 143) spricht er von Hennegan, Brabant, Flandern, Frankreich und Picardie wie von Lăndern, die er durchwandert habe, nach Hagens Vermuthung ebenfalls im Dienste Rudolfs, als dieser gegen Otto Pfalzgrafen von Hochburgund zog (1289). MSH. 1, 351-363. 4, 307-310. Germania 9, 149.

\section{Der schuolmelster von Ezzelingen.}

Wahrscheinlich der Magister Henricus rector scholarum seu doctor puerorum in Ezzelingen, der als Schiedsrichter in einem Rechtsstreit ewischen dem Pfarrer von Münster und dem von Altenburg am 16. Januar 1280 erscheint: derselbe der auch am 26. Januar und 27. Februar 1279, und 8. April 1281 vorkommt. Zu dieser Zeitbestimmung passen die Andeutungen seiner Sprliche, in deren einem $(1-13)$ er Rudolf I. (1273 bis 1291) wegen seiner Kargheit bitter tadelt. Auch in andern ist er nicht gut auf Rudolf eu sprechen; in einem macht er sich, dem von thm bekleideten Amte entsprechend, zum Schiedsrichter eines fingierten Streites zwischen Gott und dem König. Das von thm mitgetheilte Minnelied (14-34) bewegt sich in gesuchten Ausdrücken und gelehrten 
Reminiscenzen. Sein Vorbild scheint für die Spruchpoesie Walther zu sein, von dem er mehrere Töne entlehnt hat. MSH. 2, 137-140. 4, 448-454. Stälin, wirtemberg. Geschichte 3, 754; vgl. 3, 23. 28. 74.

\section{Süezkint der jude von Trimbere.}

Einen Juden Süsskind hat Hagen in einer Würzburger Urkunde von 1218 nachgewiesen. So weit hinauf reichen seine Lieder aber nicht: er steht unter den Nachträgen der Pariser Handschrift, unter Dichtern der zweiten Hälfte des 13. Jahrhunderts. Seine Sprache zeigt, der Heimath entsprechend, mitteldeutsche Färbung, in der Bindung $\hat{e}: æ$, in der Aussprache fründe $=$ friunde u. a. Dass er ein armer Sänger war, geht aus den beiden von mir mitgetheilten Strophen deutlich genug hervor, die zugleich darthun, dass er verheirathet war und Kinder hatte. Lieder hat er nicht gedichtet. MSH. 2, 258-260. 4 , $536-538$.

\section{Der von Trôstberc.}

Unter den zahlreichen seit der Mitte des 13. Jahrhunderts nackzuweisenden Gliedern dieses schweizerischen Geschlechtes am wallrscheinlichsten Rudolf von Trostberg, urkundlich 1286-1323 vorkommend. Er mag leicht derselbe sein, den Meister Hadlaub als Vermittler zwischen sich und seiner Geliebten nennt. Trostberge gab es auch in Tirol: zu den von Hagen nachgewiesenen füge ich einen Eckhart von Trostperch in einer Urkunde König Heinrichs von Böhmen vom Mai 1333 (im germanischen Museum) bei. Die Stellung in der Pariser Handschrift entscheidet weder für Tirol noch für die Schweiz. MSH. 2, 71-73. 4, 412-413. Zeitschrift 6, 398. 7, 168; und besonders Germania 9,149 .

\section{Hêr Steinmâr.}

Aus einem ritterlichen Geschlechte im Thurgau. Zwei Brüder Bertold und Konrad Steinmar sind in Urkunden von 1251-1270 nachgewiesen. Wir finden ihn im Gefolge Rudolfs bei der Belagerung von Wien (1276), wo er ein Lied, vermuthlich im Frühjahr 1277, an die Geliebte richtet $\left(2,155^{a}\right)$. Noch vorher fällt die Winterfahrt Rudolfs nach Meissen, auf der der Dichter den König auch begleitete $\left(2,158^{b}\right)$. Er dichtete noch 1294. Im Gegensatze zu den gewöhnlichen Frühlingsliedern dichtet er Herbstlieder, in denen die Freuden der Tafel besungen werden, und statt der ritterlichen Dame wählt er sich eine ländliche Schöne. Diese Richtung, die der Züricher Hadlaub fortsetzt, ist eine Erweiterung und Umgestaltung der neidhartischen Dorfpoesie. Seine 
Lieder sind wohlklingend und treffen oft den volksthümlichen Ton: aber ihnen schadet eine geflissentliche Rohheit'. MSH. 2, 154-159. 4, 468-471. Wackernagel, die Verdienste der Schweizer \$. 32, 42.

\section{Der Kanzeler.}

Ein bürgerlicher Dichter, ohne Grund vot den späteren Meistersängern für einen Steiermärker und Fischer erklärt. Ebenso grundlos ist es, wenn ihn Hagen für einen Landsmann Hadlaubs hält. Ein oberdeutscher Dichter war er in jedem Falle, etwas jünger als Boppe, in dessen Hoftone er dichtet, und als Konrad von Würzburg, dem er die überkünstliche Weise (36-59) nachgeahmt hat. Die Mehrzahl seiner Produkte sind Sprüche religiösen und moralischen Inhaltes, der zum Theil der Naturgeschichte und Thierfabel entnommen ist; aber auch eine Anzahl Lieder hat er verfasst, die ebensowenig wie die Konrads einen individuellen Charakter haben. MSH. 2, 387-399. 4, 701-705.

\section{Herman der Damen.}

Ein norddeutschèr bürgerlicher Dichter, dessen Sprache entschieden nicht oberdeutsches Gepräge hat. Er dichtete nach dem Tode Friedrichs von Sunburg und des Marners, aber noch gleichzeitig mit Konrad von Würzburg und dem Meisner (18-34), also vor 1287. Er war ein älterer Zeitgenosse Frauenlobs, den er in einem Liede (53-68) als jungen Mann ziemlich scharf zurechtweist. Dass Frauenlob den älteren Dichter hochschätzte, zeigt seine Erwähnung (Sprüche 129, 17). An den norddeutschen Höfen werden beide sich getroffen haben, hier wanderte Hermann viel umher. Er rühmt den Grafen von Ravensburg $\left(3,169^{b}\right)$, wohl denselben Otto, den auch Franenlob verherrlicht; den Grafen Heinrich von Holstein ( $\dagger$ 1310), den Grafen Alf von Sigeberg ( +1308$)$ den Markgrafen von Brandenburg $(\dagger 1308)$ und den Herzog von Schleswig, ohne Zweifel Waldemar (1272-1312). Ausser einem religiösen Leiche und einem Liede hat er nur Sprüche gedichtet; neue Spruchtöne leitet und weiht er, wie zu seiner Zeit ublich war und schon früher (z. B. bei Walther) manchmal vorkam, durch eine Strophe religiösen Inhaltes ein. MSH. 3, 160-170. 4, 742-744.

\section{Meister Heinrich Vrouwenlop.}

Heinrich von Meissen, genannt Franenlob, ein fahrender Sänger bürgerlicher Herkunft, der seine nicht unbedeutende gelehrte Bildung wahrscheinlich auf der Domschule zu Meissen empfieng. Er fieng schon 
sehr frühe an zu dichten. 1278 war er im Heere König Rudolfs auf dem Marchfelde; 1286 in Prag, als Wenzel II. von Böhmen zum Ritter geschlagen warde; zwischen 1286-95 hielt er sich in Kärnten bei Meinrad V. dem Schwager König Albrechts auf; bei Otto von Niederbajern, den er zwischen 1290 and 1312 kennen lernte; am häufigsten aber finden wir ihn an norddentschen Höfen, in Brandenburg, Meklenburg, Rügen, Bremen, Oldenburg, Dänemark, wenn auch im raschen Wechsel, zuletzt beim Ritterfeste Waldemars von Brandenburg vor Rostock 1311. Die letzte Zeit geines Lebens verbrachte er in Mainz, wo er am 29. November 1318 starb und von Frauen eu Grabe getragen wurde. Beinen Beinamen 'Frauenlob' verdankt er dem Săngerstreite mit Regenbogen, in welchem er die Bezeichnung 'Fran' über 'Weib' stellt, im Gegensatze zu Walther, der wîp als den höchsten Namen bezeichnet hatte (XXI, 846). Alle seine Dichtungen, die wenigen Lieder, die drei grossen Leiche und die Sprīche, die den Haupttheil seiner Werke bilden, sind ungemein schwülstig und wimmeln von gelehrten Beziehungen; sie verrathen nicht geringen Dünkel und Geringschătzung der lilteren Meister, von denen er doch, was gutes an ihm war, gelernt hatte. Aber grade das schwerfallig Prunkende und mit Gelehrsamkeit Ueberladene seiner Ansdrucksweise lag im Geschmacke der Zeit nnd verschaffte ihm so hohes Ansehen. Er gilt als der Begründer der ersten Meistersängerschule in Mainz; wenn auch diese Thatsache nicht genügend beglaubigt ist, so trägt sie etwas wahres in sich, da wirklich Franenlob der erste Meistersänger genannt werden kann. Heinrichs von Meissen des Franenlobes Leiche, Sprüche, Streitgedichte und Lieder. Erläutert und herausgegeben von L. Ettmüller. Quedlinburg 1843. MSH. 2, 337 bis 352. 3, 111-159. 355-405. 459-468. 4, 730-742. Vgl. meine Meisterlieder 8. 168-175, und meinen Artikel 'Frauenlob' in der Allgem. deutschen Biographie VII, $321 \mathrm{ff}$.

LXXX. Maregrate 0tte von Brandenburc mit dem pfile.

Ist Otto IV. der von 1266-1308 regierte. Beinen Beinamen crhielt er von einem Pfeile, der thm bei der Belagerung von Stassfurt an der Bode (1279) in den Kopf geschossen ward und ihm, weil er sich keinem Wundarzt anvertrauen wollte, ein ganzes $\mathrm{Jahr}$ stecken blieb, bevor er ansheilte. Er war seit 1261 mit Heilwig, Johanus von Holstein Tochter, vermählt. Im Kriege mit Magdeburg wurde er 1278 gefangen und durch seine Gemahlin gelöst. 1308 starb ex, und wurde in dem Kloster Chorin begraben. Er war ein Förderer und Pfleger der Dichtknnst, der er selbst oblag, und wird als solcher von dem 
Meisner, Franenlob, dem Goldener und Hermann dem Damen gerühmt. MSH. 1, 11-12. 4, 25-29.

\section{Herzoge Heinrioh von Pressela.}

Heinrich IV. von Breslan, beim Tode seines Vaters (Heinrich III.) noch minderjäbrig (1266), trat 1270 die Regierung an, vermählte sich 1278 mit Mathilde, einer Tochter Markgraf Otto's V. des Langen von Brandenburg, stand in den Kriegen Ottakers von Böhmen zu diesem gegen Rudolf I. und starb 1290. Er liegt in der von ihm (1288) gestifteten Collegialkirche zum heiligen Krenz in Breslan unter schönem Grabsteine begraben, der ihn selbst darstellt. Wie sein Vater Heinrich III., den wohl der Tanhauser (Hagen 2, 90) meint, war er ein Freund der Dichtkunst; rühmend gedenkt seiner Frauenlob (Sprüche 135). MSH. 1, 10-11. 4, 20-25. H. Rückert, der Minnesinger Heinrich von Breslau, als Anhang von H. Lachs, Bchlesische Fürstenbilder 9. Heft. Breslau 1869; in Rückerts kl. Schriften 1, 211-219.

\section{Herzoge Jôhans von Brabant.}

Herzog Jan I. von Brabant, berühmt durch den Sieg bei Worringen (1288) über den Grafen von Geldern, vermählte sich 1269 mit Margaretha, Ludwigs des Heiligen Tochter, und nach deren Tode 1273 mit einer Tochter des Grafen Guido von Flandern. Er starb am 3. Mai 1299 an einer Wunde, die er beim Turnier zu Bar erhalten. Von seinen Liedern habe ich einige in der niederländischen Rückübertragung von Hoffmann von Fallersleben aufgenommen. Seine Lieder haben sämmtlich Refrän und zeichnen sich durch volksthümliche Haltung und Sangbarkeit aus. Der Herzog von Brabant, von dem sich in Handschriften französische Lieder finden, wird mit grösserem Rechte auf Heinrich III. gedentet. MSH. 1, 15-17. 4, 38-47. Pfeiffers Germania 3, 154-161. Wackernagel, altfranzösische Lieder und Leiche S. 205 fg. Wanters, le duc Jean I. et le Brabant sous le règne de ce prince. Bruxelles 1862.

\section{Känic Wenzel von Beheim.}

Mit Hagen halte ich Wenzel II. für. den Dichter. Schon sein Vater Ottaker, der Gegner Rudolfs, war ein Beförderer der Dichtkunst gewesen. Wenzel vermăhlte sich 1286 mit Rudolfs Tochter Jutta su Prag, wo er sugleich den Ritterschlag empfieng. Er starb 1305, von Frauenlob, der an seinem Hofe sich reitweise aufgehalten, beklagt, wie 
wir aus Ottakers Reimchronik (Cap. 755) wissen: dieses Klagelied ist jedoch verloren gegangen. Auch der Verfasser des Gedichtes von Landgrafen Ludwigs Kreuzfahrt ertheilt ihm hohes Lob. Die böhmische Fassung des einen Liedes, die man als die ursprüngliche betrachtete und aus der man auf Wenzel I. geschlossen, ist, wie nun wohl Niemand mehr थweifelt, unecht. MSH. 1, 8-10. 4, 13-19. Höfler, König Wenzel I. von Böhmen als deutscher Minnesänger im Anzeiger für Kunde der dentschen Vorzeit 1854, 296. 1855, 1. Feifalik, über König Wenzel von Böhmen als deutschen Liederdichter und über die Unechtheit des altbōhmischen Písen' milcstná kráte Wáclava I. (Aus den Sitzungsberichten der k. k. Akademie) Wien 1858.

\section{Wizlav.}

Wizlaw IV. Furst von Rügen, urkundlich seit 1284, erbte 1302 mit seinem Bruder Zambor und erhielt bei der Theilung die Insel Rügen. Seit dem Todo des Bruders (1304) bekam er das ganze Fürstenthum. Er war zuerst mit Margaretha, einer Tochter Mestewins, des letzten Herzogs von Hinterpommern, vermāhlt, dann mit Agnes, Gräfin von Ruppin, die ihm vier Söhne gebar, die aber alle vor dem Vater starben. Er führte ein unruhiges fehdereiches Leben, meist im Dienste Erichs IX. von Dänemark, zu dem er im Lehensverhältnisse stand, so gegen Stralsund und Brandenburg, und starb am 8. November 1305. Auch er war ein Gönner der Dichtkunst; zwei auf ihn gedichtete Lobspriiche, von dem Goldener und von Frauenlob, haben sich erhalten. Er hat Sprüche und Lieder gedichtet, in deren letztem unvollständigen er nach Steinmars und Hadlanbs Art die Freuden des Herbstes feiert. Des Fürsten von Rügen Wizlaws IV. Sprüche und Lieder in niederdeutscher Sprache, herausgegeben von L. Ettmüller. Quedlinburg 1852. Hagen 3, 78-85. 4, 717-720.

\section{Grave Knonrat von Kilchberc.}

Die Stammborg der schwäbischen Grafen von Kilchberg liegt bei Ulm. Für den Minnesänger kämen in Betracht Graf Konrad, Sohn des Grafen Otto, der mit einer Gräfin von Schelklingen vermählt war, daher sich auch das Wappen der Pariser Handschrift erklärt, welches das der Schelklinger ist. Dieser Konrad erscheint von 1255 an urkundlich. Sein Sohn war Konrad, der 1286-1310 in Urkunden vorkommt, und nach dem 30. Mărz 1315 starb. Nach Sprach- und Reimgebrauch kann nur dieser jüngere der Dichter sein, dessen Lieder sich an die 
Manier Neidharts anlehnen. MSH. 1, 23-26. 4, 55-59. Stälin, wirtemberg. Geschichte 2, 406. 767. 3, 681. Anzeiger f. Kunde der dentschen Vorzeit 1865, Sp. 2.

\section{Grâve Wernher von Hônberc.}

Im Bisthum Basel heimisch; geb. 1284, erscheint er zuerst in einer Urkunde Hermanns von Bonstetten 1300 als Zenge. 1309 wurde er von Heinrich VII., dessen treuer Anhänger er war, zum Reichsvogt, 1312, am 13. Febraar, zum obersten Hauptmann des Bundes aller Reichsgetreuen in der Lombardei emannt. $\operatorname{Er} z 0 g$ dahin und starb am 21. März 1320 nach einem kampfreichen Leben vor dem belagerten Genua. Anf Italien deuten auch seine Lieder, die rum Theil dort entstanden sind. $\mathrm{Er}$ ist ohne $\mathrm{Z}$ weifel der von einem Ungenannten (Liedersaal 2, 321) beklagte, den als Gewährsmann auch der Verfasser des Gedichtes von den sechs Farben nennt. Graf Wernher von Homberg von Dr. Georg v. Wyss, in den Mittheilungen der antiquarischen Gesellschaft zu Zürich (1860) 13, 2, 1. MSH. 1, 63-65. 4, 88-95.

\section{Meister Jôhans Hadloub.}

Ein bürgerlicher Sänger der Schweiz, der meist in Zürich und dessen Umgebung gelebt $\mathrm{zu}$ haben scheint, aber vorübergehend auch in Oesterreich war. Er dichtete in den letzten Jahren des 13. und im ersten Viertel des 14. Jahrhunderts, wie ans der Erwähnung historischer Persönlichkeiten in seinen Gedichten hervorgeht. Er nennt den Fürsten von Constanz, Bischof Heinrich von Klingenberg (1293-1306), seinen Bruder Albrecht $(\dagger$ 1324) u. a., unter denen Rujdiger Manesse (1280 bis 1325), Rathsherr in Zürich, und sein Sohn Rüdiger, Chorherr ebenda (1296-1328) hervorgehoben zu werden verdienen, die sich nach Hadlaubs Zeugniss das Sammeln von Liederbüchern angelegen sein liessen; aus welcher Kunde bekanntlich die Ueberlieferang geflossen ist, es sei die Pariser Handschrift, die ohne Zweifel in der Bchweiz entstanden, die von ihnen veranstaltete Sammlung. Hadlaubs Lieder, roh und unbeholfen in der Form, sind nicht unwichtig, indem sie uns den Minnedienst seiner Zeit veranschanlichen; in andern z. B. den Herbst- und Ernteliedern schlägt er denselben Ton an, den in denselben Gegenden vor ihm schon Steinmar versucht hatte. Ausser Liedern hat er anch drei Leiche gedichtet. Jobann Hadloubes Gedichte herausgegeben von L. Ettmüller. Zürich 1840. MSH. 2, 278-308. 4, 625-633. 


\section{Der von Bûwenburc.}

Ein schwäbischer Ritter, dessen Stammschloss, jetzt Baumburg, bei Riedlingen stand. Ein Dietricus de Bûinburg erscheint in Ortliebs Zwiefalter Chronik, ein Eberhardus Dietheri filius de Buwenburg im Codex Hirsaugiensis, aber vor des Dichters Zeit, der in C unter schwäbischen Dichtern steht und in seinen Liedern den Herbst vor dem Frühling preist, daher wohl von Steinmars Dichtung Einfluss erfahren hat. MSH. 2, 261-263. 4, 539-540. Stälin, wirtemberg. Geschichte 2, 767.

\section{Der Guotære.}

Ohne Zweifel ein bürgerlicher Dichter, über den wir gar nichts näheres wissen. Seine Sprache zeigt niederdeutsche Anklänge, wie bei den meisten Dichtern der Jenaer Sammlung. Er gehört der Grenze des 13. und 14. Jahrhunderts an, und ist jünger als Konrad von Würzburg, dessen 'Welt Lohn' er gekannt und benutzt zu haben scheint. MSH. 3, 41-43. 4, 713.

XC. Der Dürner.

Seiner Sprache nach ein Schwabe, wahrscheinlich ein Freiburger, (im Breisgau), da das Wappen der Familie Turner zu dem der Pariser Handschrift passt. Seine Zeit bestimmt sich durch seine Stellung in der Pariser Handschrift, wo er unter den Nachträgen und unter Dichtern vom Ausgange des 13. Jahrhunderts erscheint. Schreibers Taschenbuch 1839, 361. MSH. 2, 336-337. 4, 646.

\section{Hêr Kuonrât von Altsteten.}

Ein Schweizer ritterlicher Sänger im Oberrheinthal (St. Gallen), gewiss nicht vor dem Ende des 13. oder dem Anfang des 14. Jahrhunderts, da er bereits gesnitten: sitten als klingenden Reim braucht und s: z bindet. Der Dietericus de Altstetin sacerdos, der als Zeuge in einer St. Galler Urkunde vom 3. April 1344 (im germanischen Museum) vorkommt, ist wohl ein Bürgerlicher. MSH. 2, 64-65. 4, 407-408.

\section{Kristân von Lupîn.}

Ein Thüringer, wie ihn $\mathrm{C}$ schon im Titel bezeichnet. Urkundlich um 1305 nachgewiesen. Fridericus Luppini et Christianus frater suus als Zeugen in einer Urkunde des Grafen Friedrich von Beichlingen, Kelbra 1305. Zu dieser Zeitbestimmung passt, dass er in $\mathrm{C}$ unter 
Nachträgen andrer Hand steht, die auch sonst Dichter späterer Zeit gibt. Seine Heimath verrathen auch seine Lieder, die ich daher in thüringischer Mundart hergestellt habe. MSH. 2, 20-22. 4, 315-316. Der urkundliche Nachweis MF. S. 269 (270), Anm.

\section{Hêr Heinrich Hetzbolt von Wîzensê.}

Ebenfalls ein Thüringer (Weissensee bei Erfurt), wohl derselben Zeit angehörend wie der vorige Dichter, dem er in der Handschrift uumittelbar folgt. Auch von seiner heimischen Mundart sind die Spuren noch deutlich zu erkennen; ich habe sie deshalb hergestellt. Merkwïrdig sind seine Lieder durch die Anwendung eines Verstecknamens für die Geliebte nach romanischem Muster (Anm. zu 8). MSH. 2, $22-25$. 4, 316-318.

\section{Regenboge.}

Ein bürgerlicher Sänger, nach der Ueberlieferung der Meistersänger Barthel mit Vornamen, und seines Handwerks ein Schmied. Er gab das Handwerk auf und widmete sich dem fahrenden Leben. In Mainz traf er mit Frauenlob zusammen und hielt mit ihm jenen Sängerwettstreit über die Namen 'Frau' und 'Weib', bei dem Regenbogen für den letztern focht. Er überlebte Frauenlob ( + 1318) und widmete ihm ein Klagegedicht $(3,354)$. Seine Sprüche, nicht so gelehrt und dunkel wie die Frauenlobs, tragen schon vollkommen den Charakter des spätern Meistersanges; daher die Scheidung von echten und in seinen Tönen so wie unter seinem Namen gedichteten Strophen späterer Zeit nicht leicht ist, um so schwieriger, als er selbst schon Rohheiten in Reim und Versball sich zu Schulden kommen lässt. MSH. 2, 309. 3, 344-355. 452 bis $453.468^{\mathrm{i}}-468^{\mathrm{m}}$. 4, 633-672. Meisterlieder der Kolmarer Handschrift S. 175-179.

\section{Albreht marchschal von Raprehtswîle.}

Von Rapperschwyl am Züricher See; in C nebst den ihn umgebenden Dichtern von jüngerer Hand nachgetragen und wie jene (Johannes von Rinkenberg und Otto vom Turne) wahrscheinlich erst dem Anfange des 14. Jahrhunderts angehörend. Wenigstens berechtigt nichts, den 1271 bis 1276 ohne Vor- und Geschlechtsnamen vorkommenden Marschall von Raprechtswil für den Dichter zu halten. Er hat schon starke Kürzungen in der Senkung vor Consonanten, sagt ruon für ruowen, was wohl mittel- aber nicht oberdeutsche Dichter früherer Zeit thun. MSH. 1, 342-343. 4, 288-290. 


\section{Hêr Otte zem Turne.}

Aus dem Wallis, nachgewiesen als Zeuge Lucerner Urkunden sei 1312, so wie als Aussteller einer deutschen Urkunde von 1322, wori er dem Kloster zu Oberndorf eine Schenknng macht und sich als Ritte bezeichnet. 1330 trat er der Verbindung bei, welche Lucern zur Wahrun sêner Rechte eingegangen war. 1331 machte er mit dem Hochstif in Lucern einen Gutstansch. Zwischen 1331 und 1339 scheint er ge storben zu sein. Zu dieser Zeit stimmt seine Stellung in $\mathbf{C}$ unter Schweize Dichtern der spătern Zeit, sowie der Umstand, dass er in einem Lied, die Titurelstrophe in der jüngern Form (mit Inreimen), die ihr de Dichter des jüngern Titurel gab, anwendet. Daher ist wohl der vor Turne, welchen der von Gliers (Hagen 1, 107 b) unter älteren Leich dichtern als verstorben nennt, ein älterer des Geschlechtes; vielleich der Ritter Otto vom Turn, der 1275 urkundlich vorkommt und schwer lich derselbe ist mit dem um 1339 verstorbenen. MSH. 1, 343-346. 4 291-293. Pfeiffers Germania 2, 444. 9, 151. 9, 460 ff. A. Lutolf, Her Otto vom Turne, der Minnesinger zu Lucern. Einsiedeln 1870. (Ab druck aus dem Geschichtsfreund XXV.)

\section{Heinrich von Mngelîn.}

Ein bürgerlicher Dichter des 14. Jahrhunderts, aus Meissen gebürtig dichtete bereits vor 1346 und lebte noch im Jahre 1369, wo er diı Uebersetzung des Valerius Maximus verfasste. Karl IV. war sein Gönne: und bei ihm in Prag lebte er die längste Zeit; aber auch in Oesterreicl muss er sich aufgehalten haben, da er dem Herzog Rudolf (1358-65 seine ungrische Chronik widmete. Von grösseren Werken verfasste e noch ein allegorisches Gedicht, der Mägde Buch, zur Verherrlichung Karls IV., und eine Uebersetzung des Psalmencommentars von Nicolau! de Lyra. Seine Fabeln und Lieder sind herausgegeben von W. Müller Göttingen 1847. Auch er war wegen seiner an gelehrtem Prunke reicher Sprüche bei den Meistersăngern hochgeehrt; unter seinem Namen unc in seinen Tönen wurde später vieles gedichtet. Seine gelehrte Bildung bekundete er in der von ihm verfassten lateinischen Reimchronik vor Ungern. K. J. Schröer, die Dichtungen Heinrichs von Mügeln (Mogelîn nach den Handschriften besprochen. Vgl. Meisterlieder der Kolmarel Handschrift S. 180. Schröer in der Germania 13, 212 ff. Wilmanns it der Zeitschrift f. d. Altherthum 14, 155 ff. 